UNIVERSIDADE DE SÃO PAULO

FACULDADE DE SAÚDE PÚBLICA

FERNANDA DIAS BATISTA MONTICELLI

CONSUMO ALIMENTAR DE ADOLESCENTES DE ESCOLAS DA REDE MUNICIPAL DE ENSINO DA CIDADE DE CURITIBA

São Paulo

2010 


\title{
CONSUMO ALIMENTAR DE ADOLESCENTES DE ESCOLAS DA REDE MUNICIPAL DE ENSINO DA CIDADE DE CURITIBA
}

\author{
Dissertação apresentada ao Programa de \\ Pós Graduação em Nutrição em Saúde \\ Pública da Faculdade de Saúde Pública da \\ Universidade de São Paulo, para obtenção \\ do título de Mestre em Nutrição em Saúde \\ Pública. \\ Área de Concentração: Nutrição em Saúde \\ Pública
}

Orientadora: Sonia Buongermino de Souza.

São Paulo

2010 


\title{
CONSUMO ALIMENTAR DE ADOLESCENTES DE ESCOLAS DA REDE
} MUNICIPAL DE ENSINO DA CIDADE DE CURITIBA

\author{
Dissertação apresentada ao Programa de Pós Graduação \\ em Nutrição em Saúde Pública da Faculdade de Saúde \\ Pública da Universidade de São Paulo, para obtenção do \\ título de Mestre em Nutrição em Saúde Pública. \\ Área de Concentração: Nutrição em Saúde Pública
}

Orientadora: Sonia Buongermino de Souza.

COMISSÃO EXAMINADORA

Prof $^{a}$ Dra Sonia Buongermino de Souza

Prof Dra Ana Maria Dianezi Gambardella

Prof $^{\mathrm{a}}$ Dra Flávia Emília Leite de Lima

São Paulo, 22 de Janeiro de 2010. 
"Eu é que sei que pensamentos tenho a vosso respeito, diz o Senhor; pensamentos de paz e não de mal, para vos dar o fim que desejais. Então me invocareis, passareis a orar a mim, e eu vos ouvirei. Buscar-me-eis e me achareis quando me buscardes de todo $o$ vosso coração. Serei achado de vós, diz o

Senhor, e farei mudar a vossa sorte." 


\section{AGRADECIMENTOS}

Inicialmente, à Deus pela capacitação e ânimo em todos os momentos.

À Professora Dra. Sonia Buongermino de Souza pela sua orientação não só técnica, mas também como exemplo de vida.

À Professora Dra. Flávia Emília L. Lima pelo seu apoio e dedicação desde a Graduação, que, com seus sábios conselhos, me orientou na vida pessoal e profissional.

À Professora Ana Maria D. Gambardella pelos ricos comentários e sugestões, que muito acrescentaram ao trabalho. À Professora Lenise Mondini pelas considerações e sugestões para o aprimoramento do resultado final.

À Secretaria Municipal de Educação pela confiança e colaboração imprescindíveis na pesquisa. Em especial às nutricionistas e estagiárias que com sua dedicação tanto me ajudaram nos dias de entrevista.

À direção das escolas nas quais foi realizado o estudo, por possibilitarem a execução do mesmo. Aos pais ou responsáveis que permitiram a participação dos escolares, e à estes pelas informação cedidas que viabilizaram o projeto.

Aos professores de mestrado pelo conhecimento fornecido durante as disciplinas.

Aos colegas de mestrado pelo convívio e amizade.

À minha tia Cecília e família pelo apoio, e por investirem no meu crescimento. À Sabrina e à Fernanda, pelo acolhimento e amizade durante o período em São Paulo.

Em especial, ao meu marido Gustavo, pela paciência, compreensão e amor com que me apoiou em todos os momentos; e aos meus pais e irmã pela formação que me deram, pelo desprendimento pessoal em meu favor e pelo carinho incondicional. 
INTRODUÇÃO: Evidências sobre a disponibilidade de alimentos no Brasil indicam que a transição alimentar tem sido, em geral, desfavorável em relação à prevenção e controle da obesidade e das demais doenças crônicas não transmissíveis, como comprovado pelos dados antropométricos nacionais ao longo dos anos. Mudanças dietéticas adversas incluem maior ingestão de refrigerantes, biscoitos e alimentos ricos em gordura saturada, e queda no consumo de frutas e verduras, fontes de carboidratos complexos e fibras alimentares, especialmente entre adolescentes. OBJETIVOS: Verificar a relação entre a frequência de consumo de alimentos e grupos de alimentos com variáveis demográficas, socioeconômicas e comportamentais de escolares adolescentes no município de Curitiba.

MÉTODOS: Trata-se de um estudo transversal. A amostra foi de adolescentes de duas escolas municipais (EM), sendo uma de área central e uma de área periférica. O consumo de alimentos foi avaliado por um questionário baseado nos "Dez passos para uma alimentação saudável" do Ministério da Saúde. As informações socioeconômicas foram obtidas de um questionário respondido pelos pais ou responsáveis pelos escolares. Para caracterização da população foram utilizadas frequências, médias, medianas e desvios padrão. A resposta para cada grupo de alimentos foi dicotômica, ou seja, frequência adequada e frequência não adequada. A análise da relação entre as variáveis "frequência de consumo" e "número de refeições/dia" (variáveis dependentes) e as variáveis demográficas, socioeconômicas e comportamentais (variáveis independentes) foi feita para cada uma das questões sobre consumo de alimentos ou grupos de alimentos (8 questões) e para a questão sobre número de refeições. Utilizou-se regressão logística múltipla, com a técnica stepwise, sendo obtidos Odds Ratio de consumo adequado entre as categorias das variáveis independentes. A análise dos dados foi realizada utilizandose o pacote estatístico R.

RESULTADOS: Houve maior participação no estudo de adolescentes do sexo feminino, nas duas escolas, e a média de idade foi de 13 anos. A maioria dos pais e mães dos alunos da EM central (EM1), completou o $2^{\circ}$ grau, e na EM periférica (EM2), a maioria estudou até a $8^{\circ}$ série. Renda familiar de até dois salários mínimos (SM), foi mais comum na regional periférica, e rendas superiores a $3 \mathrm{SM}$ foram mais presentes nas famílias da EM 1. Os adolescentes das duas escolas consomem, em média, 2 porções de frutas/suco natural de frutas, verduras, carnes e leite/derivados (cada). Arroz e feijão são consumidos 6 e 7 vezes na semana, salgados e frituras, 2 e 3 vezes, por adolescentes da EM1 e EM2, respectivamente. A maioria dos adolescentes das duas escolas consome doces e refrigerantes/sucos industrializados diariamente, realizam em média 4 refeições/dia, assistem à televisão por 3 horas (EM1) ou 4 horas (EM2), e jogam videogame por 1 hora, e utilizam o computador por 2 horas, nas duas escolas. Pelo ajuste do modelo logístico pode-se inferir que: o fato do pai não trabalhar fora, associou-se positivamente ao consumo adequado de frutas pelo adolescente; o aumento do tempo utilizando o vídeo game, associou-se ao consumo adequado de carnes; o aumento do tempo de uso do computador associou-se ao consumo inadequado de carne, consumo inadequado de doces e refrigerantes, e número de refeições inadequado; o aumento do tempo de uso da TV associou-se ao consumo inadequado de doces; o aumento da idade associou-se ao consumo inadequado de salgados, e adequado de refrigerante; o 
sexo masculino relacionou-se a um número de refeições adequado; não se tem evidências significativas, para dizer que algumas das covariáveis consideradas influenciam o consumo de leite/derivados, verduras e arroz/feijão.

CONCLUSÃO: A frequência de consumo de frutas/suco natural de frutas, verduras e leite/derivados está inferior ao recomendado pelo MS nos "10 passos para uma alimentação saudável", para a maioria dos adolescentes. O consumo de carnes, arroz/feijão e o numero de refeições ao dia está dentro do recomendado, para a maior proporção dos escolares. As frequências do consumo de frutas, carnes, doces, salgados, refrigerante e numero de refeições foram as que se associaram às variáveis demográficas, socioeconômicas e uso do tempo de lazer.

Palavras-chaves: consumo alimentar, saúde dos adolescentes, recomendações nutricionais, alimentação escolar. 
BACKGROUND: Evidence on food availability in Brazil indicates that the food transition has been, generally unfavorable to prevent and control obesity and other chronic noncommunicable diseases, as evidenced by the national demographics over the years. Adverse dietary changes include increased intake of soft drinks, snacks and foods high in saturated fat, and decrease in consumption of fruits and vegetables, sources of complex carbohydrates and fiber, especially among adolescents.

OBJECTIVES: To investigate the relationship between the frequency of consumption of foods and food groups with demographic, socioeconomic and behavioral characteristics of schoolchildren in the city of Curitiba.

METHODS: This is a cross-sectional study. The sample of adolescents was from two public schools (PS), one of the central area and a peripheral area. The dietary intake was assessed by a questionnaire based on the "Ten steps to a healthy diet", of Ministry of Health. The socioeconomic information were obtained from a questionnaire answered by parents or guardians by the school. To characterize the population were used frequencies, means, medians and standard deviations. The answer to each food group was dichotomous, ie, at often appropriate and often not adequate. The analysis of the relationship between the variables "frequency of consumption" and "number of meals per day" (dependent variables) and demographic, socioeconomic and behavioral variables (independent variables) was performed for each of the questions about consumption of foods or food groups food (8 questions) and to the question about number of meals. We used multiple logistic regression with the stepwise technique, and obtained an odds ratio of consumption between the appropriate categories of independent variables. Data analysis was performed using the statistical package $\mathrm{R}$.

RESULTS: There was greater participation in the study of female adolescents in two schools, and the average age was 13 years. Most parents of students in central PS (PS1), completed the 2nd degree, and in peripheral PS (PS2), most studied up to 8th degree. Family income of up to two minimum wages (MW), was more common in peripheral regional, and incomes over $3 \mathrm{MW}$ were more common in families of central PS. The adolescents from two schools consume an average of 2 servings of fruit/ natural juice of fruits, vegetables, meat and milk/dairy products (each). Rice and beans is consumption 6 and 7 times a week, snacks and fried foods, 2 and 3 times for adolescents in PS1 and PS2, respectively. Most adolescents from two schools consume sweets and soft drinks/juices industrialized daily, realize an average of 4 meals a day, watch television for 3 hours (PS 1) or 4 hours (PS 2), and play video games for 1 hour, and use the computer for 2 hours, the two schools. By adjusting the logistic model can be inferred that: the fact that the father did not work out, was positively associated with the adequate intake of fruit by the adolescent; the increase in time using the video game, was associated with adequate intake of meat; the increased in time using the computer was associated with inadequate intake of meat, inadequate intake of sweets and soft drinks, and inadequate number of meals; the time increased use of TV was associated with inadequate intake of sweets; increasing age was associated with inadequate intake of salt, and appropriate refrigerant; the male was related to an appropriate number of meals; not have 
significant evidence to say that some of the covariates considered influencing the consumption of milk / milk products, vegetables and rice / beans.

CONCLUSION: The frequency of fruit/ natural juice of fruits, vegetables and milk/ dairy products is lower than that recommended by Ministry of Health in the "10 steps to a healthy diet," for most teenagers. The consumption of meat, rice/beans and the number of meals a day is within the recommended for the largest proportion of students. The frequency of consumption of fruits, meats, sweets, snacks, soft drinks and number of meals were those associated with demographic, socioeconomic and use of leisure time.

Keywords: food intake, adolescent health, nutritional recommendations, school feeding. 



\section{LISTA DE FIGURAS}

Figura 1 - Boxplots da adequação no consumo de frutas/suco natural de frutas segundo as covariáveis contínuas.

Figura 2 - Boxplots da adequação no consumo de verduras/legumes segundo as covariáveis contínuas.

Figura 3 - Boxplots da adequação no consumo de arroz/feijão segundo as covariáveis contínuas.

Figura 4 - Boxplots da adequação no consumo de carnes segundo as covariáveis contínuas.

Figura 5 - Boxplots da adequação no consumo de leite/derivados segundo as covariáveis contínuas.

Figura 6 - Boxplots da adequação no consumo de doces segundo as covariáveis contínuas.

Figura 7 - Boxplots da adequação no consumo de salgados segundo as covariáveis contínuas.

Figura 8 - Boxplots da adequação no consumo de refrigerantes/suco industrializado segundo as covariáveis contínuas.

Figura 9 - Boxplots da adequação no numero de refeições ao dia segundo as covariáveis contínuas.

\section{LISTA DE QUADROS}

Quadro 1 - Níveis de evidências em pesquisas científicas. São Paulo: 2009. 


\section{LISTA DE TABELAS}

Tabela 1 - Distribuição dos adolescentes segundo a série e as escolas municipais das regionais. Curitiba, 2009.

Tabela 2 - Frequência dos alunos respondentes aos questionários por escola e série. Curitiba, 2009.

Tabela 3 - Distribuição dos adolescentes das EMs, segundo sexo e idade. Curitiba, 2009.

Tabela 4 - Distribuição dos adolescentes nas categorias das variáveis socioeconômicas, segundo escola. Curitiba, 2009.

Tabela 5 - Distribuição dos adolescentes nas categorias de frequência do consumo de alimentos/grupos de alimentos, segundo escola. Curitiba, 2009.

Tabela 6 - Distribuição dos adolescentes das EMs, segundo as refeições diárias. Curitiba, 2009.

Tabela 7 - Distribuição dos adolescentes das EMs, segundo horas despendidas em cada atividade. Curitiba, 2009.

Tabela 8 - Adequação no consumo de frutas/suco natural de frutas segundo as covariáveis. Curitiba, 2009.

Tabela 9 - Ajuste do modelo logístico para a variável resposta "Consumo de Frutas/suco natural de frutas".

Tabela 10 - Adequação no consumo de verduras/legumes segundo as covariáveis. Curitiba, 2009.

Tabela 11 - Adequação no consumo de arroz/feijão segundo as covariáveis. Curitiba, 2009.

Tabela 12 - Adequação no consumo de carnes segundo as covariáveis. Curitiba, 2009.

Tabela 13 - Ajuste do modelo logístico para a variável resposta "Consumo de Carnes".

Tabela 14 - Adequação no consumo de leite/derivados segundo as covariáveis. Curitiba, 2009.

Tabela 15 - Adequação no consumo de doces segundo as covariáveis. Curitiba, 2009.

Tabela 16 - Ajuste do modelo logístico para a variável resposta "Consumo de Doces".

Tabela 17 - Adequação no consumo de salgados segundo as covariáveis. Curitiba, 2009.

Tabela 18 - Ajuste do modelo logístico para a variável resposta "Consumo de Salgados". 
Tabela 19 - Adequação no consumo de refrigerante/suco industrializado segundo as covariáveis. Curitiba, 2009.

Tabela 20 - Ajuste do modelo logístico para a variável resposta "Consumo de Refrigerante".

Tabela 21 - Adequação do número de refeições segundo as covariáveis. Curitiba, 2009.

Tabela 22 - Ajuste do modelo logístico para a variável resposta "Número de refeições".

\section{LISTA DE ABREVIATURAS}

DCNT - Doenças crônicas não transmissíveis

DP - Desvio padrão

EG/OMS - Estratégia Global sobre Alimentação, Atividade Física e Saúde da Organização Mundial da Saúde

ENDEF - Estudo Nacional de Despesas Familiares

EM 1 - Escola Municipal da regional central

EM 2 - Escola Municipal da regional periférica

FAO - Organização das Nações Unidas para a Agricultura e a Alimentação

FLV - Frutas, Legumes e Verduras

HDL - Lipoproteína de alta densidade

IBGE - Instituto Brasileiro de Geografia e Estatística

IPPUC - Instituto de Pesquisa e Planejamento Urbano de Curitiba

LDL - Lipoproteína de baixa densidade

MS - Ministério da Saúde

OMS - Organização Mundial da Saúde

POF - Pesquisa de Orçamentos Familiares

SM - Salário mínimo

SME - Secretaria Municipal de Educação

UNU - Universidade das Nações Unidas 
1 INTRODUÇÃO

1.1 EVOLUÇÃO DO PADRÃO ALIMENTAR E DO ESTILO DE VIDA .................15

1.2 CONSUMO ALIMENTAR DE ADOLESCENTES …................................18

1.3 ESTRATÉGIA GLOBAL SOBRE ALIMENTAÇÃO, ATIVIDADE FíSICA E

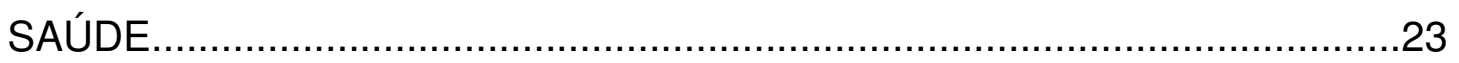

1.4 DEZ PASSOS PARA UMA ALIMENTAÇÃO SAUDÁVEL …........................27



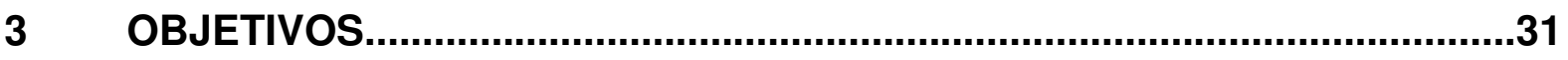



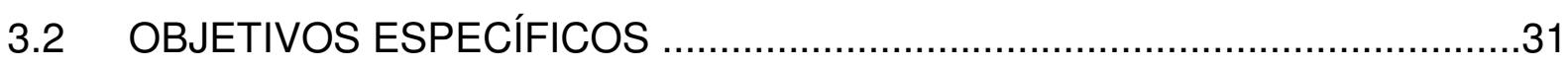

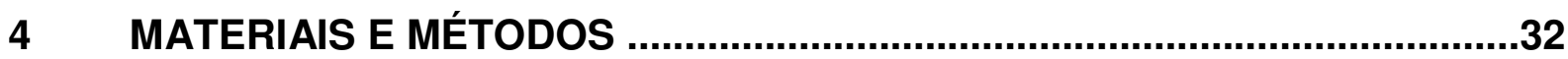

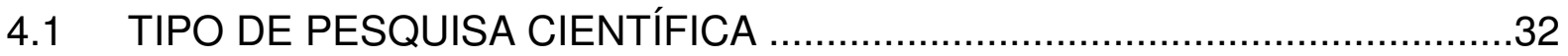

4.2 DESCRIÇÃO DO LOCAL DA PESQUISA E POPULAÇÃO DE

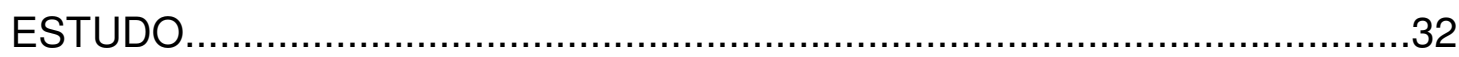

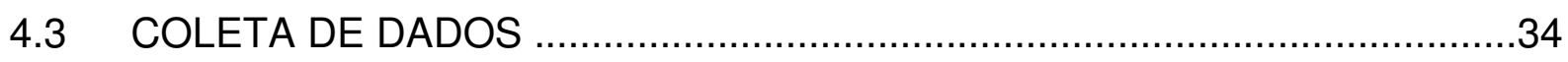

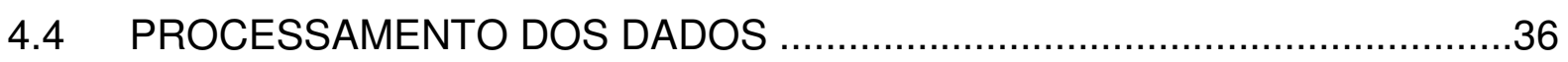

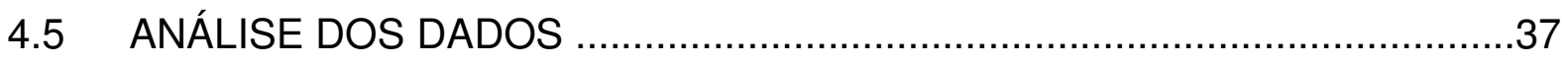

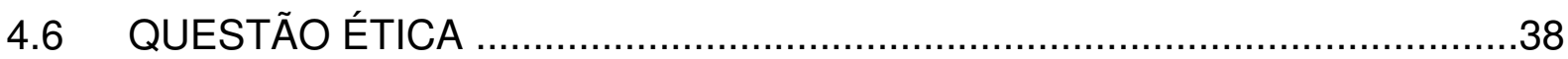



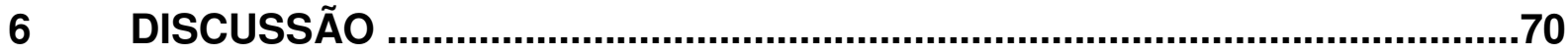

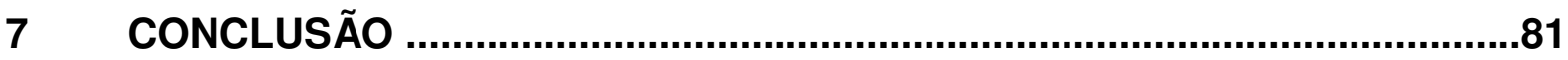

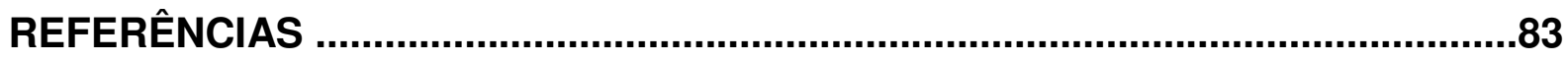

APÊNDICE 1 - CARTA AOS DIRETORES DAS ESCOLAS …...............................89

APÊNDICE 2 - DECLARAÇÃO DE ANUÊNCIA e TERMO DE COMPROMISSO ....90 APÊNDICE 3 - CARTA AOS PAIS OU RESPONSÁVEIS .....................................91

APÊNDICE 4 - TERMO DE CONSENTIMENTO LIVRE E ESCLARECIDO ..............92

APÊNDICE 5 - QUESTIONÁRIO SOBRE O CONSUMO ALIMENTAR ....................93

APÊNDICE 6 - QUESTIONÁRIO SOCIOECONÔMICO ...........................................96

ANEXO 1 - APROVAÇÃO DO COMITÊ DE ÉTICA …........................................98 



\subsection{EVOLUÇÃO DO PADRÃO ALIMENTAR E DO ESTILO DE VIDA}

A questão nutricional tem ocupado uma posição de destaque no contexto mundial. Percebe-se uma grande preocupação em se alcançar o hábito de uma nutrição adequada e com as consequências de uma prática alimentar incorreta (ZANCUL et al, 2004).

Inquéritos antropométricos de abrangência nacional e regional permitem avaliar, de modo bastante razoável, a presença e a tendência secular da obesidade no Brasil. Segundo o inquérito antropométrico restrito às regiões Nordeste e Sudeste (Pesquisa sobre Padrões de Vida - PPV, 1996/97), notam-se aumentos rápidos na prevalência de sobrepeso na população brasileira em crianças entre 6 e 17 anos de idade, sendo que apenas a população pré-escolar ainda parece protegida contra a obesidade no país (WANG et al, 2002).

Evidências sobre a evolução da disponibilidade de alimentos no Brasil indicam que a transição alimentar no país tem sido, em geral, favorável para o controle de problemas associados à subnutrição devido ao aumento na disponibilidade de calorias per capita e ao aumento da participação de alimentos de origem animal na alimentação. Porém, desfavorável em relação à prevenção e controle da obesidade e das demais Doenças Crônicas não Transmissíveis (DCNT) em decorrência do aumento da participação na alimentação de gorduras em geral, gorduras de origem animal e açúcar, e diminuição de cereais, leguminosas, frutas e verduras (LEVY-COSTA et al, 2005).

A mudança de padrão alimentar ao longo do tempo é influenciada por muitos fatores e interações complexas tais como renda, custo dos alimentos, preferências individuais, crenças, tradições culturais, bem como aspectos geográficos, ambientais, sociais e econômicos (WHO, 2003).

Nota-se que a disponibilidade total de alimentos no Brasil tem aumentado continuamente nas últimas décadas propiciando aumento do aporte energético médio de $2.330 \mathrm{kcal}$ por pessoa/dia em 1965 para $2.960 \mathrm{kcal}$ por pessoa/dia em 1997 (MS, 2005a). Em suma, parece que o mundo tem feito progressos significativos no aumento do consumo de alimento por pessoa (WHO, 2003). 
Vê-se que não há problemas com a quantidade média de alimentos disponível para consumo no país, visto que em 1965 a quantidade média de alimentos disponível para cada brasileiro excedia em mais de $10 \%$ as necessidades médias de energia e em 1997 essa margem de segurança passou para 25\% (FAO, 1999).

A evolução nos dados nacionais de padrão alimentar divulgada pelo Instituto Brasileiro de Geografia e Estatística (IBGE), das pesquisas Estudo Nacional de Despesa Familiar (ENDEF) de 1974-75 e Pesquisa de Orçamentos Familiares (POF) 2002-03, revela que as maiores mudanças foram:

- Redução no consumo de:

- cereais e derivados - de $5 \%$ :

- arroz - diminuiu em $23 \%$;

- pão francês - diminuiu em 13\%,

○ feijão - de $31 \%$;

- raízes e tubérculos - de $32 \%$

- ovos - de $84 \%$;

- Aumento no consumo de:

○ biscoitos - de $400 \%$;

- refrigerantes - de $400 \%$;

- carnes - cerca de 50\%;

○ leite - de 36\% (IBGE, 2004).

A evolução dos padrões de consumo alimentar nas últimas três décadas, passível de estudo apenas nas áreas metropolitanas do Brasil, evidenciou declínio no consumo de alimentos básicos e tradicionais da dieta do brasileiro como o arroz e o feijão (LEVY-COSTA et al, 2005).

Outra mudança desfavorável foi o aumento excessivo no consumo de biscoitos que corresponde a uma das principais fontes de ácidos graxos trans da dieta, ao lado de margarinas e produtos fritos, principalmente aqueles comercializados em redes de fast foods. Os ácidos graxos trans tem configuração parecida com a dos ácidos graxos saturados e são considerados um dos principais fatores da dieta com importante efeito na elevação dos níveis da lipoproteína de baixa densidade (LDL) e na redução da lipoproteína de alta densidade (HDL). 
Portanto, seu consumo deve ficar abaixo de 1\% do consumo calórico total (WHO, 2003).

Com o aumento da renda há tendência de maior participação na dieta de produtos como carnes, legumes, verduras, refrigerantes, condimentos, refeições prontas e frutas (quase seis vezes mais elevado do que na classe de menor renda). Merece ser destacado que, na classe de maior renda, o consumo de leite e derivados é três vezes superior ao da classe inferior de rendimentos. Observa-se, porém, que com o aumento da renda familiar há diminuição na participação de alguns grupos alimentares, com destaque para os feijões, tubérculos, raízes e açúcares. Entretanto, vale ressaltar que a POF não avalia o consumo fora do domicílio, o que pode alterar os valores apresentados (IBGE, 2004).

Em geral, as mudanças dietéticas adversas incluem maior densidade energética da dieta devido a um aumento expressivo na adição de açúcares e gordura nos alimentos, maior ingestão de gordura saturada, e queda substancial na disponibilidade relativa de carboidratos complexos e fibras alimentares de frutas e verduras (DREWNOWSKI \& POPKIN, 1997).

Recente estudo analisando a disponibilidade domiciliar de alimentos no Brasil constatou excesso de consumo de açúcar e presença insuficiente de frutas e hortaliças na dieta. Nas regiões economicamente mais desenvolvidas, no meio urbano e entre famílias com maior rendimento, houve também excesso de consumo de gorduras em geral e de gorduras saturadas (LEVY-COSTA et al, 2005).

$O$ aumento na quantidade da gordura consumida na dieta é uma característica importante da transição nutricional dos países. Isto reflete o aumento no consumo de produtos animais, ricos em gordura saturada, principalmente em paises desenvolvidos. Existe forte relação positiva entre nível de renda e consumo de proteína animal de carnes, leite e ovos (WHO, 2003).

A quota de energia da dieta fornecida pelos cereais parece ter permanecido relativamente estável ao longo do tempo, porém, aprofundando a verificação nota-se que diminuiu em países desenvolvidos, sendo que grande parte dessa tendência é imputável à redução no consumo de trigo e arroz (WHO, 2003).

Em relação às frutas e verduras, atualmente apenas uma minoria da população mundial consome a quantidade mínima diária recomendada pela Organização Mundial de Saúde (OMS) que é de 400g/dia. A importância desses alimentos como componentes de uma dieta saudável foi apontada no relatório anual 
da OMS, que revela que o consumo adequado de frutas e verduras pode ajudar a prevenir doenças cardiovasculares e alguns cânceres (WHO, 2002; 2003).

No que diz respeito aos produtos ricos em açúcares simples, é reconhecido que a maior ingestão de tais alimentos compromete a qualidade nutricional da dieta, fornecendo energia significativa sem nutrientes específicos, contribuindo para aumentar a densidade energética total da dieta. Dietas que são limitadas em açúcares simples foram eficazes para reduzir a ingestão total de energia e induzir a perda de peso. Em particular, bebidas ricas em açúcares aumentam a ingestão energética total da dieta e reduzem o controle do apetite, pois não promovem distensão gástrica expressiva (ROLLS, 1997; LEVY-COSTA et al, 2005).

$O$ elevado e crescente consumo de bebidas açucaradas por crianças e adolescentes é preocupante em muitos países. Crianças e jovens com alto consumo de refrigerantes ricos em açúcares são mais susceptíveis a ter ganho de peso excessivo. Estima-se que, o consumo excessivo de alimentos com adição de açúcar, pode aumentar em $60 \%$ o risco das pessoas se tornarem obesas. Pelos dados apresentados há, necessariamente, que se estabelecerem estratégias de redução em seu consumo para atender o limite superior de recomendação do consumo de açúcares proposto pela OMS, que é de $10 \%$ do total calórico da dieta (MATTES, 1996; LUDWIG el al, 2001).

Documentos de estratégias alimentares, como os da OMS, não devem ser apenas para garantir a segurança alimentar para todos, mas também devem favorecer o consumo de quantidades adequadas de alimentos seguros e de boa qualidade que juntos formam uma dieta saudável (WHO, 2003).

Existe, portanto, necessidade de monitorar a forma como as recomendações contidas nos relatório da OMS podem influenciar o comportamento dos consumidores, e que outras medidas são necessárias para mudar as suas dietas (e estilos de vida) em direção a padrões mais saudáveis de vida (WHO, 2003).

\subsection{CONSUMO ALIMENTAR DE ADOLESCENTES}

A adolescência é cronologicamente definida pela OMS para caracterizar indivíduos com idades entre 10 e 20 anos incompletos, de ambos os sexos. Esse período da vida é marcado por transformações físicas, de crescimento e 
desenvolvimento; sociais, quando o adolescente começa a adquirir independência e responsabilidades; e psicológicas, como o aumento da capacidade cognitiva e adaptações de personalidade (LERNER, 1994).

Diversos estudos realizados ao longo dos anos com essa faixa etária apontam para um crescente aumento do excesso de peso, a exemplo do que vem ocorrendo com os adultos. Provavelmente, essa tendência tem relação com transformações socioeconômicas que envolvem a incorporação de hábitos alimentares e de estilo de vida característicos de países desenvolvidos, como o sedentarismo e o consumo de alimentos industrializados (LAMOUNIER, 2000).

Em 2003, estudo transversal realizado na capital do Rio de Janeiro com adolescentes de 12 a 17,5 anos, verificou que o consumo alimentar caracterizava-se por ingestão elevada de produtos de alta densidade energética. Esses comportamentos alimentares, associados à diminuição do gasto energético, são consistentes com a importância crescente de DCNT no perfil de morbimortalidade e com o aumento contínuo da prevalência de obesidade no país (ANDRADE et al, 2003).

Dietz (1993) sustenta que a obesidade em adolescentes resulta da combinação entre atividade física reduzida e consumo de alimentos densamente calóricos em excesso. Muitos adolescentes não fazem nenhum tipo de atividade física, restringindo seu lazer à televisão, ao videogame ou ao computador (FISBERG et al, 2000).

Em relação ao sedentarismo, o mesmo estudo mostrou que o número de horas que um adolescente passa assistindo TV, jogando videogame ou no computador é um importante fator associado ao excesso de peso, acarretando um aumento de $2 \%$ na prevalência de obesidade para cada hora adicional assistindo televisão em jovens de 12 a 17 anos (DIETZ et al, 1985; DIETZ,1993).

Em Curitiba, dados divulgados pela Secretaria Municipal da Educação (SME) sobre o perfil nutricional de escolares da rede pública de ensino, entre os anos de 1996 e 2002, apontam que a obesidade aumentou de 5,5\% para 7,6\%, no período. Desse ultimo ano até 2006, após algumas variações, a prevalência de obesidade atingiu sua maior taxa até então, 8,6\% (SME, 2007).

Dados nacionais divulgados da POF 2002-2003 revelam que, para o excesso de peso, a proporção de adolescentes foi de $16,7 \%$, sendo o problema um pouco mais frequente em meninos do que em meninas. Em ambos os sexos a frequência 
do excesso de peso foi máxima entre adolescentes de 10-11 anos (cerca de 20\%), diminuindo para $12 \%-15 \%$ no final da adolescência (IBGE, 2006).

As transformações ocorridas na adolescência têm efeitos no estado nutricional, mas também no comportamento alimentar, que sofre influência de fatores internos: a crescente preocupação com a imagem corporal, necessidades fisiológicas e saúde individual, valores, preferências e desenvolvimento psicossocial; e externos: hábitos familiares, influência dos amigos, valores e regras sócioculturais, aspectos econômicos, impacto da mídia, modismos do grupo etário, experiências e conhecimentos do indivíduo (FISBERG et al, 2000). Portanto, os adolescentes são comumente apontados como um grupo de risco para os distúrbios nutricionais devido, principalmente, a padrões inadequados de hábitos alimentares comuns nessa faixa etária.

Fisberg e colaboradores (2000) ressaltam a importância de uma alimentação nutricionalmente adequada, com a presença de energia e nutrientes em quantidades suficientes para suprir o crescimento acelerado, as modificações na composição corporal que ocorrem neste período e os gastos com atividade física. Entretanto, as informações disponíveis sobre o consumo alimentar de adolescentes têm revelado que esse grupo da população frequentemente omite refeições, como o desjejum, ou substituem as grandes refeições por lanches ou refeições rápidas, geralmente compostas por alimentos ricos em gorduras e carboidratos, e pobres em vitaminas, sais minerais e fibras (DAMIANI et al, 2000).

Os resultados de um estudo realizado com adolescentes com idade média de 14 anos, remetem à hipótese de que o lanche está tomando o lugar do jantar tradicional. Este fato é comprovado também em outro estudo com adolescentes universitários, em que 49\% dos estudados preferiam lanchar no horário característico do jantar a realizar o jantar tradicional (VIEIRA et al, 2002; GAMBARDELLA et al, 1999).

Evidências indicam também ingestão excessiva de alimentos com elevada densidade energética, ricos em gorduras, açúcares e sódio nessas e nas demais refeições (AQUINO \& PHILIPPI, 2000). Concomitantemente, há carência no consumo de produtos lácteos, frutas e hortaliças (GAMBARDELLA et al, 1999).

Esses resultados chamam a atenção, pois demonstram falhas importantes na alimentação dos adolescentes, como baixa ingestão de fontes de vitaminas, minerais e fibras, e consumo acentuado de açúcares e gorduras. Neutzling et al., 
constataram em seu estudo com adolescentes de 10 a 12 anos, realizado em 2004/2005 em Pelotas (RS), que mais de um terço dos adolescentes consome frequentemente alimentos ricos em gordura. A frequência de consumo de dietas ricas em gordura foi mais alta em adolescentes de nível socioeconômico elevado e com mães de maior escolaridade, ao contrário do que ocorre em países ricos, onde as maiores prevalências de obesidade e de consumo de dietas ricas em gordura são encontradas entre indivíduos mais pobres (ARANCETA et al, 2003; NEUTZLING et al, 2007). Com relação às fibras, identificou-se elevada frequência de consumo de dietas pobres nesse nutriente em todos os subgrupos populacionais (NEUTZLING et al, 2007).

Outro estudo, com adolescentes recém-ingressos na universidade, encontrou que $57,3 \%$ dos entrevistados omitiam uma das refeições principais, no qual $31,7 \%$ não realizavam o desjejum. O grupo das hortaliças foi o mais rejeitado, sendo que mais de $28 \%$ dos estudados ingeriam quatro vezes ou menos, por semana, alimentos desse grupo. As frutas eram ingeridas com essa frequência por mais de $75 \%$ dos estudados, sendo que aproximadamente $35 \%$ ingeriam uma vez ou menos por semana. Por outro lado, 37\% ingeriam alimentos doces ou gordurosos todos os dias (VIEIRA et al, 2002).

Segundo Tojo et al (1995) o número de refeições que os mais jovens realizam dá-se muito por influência das tradições, do nível socioeconômico e educacional da família, da influência dos colegas e até da mídia. As implicações de uma distribuição inadequada da dieta e de um descontrole de horários para se alimentar podem incluir problemas decorrentes do jejum prolongado, como maior propensão à gastrite ou realização de refeições excessivamente volumosas para "compensar" o jejum, situação que pode favorecer sintomas como a dispepsia e a distensão gástrica (MAHAN \& ESCOTT-STUMP, 2005).

A diferença entre os sexos em relação à omissão do jantar também foi encontrada em estudo com adolescentes de 12 a 18 anos no município de São Paulo. A tendência de restringir a alimentação no período noturno pode indicar maior preocupação com o controle do peso, sobretudo entre as adolescentes, uma vez que, segundo o senso comum, deve-se evitar refeições "pesadas" à noite para não engordar (PRIORE, 1998).

Talvez, visando controle do peso e baseando-se em pré-concepções a respeito de dietas de emagrecimento, muitos adolescentes tenham reduzido a 
ingestão de cereais, carnes, ovos, leguminosas, leite e derivados. Este último grupo também pode ter seu consumo reduzido pelo estigma do leite como um "alimento de criança", muitas vezes considerado próprio da infância por parte dos adolescentes, que passam a restringir sua ingestão e preferir outras bebidas (CARLINI-COTRIM et al, 2000).

A redução indiscriminada no consumo dos grupos de alimentos base da alimentação como os cereais, ou fonte de importantes nutrientes como o leite, as carnes e as frutas, é contra-indicada para qualquer grupo da população, sobretudo para os adolescentes que estão em fase de intenso crescimento e desenvolvimento (TOJO et al, 1995).

De acordo com Fisberg et al (2000) muitos adolescentes tem atitudes que não correspondem a uma alimentação adequada, pois, apesar de terem bom conhecimento sobre esse assunto, grande porcentagem deles ingere regularmente "salgadinhos" e outros alimentos ricos em gorduras ou açúcares simples entre as refeições.

A análise do consumo alimentar de adolescentes americanos de 11 a 18 anos de idade de quatro pesquisas de representatividade nacional do Departamento de Agricultura dos EUA mostrou claramente uma primeira substituição de leite por refrigerantes e, posteriormente, a parcial substituição dos refrigerantes por sucos com grande adição de xarope de frutose (CAVADINI et al, 2000).

Analisando-se os resultados apresentados no Estudo Multicêntrico sobre Consumo Alimentar de amostra populacional de cinco cidades do país (Campinas, Curitiba, Goiânia, Ouro Preto e Rio de Janeiro), durante os anos de 1996 e 1997, desenvolvido por Galeazzi et al (1997), observou-se que na cidade de Curitiba o consumo de gorduras e colesterol foi o mais alto dentre as cidades pesquisadas e que o açúcar é o alimento que mais contribui para o total de calorias consumidas pela população.

Portanto, a avaliação adequada do consumo alimentar de adolescentes é de grande preocupação, principalmente entre os profissionais da saúde, pois a formação de hábitos alimentares "não-ideais" nessa faixa etária pode ser considerada um potencial fator de risco para doenças crônicas não transmissíveis na idade adulta (VILLAR, 2001).

Em documento científico, o Comitê de Experts da Organização das Nações Unidas para a Agricultura e a Alimentação (FAO), OMS e Universidade das Nações 
Unidas (UNU) para Nutrição Humana, chama atenção para as dificuldades de se medir a ingestão de alimentos de crianças e adolescentes. Segundo esse Comitê, os critérios mais importantes a considerar na escolha do método para coletar dados sobre a ingestão de alimentos de crianças e adolescentes são: que a técnica não interfira nos hábitos dietéticos, que os dados possam ser representativos da dieta usual ou habitual e que a técnica possa ser, preferencialmente, aplicada em estudos de grupos (CAVALCANTE, 2004).

Fatores como complexidade da dieta, hábitos alimentares, qualidade da informação, idade, imagem corporal, memória do entrevistado, crenças, comportamento, cultura e status socioeconômico, são variáveis que interferem e tornam muito difícil o ato de registrar a ingestão de um indivíduo sem exercer influência sobre o mesmo (CAVALCANTE, 2004).

Inerente a todos os métodos de avaliação da ingestão alimentar que dependem de relato individual, há limitação pela dificuldade de se mensurar o consumo de forma acurada (SCAGLIUSI et al, 2003).

Para medir a informação dietética são necessários instrumentos adequados que possam "responder" às questões referentes à exposição à dieta, uma vez que “... a fidedignidade dos resultados encontrados dependerá da qualidade da informação obtida por meio desses instrumentos de medição" (VILLAR, 2001).

Apesar das limitações inerentes aos métodos de avaliação do consumo alimentar de populações, destaca-se a importância de tais resultados para compor o conhecimento dos parâmetros atuais da alimentação de grupos populacionais como o de adolescentes.

\subsection{ESTRATÉGIA GLOBAL SOBRE ALIMENTAÇÃO, ATIVIDADE FÍSICA E SAÚDE}

Em 2004, o grupo técnico do Ministério da Saúde (MS) apresentou um documento sobre a análise da Estratégia Global sobre Alimentação, Atividade Física e Saúde da Organização Mundial da Saúde (EG/OMS). A meta geral desse documento é: 
em conjunto, dão lugar à redução da morbidade $e$ da mortalidade associadas a uma alimentação pouco saudável e a falta de atividade física" (MS, 2005a).

A estratégia mundial tem três objetivos principais:

- reduzir os fatores de risco de doenças não transmissíveis associadas a uma alimentação pouco saudável e à falta de atividade física por meio de medidas de promoção da saúde e prevenção da morbidade;

- promover a consciência e o conhecimento geral acerca da influência da alimentação saudável e da atividade física na saúde, assim como do potencial positivo das intervenções de prevenção;

- fomentar o estabelecimento, o fortalecimento e a aplicação de políticas e planos de ação mundial, regionais, nacionais e comunitários direcionados a melhorar a alimentação e aumentar a atividade física (WHO, 2004);

Padrões de ingestão alimentar populacional representam a ingestão alimentar média que é julgada ser consistente com a manutenção da saúde na população. Caso as médias populacionais existentes não estejam dentro deste intervalo ideal, preocupações com a saúde podem surgir (WHO, 2003).

A análise das evidências sobre cada recomendação determinou a classificação delas em convincente, provável, possível e insuficiente, e a definição de cada uma é a apresentada no quadro abaixo.

\begin{tabular}{|c|c|c|c|}
\hline ENTE & PROVAVEL & VEL & $E$ \\
\hline $\begin{array}{l}\text { Baseada em } \\
\text { estudos } \\
\text { epidemiológicos } \\
\text { que demonstram } \\
\text { associações } \\
\text { convincentes entre } \\
\text { a exposição e o } \\
\text { desfecho, e pouca } \\
\text { ou nenhuma } \\
\text { evidencia contrária. }\end{array}$ & \begin{tabular}{lrr}
\multicolumn{3}{l}{ Baseada em estudos } \\
que demonstram \\
associações \\
consistentes entre a \\
exposição e r o \\
desfecho, mas & há \\
limitações & na \\
avaliação & das \\
evidências, riar & ou \\
alguma evidencia \\
contraria.
\end{tabular} & $\begin{array}{l}\text { Baseada } \\
\text { principalmente em } \\
\text { resultados de estudos } \\
\text { com menor rigor de } \\
\text { delineamento científico, } \\
\text { como os caso-controle } \\
\text { ou transversais, ou em } \\
\text { resultados insuficientes } \\
\text { de ensaios clínicos } \\
\text { randominzados. }\end{array}$ & $\begin{array}{l}\text { Baseada em resultados } \\
\text { de poucos estudos, onde } \\
\text { a associação entre } \\
\text { exposição e doença é } \\
\text { sugerida, } \\
\text { estabelecida } \\
\text { insuficientemente, sendo } \\
\text { necessárias pesquisas } \\
\text { com melhores } \\
\text { delineamentos para } \\
\text { confirmar practoras em estudo. } \\
\text { associacões }\end{array}$ \\
\hline
\end{tabular}

FONTE: WHO, 2003.

Quadro 1 - Níveis de evidências em pesquisas científicas. São Paulo: 2009. 
Segundo os níveis de evidências propostos pelo grupo de peritos da OMS, pode-se destacar as seguintes recomendações para prevenção do ganho de peso: com evidências convincentes, a redução de alimentos de alta densidade calórica e aumento regular da atividade física; e com evidências prováveis, aumento da ingestão de frutas e outros vegetais, e redução de bebidas açucaradas (MS, 2004).

\subsubsection{Redução da ingestão de alimentos de alta densidade calórica}

Os estudos neste assunto têm verificado que alimentos de alta densidade calórica promovem ganho de peso. Isso ocorre pois esses alimentos, em geral processados, são ricos em gorduras, carboidratos simples ou amido, e pobres em micronutrientes. Em oposição a eles estão os alimentos de baixa densidade calórica, ricos em água e micronutrientes, como frutas, verduras e legumes, cujo consumo deve ser estimulado (MS, 2004).

Com base nessa evidência, orienta-se que a população evite o consumo de bolos, biscoitos doces e recheados, sobremesas e outras guloseimas como regra da alimentação, bem como a ingestão de frituras e fast foods (MS, 2005b).

\subsubsection{Aumento da ingestão de frutas e outros vegetais}

O aumento na ingestão de frutas e outros vegetais reduz a densidade energética e aumenta a quantidade de alimento que pode ser consumida para um determinado nível de calorias (MS, 2004).

A base principal para recomendar o aumento do consumo de frutas, verduras (folhosos como alface, couve, espinafre) e legumes (tomate, abóbora, berinjela) está na possibilidade desses alimentos poderem substituir outros de valor energético elevado e baixo valor nutritivo, como cereais e grãos processados e açúcar refinado, básicos na preparação de alimentos industrializados e fast food (MS, 2004).

Assim sendo, deve-se estimular o consumo diário de pelo menos 3 porções de legumes e verduras como parte das refeições e 3 porções ou mais de frutas nas sobremesas e lanches (MS, 2005b). 


\subsubsection{Redução no consumo de bebidas açucaradas}

O consumo frequente de refrigerantes e outras bebidas adoçadas tem sido associado, em alguns estudos, ao ganho de peso. Uma explicação para isso é que os efeitos fisiológicos do aporte energético sobre a saciedade são diferentes para líquidos e para alimentos sólidos. Dessa forma, o carboidrato quando ingerido em líquidos promoveria um balanço energético positivo maior (MS, 2004).

Portanto, a recomendação para se reduzir ou evitar o consumo de refrigerante e sucos industrializados deve ser associada a todas as demais recomendações para uma dieta saudável (MS, 2004).

\subsubsection{Aumento regular da atividade física}

Há evidência convincente de que a atividade física regular protege o individuo contra o ganho excessivo de peso, enquanto que o estilo de vida sedentário, especialmente as ocupações e recreações sedentárias, como assistir televisão e o tempo excessivo à frente do computador ou videogame (muito presente entre os adolescentes) o promove (MS, 2004).

Portanto, recomenda-se um estilo de vida mais ativo, principalmente no lazer, com incentivo à pratica de pelo menos 30 minutos de atividade física todos os dias (MS, 2004).

Para crianças e adolescentes a prevenção da obesidade implica na necessidade, especialmente de: promoção de um estilo de vida ativo; limite do tempo gasto em frente à televisão ou computador; promoção do consumo de frutas e verduras; restrição do consumo de alimentos altamente energéticos e pobres em micronutrientes (por exemplo, salgadinhos, bolachas recheadas, fast foods, entre outros); restrição do consumo de açúcares, doces, refrigerantes e frituras; além de receberem as informações necessárias para fazer escolhas alimentares saudáveis (WHO, 2003).

Dessa maneira, o desafio de uma alimentação saudável implica na mobilização do poder público, dos segmentos da produção, transformação e comercialização de alimentos dentro de uma nova ética que considere a saúde 
como fator essencial e orientador das estratégias e relações sociais e econômicas intra e inter países (MS, 2004).

Experiências de sucesso de intervenções de Saúde Pública com reversão e com mudanças positivas nas tendências de morbi-mortalidade por doenças cardiovasculares, em diversos países, mostram que a simples difusão de conhecimento é um fator insuficiente para mudanças sustentáveis no estilo de vida e hábitos da população, já que o comportamento e o estilo de vida dos indivíduos e grupos sociais são largamente determinados pelo ambiente físico, socioeconômico e cultural (PUSKA, 2003 apud MS, 2004).

Para que haja intervenções sustentáveis necessita-se a parceria dos atores sociais e econômicos, locais e nacionais, que direta ou indiretamente, determinam ou condicionam o modo de vida dos indivíduos e grupos segundo o gênero e as diversas classes socioeconômicas (PUSKA, 2003 apud MS, 2004).

\subsection{DEZ PASSOS PARA UMA ALIMENTAÇÃO SAUDÁVEL}

O Guia Alimentar para a População Brasileira contém as adaptações das diretrizes alimentares oficiais da OMS para a nossa população. Existem evidências cientificas que apontam de forma inequívoca o impacto da alimentação saudável na prevenção das DCNT, como diabetes e hipertensão, além das mortes prematuras por doenças cardíacas e câncer (MS, 2006).

Com base nos resultados de estudos e na força de evidências, o Ministério da Saúde lançou uma versão resumida do Guia Alimentar para a População Brasileira em formato de "Dez Passos para uma Alimentação Saudável", com o objetivo de orientar a população a fazer escolhas alimentares adequadas (MS, 2005b).

Os dez passos se baseiam nas diretrizes do Ministério da Saúde, sendo elas:

- Consumo diário de 6 porções do grupo de arroz, pães, massas, tubérculos e raízes, com preferência para os grãos integrais;

- Consumo diário de pelo menos 3 porções de legumes e verduras como parte das refeições e 3 porções ou mais de frutas nas sobremesas e lanches;

- Consumo diário de 3 porções de leite ou de seus derivados, e 1 porção de carnes, peixes ou ovos; 
- Consumo diário de 1 porção de feijão ou outro alimento vegetal rico em proteína, como soja, grão-de-bico, ervilha e lentilha;

- Consumo reduzido de alimentos e bebidas concentrados em gorduras e sal;

- Consumo, no máximo, de 1 porção por dia de açúcares e doces. Devem-se evitar bolos biscoitos doces, sobremesas, como regra de alimentação;

- Evitar o consumo de refrigerantes e bebidas industrializadas, pois contém muito açúcar, o que favorece o aparecimento do sobrepeso e da obesidade, alem de não serem nutritivos;

- Diminuir o tempo em frente à televisão e computador nas horas de lazer;

As diretrizes acima fundamentaram as orientações que compõem os passos para uma alimentação saudável, sendo estes:

1. Faça pelo menos três refeições (café da manhã, almoço e jantar) e dois lanches saudáveis por dia. Não pule as refeições: dessa maneira, evita-se o jejum prolongado, diminuindo o risco de ter gastrite e de fome excessiva, o que pode gerar exagero na quantidade de alimentos a serem consumidos na próxima refeição.

2. Inclua diariamente seis porções do grupo de cereais (arroz, milho, trigo, pães e massas), tubérculos como as batatas e raízes como a mandioca nas refeições. Dê preferência aos grãos integrais e aos alimentos na sua forma mais natural: estes alimentos são a mais importante fonte de energia, e devem ser o principal componente da maioria das refeições, pois são ricos em carboidratos.

3. Coma diariamente pelo menos três porções de legumes e verduras como parte das refeições e três porções ou mais de frutas nas sobremesas e lanches: frutas, legumes e verduras são ricos em vitaminas, minerais e fibras, e devem estar presentes diariamente nas refeições, pois contribuem para a proteção à saúde e diminuição do risco de ocorrência de várias doenças.

4. Coma feijão com arroz todos os dias ou, pelo menos, cinco vezes por semana: essa composição é uma combinação completa de proteínas e elementos essenciais para a saúde. 
5. Consuma diariamente três porções de leite e derivados e uma porção de carnes, aves, peixes ou ovos: orienta-se ainda retirar a gordura aparente das carnes e a pele das aves antes da preparação, o que torna esses alimentos mais saudáveis. $O$ grupo de leite e derivados são as principais fontes de cálcio na alimentação. Todos eles são fontes de proteínas, vitaminas e minerais.

6. Consuma, no máximo, uma porção por dia de óleos vegetais, azeite, manteiga ou margarina: é importante ainda ficar atento aos rótulos dos alimentos e escolher aqueles com menores quantidades de gorduras trans.

7. Evite refrigerantes e sucos industrializados, bolos, biscoitos doces e recheados, sobremesas doces e outras guloseimas como regra da alimentação: deve-se diminuir o consumo de refrigerantes e de sucos industrializados, pois a maioria dessas bebidas contém corantes, aromatizantes, açúcar ou edulcorantes (adoçantes artificiais), que não são bons para a saúde.

8. Diminua a quantidade de sal na comida e retire o saleiro da mesa. Evite consumir alimentos industrializados com muito sal (sódio) como hambúrguer, charque, salsicha, linguiça, presunto, salgadinhos, conservas de vegetais, sopas, molhos e temperos prontos.

9. Beba pelo menos dois litros (seis a oito copos) de água por dia.

10. Torne sua vida mais saudável: pratique pelo menos 30 minutos de atividade física todos os dias e evite as bebidas alcoólicas e o fumo. Mantenha o peso dentro de limites saudáveis (MS, 2005b). 


\section{JUSTIFICATIVA}

Com base em evidências científicas que comprovam ou indicam alguns comportamentos alimentares associados à qualidade de vida e condições de saúde, e estudos com adolescentes que têm apontado comportamentos alimentares inadequados, este estudo visa estimar a frequência do consumo de alguns grupos alimentares, com base na recomendação dos "Dez passos para uma alimentação saudável", do Ministério da Saúde, e analisar a influência de variáveis demográficas, socioeconômicas e comportamentais na determinação dos padrões de consumo em adolescentes da cidade de Curitiba.

A presente proposta de diagnóstico do consumo alimentar dos alunos foi desenvolvida em função da constante preocupação direcionada à qualidade do consumo alimentar desse grupo etário.

Este estudo se refere a um estudo piloto, que poderá subsidiar ações de intervenção direcionadas à realidade do consumo alimentar dessa população, com posterior extensão para todas as escolas da Rede Municipal de Ensino de Curitiba. 


\section{OBJETIVOS}

\subsection{OBJETIVO GERAL}

Estimar a frequência do consumo de alguns alimentos/grupo de alimentos e o número de refeições ao dia, e verificar a relação com variáveis demográficas, socioeconômicas e comportamentais de escolares adolescentes.

\subsection{OBJETIVOS ESPECÍFICOS}

- Estimar a frequência do consumo de alguns alimentos/grupo de alimentos;

- Classificar o consumo de alimentos e o número de refeições realizadas ao dia com base nos "Dez Passos Para uma Alimentação Saudável";

- Correlacionar o consumo de alimentos e o número de refeições realizadas ao dia, com variáveis demográficas, socioeconômicas e tempo de lazer com televisão, videogame ou computador. 


\section{MATERIAIS E MÉTODOS}

\subsection{TIPO DE PESQUISA CIENTÍFICA}

Esta pesquisa é um estudo transversal (também denominado de prevalência), observacional e descritivo. Um dos objetivos desse tipo de estudo na área de nutrição é

Identificar ou descrever fatores dietéticos
e/ou problemas nutricionais de uma
população em um dado momento,
relacionando-os com as características do
indivíduo (idade, sexo, nível socioeconômico,
entre outras) e lugar ou área geográfica
(BARBA et al, 1995).

Em geral, os estudos transversais são úteis para descrever o consumo de alimentos e/ou nutrientes de um grupo populacional, avaliar a prevalência de um estado nutricional, analisar associações entre dieta e comorbidades, realizar comparações entre populações, entre outras aplicações (BARBA et al, 1995).

São de mais fácil execução, pouco custo e reproduzíveis, além de permitir o estudo de diversas variáveis e obter grande quantidade de informações. Porém, entre as principais limitações do método destaca-se a ausência de sequência temporal e o fato do seu uso na investigação etiológica ser muito limitado, basicamente porque os casos não são incidentes (novos) e sim prevalentes (BARBA et al, 1995).

\subsection{DESCRIÇÃO DO LOCAL DA PESQUISA E POPULAÇÃO DE ESTUDO}

Segundo dados obtidos pela SME, existem em Curitiba onze escolas municipais que possuem turmas da segunda fase do ensino fundamental, distribuídas em seis das nove regionais do Município, totalizando em Setembro de 2007 o número 15.418 alunos matriculados na rede de ensino. 
A pesquisa foi desenvolvida em duas escolas municipais da Rede Municipal de Ensino, uma delas localizada em uma regional central e outra em uma periférica da cidade de Curitiba, que possuíam a segunda fase do ensino fundamental.

Devido à necessidade de se realizar uma pesquisa factível, com a estrutura, tempo e recursos disponíveis, optou-se pela realização da mesma em duas escolas, tendo como população de estudo o universo dos alunos da segunda fase do ensino fundamental (do período da manhã) dessas escolas. Trata-se, portanto de uma amostra não probabilística, por conveniência.

Entre as regionais consideradas centrais e periféricas pela SME, foi sorteada uma escola municipal de cada regional. A distribuição de alunos por escola e série do período da manhã do ano de 2009 está contemplada na Tabela 1.

Tabela 1 - Distribuição dos adolescentes segundo a série e as escolas municipais das regionais. Curitiba, 2009.

\begin{tabular}{ccc}
\hline Séries & EM 1 (Central) & EM 2 (Periférica) \\
\hline $5^{\circ}$ & 123 alunos (4 turmas) & 131 alunos (4 turmas) \\
$6^{\circ}$ & 129 alunos (4 turmas) & 142 alunos (4 turmas) \\
$7^{\circ}$ & 129 alunos (4 turmas) & 107 alunos (3 turmas) \\
$8^{\circ}$ & 102 alunos (3 turmas) & 125 alunos (4 turmas) \\
TOTAL & 483 alunos (15 turmas) & 505 alunos (15 turmas)
\end{tabular}

Fonte: Planilha de maio, 2009 - Departamento de Informação - Secretaria Municipal de Educação de Curitiba (PR).

As regiões de localização das escolas das duas regionais foram caracterizadas por informações demográficas, educacionais e socioeconômicas disponibilizadas pelo Instituto de Pesquisa e Planejamento Urbano de Curitiba (IPPUC) com base em dados do Censo de 2000 realizado em parceria com o IBGE (IPPUC, 2008).

\subsubsection{Regional Central}

A escola municipal 1, está localizada no bairro Novo Mundo que integra a regional Portão. A distância, em linha reta, deste bairro até o "marco zero" (ponto mais central do município) é de 6,9 km (IPPUC, 2008). 
Os dados de pessoas responsáveis pelos domicílios avaliados (total de 12.917) revelam que $71,0 \%$ delas são do sexo masculino e, destas, $32,1 \%$ possuem de 11 a 14 anos de estudo (maior porcentagem). A maior parte dos chefes dos domicílios (aproximadamente 25,0\%) possui renda de 5 a 10 salários mínimos (IPPUC, 2008).

A classe de rendimento familiar revela que 19,5\% recebem até 3 salários mínimos e 76,7\% recebem mais de 3 salários mínimos (IPPUC, 2008).

\subsubsection{Regional Periférica}

A escola municipal 2, localiza-se no bairro da Cidade Industrial de Curitiba (CIC) e integra a regional que recebe o mesmo nome. A distância desse local até 0 ponto mais central de Curitiba é de, aproximadamente, $10 \mathrm{~km}$ (IPPUC, 2008).

Sobre os responsáveis pelos domicílios (total de 43.494 avaliados), pode-se verificar que $72,1 \%$ são do sexo masculino e, destes, a maioria, $35,0 \%$ possuem de 4 a 7 anos de estudo. Quanto à renda dos chefes de domicílios, a maioria, 23,6\% recebe uma faixa salarial de 3 a 5 salários mínimos (IPPUC, 2008).

A classe de rendimento familiar nesta região é de até 3 salários mínimos para $27,8 \%$ dos domicílios e superior a 3 salários mínimos para $67,5 \%$ deles (IPPUC, 2008).

\subsection{COLETA DE DADOS}

Nas escolas sorteadas, foi realizada uma reunião com a direção e com os orientadores pedagógicos, a fim de explanar os pontos principais do estudo. A direção das escolas recebeu também uma carta de apresentação da pesquisa (APÊNDICE 1). Com concordância da escola, o diretor assinou uma Declaração de Anuência (APÊNDICE 2) para formalizar a participação da mesma no estudo.

Após essa etapa, os alunos de todas as turmas de $5^{\mathrm{a}}$ a $8^{\mathrm{a}}$ série do período da manhã de ambas as escolas, foram informados pela equipe coordenadora do projeto, sendo feita a distribuição, a todos os presentes dos documentos a seguir descritos. 
Os alunos receberam uma carta de apresentação da pesquisa, um questionário socioeconômico e um Termo de Consentimento livre e esclarecido, segundo resolução n 196/MS/CNS, de 10 de outubro de 1996. A participação do estudante se deu mediante assinatura, pelo responsável, desse documento (que deveria ser devolvido à escola) e concordância do estudante em participar. A direção da escola se comprometeu, também, em lembrar os alunos da necessidade de devolução desses documentos (APÊNDICES 3 e 4).

Foram entregues para a coordenação das escolas, cópias para os alunos que não estavam presentes no dia.

No dia da coleta de dados, antes de responderem ao questionário, os alunos eram informados, novamente, sobre a proposta do estudo, sobre a inexistência de respostas certas ou erradas, sobre a individualidade das respostas, e sobre o anonimato das informações. Durante o preenchimento e na entrega do questionário, os entrevistadores verificavam se o mesmo estava preenchido em todos os itens, para evitar falta de informações.

\subsubsection{Questionário sobre o consumo alimentar}

Para avaliar o consumo de grupos alimentares específicos foi elaborado um questionário baseado nas recomendações do Ministério da Saúde que compõem os "Dez passos para uma alimentação saudável".

Esse questionário não contempla todos os passos, mas buscou avaliar a frequência de consumo de frutas; legumes e verduras; carnes; leite e derivados; arroz e feijão; refrigerante e sucos industrializados; doces (bolo, biscoito recheado, balas, sorvetes, chocolate, entre outras guloseimas); e salgados (frituras: coxinha, pastel, batata-frita, mandioca frita, entre outras; salgadinhos de pacote; sanduíches: cachorro-quente, x-salada, entre outros). Os demais alimentos ou grupos alimentares para os quais existe orientação de consumo no documento, não foram abordados devido à complexidade de avaliá-los em adolescentes. Julgou-se que os passos utilizados na avaliação, se cumpridos adequadamente, podem promover um estilo de vida saudável; por outro lado, sua inadequação pode contribuir para o quadro de excesso de peso. 
O questionário incluiu, também, questões sobre o numero de refeições realizadas ao dia, e sobre o uso do tempo de lazer, a fim de avaliar as atividades de lazer sedentárias, como o tempo gasto assistindo televisão ou em frente ao computador e videogame.

Os estudantes participantes, de cada turma, eram chamados em pequenos grupos (aproximadamente 10 alunos) para responderem ao questionário em outra sala, onde receberam a instrução e supervisão de entrevistadores treinados (nutricionistas e/ou estudantes de nutrição).

Foi realizado um pré-teste do instrumento com um grupo de adolescentes para verificar a necessidade de correções conforme a compreensão do questionário. O questionário não precisou ser alterado, apenas as orientações sobre seu preenchimento foram estabelecidas de forma mais adequada, com objetivo de total esclarecimento do mesmo (APÊNDICE 5).

\subsubsection{Avaliação demográfica e socioeconômica}

As variáveis socioeconômicas individuais foram coletadas por meio de um questionário (APÊNDICE 6) contendo questões de identificação do responsável pelo adolescente que preencheu o questionário, número de moradores na residência, quantos deles trabalham, escolaridade e ocupação dos pais, e renda familiar total. As questões demográficas consideradas no estudo foram sexo e idade dos adolescentes.

Tal questionário também foi pré-testado com adultos, e pequenas alterações foram realizadas. O questionário era entregue a todos os alunos das turmas de $5^{\mathrm{a}}$ a $8^{a}$ série, para ser encaminhado, juntamente com o Termo de Consentimento, aos responsáveis pelo adolescente para preenchimento e devolução juntamente com o termo assinado.

\subsection{PROCESSAMENTO DOS DADOS}

Só foram considerados os dados de participantes que tinham: termo de consentimento livre e esclarecido devidamente assinado e devolvido, completo 
preenchimento do questionário sobre consumo alimentar, e do questionário socioeconômico.

Para as variáveis demográficas, socioeconômicas, frequência de consumo dos alimentos, número de refeições realizadas ao dia e uso do tempo de lazer, em horas, foi construído um banco de dados utilizando o programa Microsoft Excel $\AA$ 2002, com revisão posterior do banco completo.

\subsection{ANÁLISE DOS DADOS}

Inicialmente, para caracterização da população foram utilizadas medidas de frequências, médias, medianas e desvios padrão (DP).

Para a análise, as variáveis dependentes "frequência de consumo" e "número de refeições/dia" foram classificadas em duas categorias: inadequada (0) e adequada (1) utilizando como base as recomendações dos "Dez Passos para uma Alimentação Saudável". Algumas recomendações lá contidas foram adaptadas, devido à inexistência de frequência recomendada e, para tais passos, foram estipuladas frequências com base em estudos que avaliaram o consumo desses alimentos ou grupos de alimentos em adolescentes. Os critérios finais foram:

- Consumo diário de, no mínimo, 3 porções de frutas ou suco natural de frutas;

- Consumo diário de, no mínimo, 3 porções de legumes e verduras;

- Consumo diário de 1 porção de carne bovina, de aves, peixes ou ovos;

- Consumo diário de 3 porções de leite ou derivados;

- Consumo diário ou de, no mínimo, 5 vezes na semana de arroz e feijão;

- Consumo de, no máximo, 2 vezes na semana de bolos, biscoitos recheados, guloseimas (balas, doces, chocolates, entre outras);

- Consumo de, no máximo, 2 vezes na semana de salgados em geral, como: frituras (coxinha, pastel, batata frita, mandioca frita, entre outras), salgadinhos de pacote, ou sanduíches (cachorro-quente, x-salada, entre outros);

- Consumo de, no máximo, 2 vezes na semana de refrigerantes ou suco industrializado; 
- Consumo de pelo menos 3 refeições (café-da-manhã, almoço e jantar) e 2 lanches saudáveis por dia;

O uso do tempo de lazer foi analisado na forma contínua (número de horas utilizadas com as atividades "assistindo televisão", "jogando videogame", "utilizando computador"); e as variáveis independentes categóricas foram: Sexo (feminino; masculino); Escolaridade pai/mãe (até $4^{\mathrm{a}}$ série; $5^{\mathrm{a}}$ a $8^{\mathrm{a}}$ série; $2^{\circ}$ grau; Ensino superior; Não sabe); Trabalho pai/mãe (sim; não); Renda (até 1 SM; 1 a 3 SM; 3 a 5 $\mathrm{SM}$; mais de $5 \mathrm{SM}$; não sabe).

A análise da relação entre a variável "frequência de consumo" e as variáveis demográficas, socioeconômicas e comportamentais foi feita para cada uma das questões sobre consumo de alimentos ou grupos de alimentos (8 questões), gerando 8 modelagens, o que permitiu discutir a relação das variáveis independentes com o consumo de cada alimento/grupo de alimentos. Para a variável "número de refeições/dia", foi feita uma modelagem com as mesmas variáveis independentes. Portanto, foram conduzidas 9 modelagens.

Inicialmente, foi feita a descrição das variáveis com frequências de cada categoria da variável resposta (adequado e inadequado) segundo cada categoria das covariáveis. O segundo passo foi verificar o comportamento de cada categoria das variáveis resposta (adequada e inadequada) segundo as covariáveis contínuas, utilizando-se boxplots. O terceiro e último passo foi ajustar modelos de regressão logística para as variáveis resposta (9 modelos) relacionado-as com as possíveis covariáveis contínuas e categóricas.

$\mathrm{Na}$ análise foram obtidos odds ratios por meio de regressão logística múltipla, usando função de ligação logit, e família binomial, com a técnica stepwise para a seleção das covariáveis. Adotou-se nível de $5 \%$ de significância.

A análise dos dados foi realizada utilizando-se o pacote estatístico $R$.

\subsection{QUESTÃO ÉTICA}

Em se tratando de pesquisa que envolve seres humanos, foram contempladas as seguintes características, em conformidade com a Resolução n ${ }^{\circ 196 / M S / C N S ~ d e ~}$ 10 de Outubro de 1996. 
- Garantia da obtenção de consentimento livre e esclarecido dos sujeitos, indivíduos ou grupos que por si e/ou por seus representantes legais manifestem a sua anuência à participação na pesquisa;

- A ponderação entre riscos e benefícios, assegurando aos sujeitos da pesquisa os benefícios resultantes do projeto;

- A justificativa da relevância social da pesquisa;

- Garantia da confidencialidade e inviolabilidade dos dados obtidos;

- O respeito aos valores culturais, sociais, morais, religiosos e éticos, bem como hábitos e costumes da comunidade alvo;

- Inexistência de conflitos de interesse entre os pesquisadores e os sujeitos da pesquisa.

O projeto do estudo em questão foi aprovado pelo Comitê de Ética em Pesquisa da Faculdade de Saúde Pública da Universidade de São Paulo, em Dezembro de 2008, sob o protocolo n` 1843 - FSP - USP (ANEXO 1).

Os resultados e sugestões obtidos a partir deste estudo serão apresentados às escolas participantes é à Secretaria de Educação, a fim de que possam ser utilizados pela comunidade participante do estudo, como subsidio para a fundamentação de estratégias de intervenção a serem planejadas. 
As respostas dos questionários sobre o consumo alimentar dos alunos e sobre suas características socioeconômicas foram, inicialmente, descritas por escola. Após isso, foram construídos modelos de análise, para verificar a existência da relação das variáveis independentes (demográficas, socioeconômicas e comportamentais) com o consumo de cada alimento/grupo de alimentos e com o numero de refeições ao dia.

\subsection{PARTICIPAÇÃO}

$\mathrm{Na}$ Tabela 2 estão contemplados os participantes da pesquisa por escola e série, ou seja, aqueles que aceitaram participar e que apresentaram todos os documentos respondidos e devolvidos, em relação ao numero total de adolescentes convidados à participar.

Tabela 2 - Frequência dos alunos respondentes aos questionários por escola e série. Curitiba, 2009.

\begin{tabular}{|c|c|c|c|c|c|c|c|c|c|}
\hline \multicolumn{10}{|c|}{ ESCOLAS } \\
\hline & \multicolumn{3}{|c|}{ EM 1 (central) } & \multicolumn{3}{|c|}{ EM 2 (periférica) } & \multicolumn{3}{|c|}{ TOTAL } \\
\hline \multirow{3}{*}{ SÉRIES } & \multirow{3}{*}{$\begin{array}{c}\text { Total de } \\
\text { Alunos } \\
\mathrm{N}\end{array}$} & \multirow{2}{*}{\multicolumn{2}{|c|}{$\begin{array}{c}\text { Alunos } \\
\text { Participantes }\end{array}$}} & \multirow{3}{*}{$\begin{array}{c}\text { Total de } \\
\text { Alunos } \\
\mathrm{N}\end{array}$} & \multirow{2}{*}{\multicolumn{2}{|c|}{$\begin{array}{c}\text { Alunos } \\
\text { Participantes }\end{array}$}} & \multirow{3}{*}{$\begin{array}{c}\text { Total de } \\
\text { Alunos } \\
\mathrm{N}\end{array}$} & \multirow{2}{*}{\multicolumn{2}{|c|}{$\begin{array}{c}\text { Alunos } \\
\text { Participantes }\end{array}$}} \\
\hline & & & & & & & & & \\
\hline & & $\mathrm{n}$ & $\%$ & & $\mathrm{n}$ & $\%$ & & $\mathrm{n}$ & $\%$ \\
\hline $5^{a}$ & 123 & 57 & 46,3 & 131 & 47 & 35,9 & 254 & 104 & 40,9 \\
\hline $6^{a}$ & 129 & 52 & 40,3 & 142 & 41 & 28,9 & 271 & 93 & 34,3 \\
\hline $7^{a}$ & 129 & 46 & 35,7 & 107 & 27 & 25,2 & 236 & 73 & 30,9 \\
\hline $8^{a}$ & 102 & 24 & 23,5 & 125 & 49 & 39,2 & 227 & 73 & 32,2 \\
\hline Total & 483 & 179 & 37,1 & 505 & 164 & 32,5 & 988 & 343 & 34,7 \\
\hline
\end{tabular}

O total de participantes da escola central $37,1 \%$, enquanto da periférica foi $32,5 \%$. Em ambas ocorreu perda elevada, de $62,9 \%$ na primeira, e $67,5 \%$ na ultima. Portanto, do total de alunos das duas escolas, $65,3 \%$ não participaram do estudo. 
A participação dos alunos foi reduzida em função de alguns fatores, como a não permissão dos pais ou responsáveis, o desinteresse dos escolares com a pesquisa no momento da apresentação do estudo e distribuição dos documentos, e a não devolução dos documentos por esquecimento dos alunos, condição para participação no estudo. Isso aconteceu apesar de ter sido reforçada a necessidade de devolução dos questionários, durante o prazo estabelecido para isso, por parte de monitores das escolas e dos cordenadores da pesquisa. Também foram avaliados, em outro dia de coleta, os estudantes que estavam ausentes no devido dia da pesquisa em sua turma, com o objetivo de evitar maiores perdas.

O numero de participantes por série foi semelhante em todas as séries, porém decrescente da $5^{\mathrm{a}}$ para a $8^{\mathrm{a}}$ série, com exceção dos alunos das $8^{\mathrm{a}}$ séries da escola periférica, que apresentou boa participação. Percebe-se que a adesão foi maior de alunos das $5^{\mathrm{a}}$ séries, sendo que estes alunos, quando eram convidados a participar, mostravam maior interesse, em comparação com alunos de outras séries.

\subsection{SEXO E IDADE DOS PARTICIPANTES}

Como pode ser visto na Tabela 3, na escola central, do total de 179 participantes, $52,5 \%$ são do sexo feminino e $47,5 \%$ do sexo masculino, enquanto que na escola periférica, dos 164 participantes, essa porcentagem é de 68,3\% e $31,7 \%$, respectivamente. Portanto, houve maior participação de escolares do sexo feminino. As alunas mostraram maior interesse em participar, e pareceram mais comprometidas no preenchimento do questionário.

Quanto à idade, nota-se que a maior participação foi de escolares com idades entre 12 e 13 anos. Na EM 1, a idade máxima foi de 17 anos, e na EM 2, foi de 19 anos.

A média de idade na escola da regional central foi de 12,5 anos (DP de 1,4), enquanto que na periférica, a média foi 12,8 anos (DP de 1,6), sendo os valores das medianas iguais aos das médias nas duas escolas. A média de idade dos adolescentes das duas escolas foi de 13 anos, e a mediana foi um ano inferior (12 anos). 
Tabela 3 - Distribuição dos adolescentes das EMs, segundo sexo e idade. Curitiba, 2009.

\begin{tabular}{|c|c|c|c|c|c|c|c|c|c|c|}
\hline \multirow{4}{*}{$\begin{array}{l}\text { IDADE } \\
\text { (anos) }\end{array}$} & \multicolumn{8}{|c|}{ ESCOLAS } & \multirow{2}{*}{\multicolumn{2}{|c|}{ TOTAL }} \\
\hline & \multicolumn{4}{|c|}{ EM 1} & \multicolumn{4}{|c|}{ EM 2} & & \\
\hline & \multicolumn{2}{|c|}{ Feminino } & \multicolumn{2}{|c|}{ Masculino } & \multicolumn{2}{|c|}{ Feminino } & \multicolumn{2}{|c|}{ Masculino } & \multirow[b]{2}{*}{$\mathrm{n}$} & \multirow[b]{2}{*}{$\%$} \\
\hline & $n$ & $\%$ & $n$ & $\%$ & $\mathrm{n}$ & $\%$ & $\mathrm{n}$ & $\%$ & & \\
\hline 10 a 11 & 24 & 28,2 & 28 & 32,9 & 22 & 25,9 & 11 & 12,9 & 85 & 24,8 \\
\hline 12 a 13 & 51 & 31,7 & 37 & 23,0 & 54 & 33,5 & 19 & 11,8 & 161 & 46,9 \\
\hline 14 a 19 & 19 & 19,6 & 20 & 20,6 & 36 & 37,1 & 22 & 22,7 & 97 & 28,3 \\
\hline TOTAL & 94 & 52,5 & 85 & 47,5 & 112 & 68,3 & 52 & 31,7 & 343 & 100 \\
\hline
\end{tabular}

\subsection{VARIÁVEIS SOCIOECONÔMICAS}

Em relação às variáveis socioeconômicas (número de pessoas que reside na casa, quantas delas trabalham, escolaridade e trabalho fora da residência dos pais, e renda família) as respostas dos pais ou responsáveis, apresentadas na Tabela 4, foram classificadas por escola.

Tabela 4 - Distribuição dos adolescentes nas categorias das variáveis socioeconômicas, segundo escola. Curitiba, 2009.

\begin{tabular}{|c|c|c|c|c|c|c|}
\hline \multirow[b]{2}{*}{ VARIÁVEL } & \multicolumn{2}{|c|}{ EM1 } & \multicolumn{2}{|c|}{ EM2 } & \multicolumn{2}{|c|}{ Total } \\
\hline & $\mathbf{n}$ & $\%$ & $\mathbf{n}$ & $\%$ & $\mathbf{n}$ & $\%$ \\
\hline \multicolumn{7}{|l|}{ Numero de moradores } \\
\hline 2 & 12 & 6,7 & 5 & 3,0 & 17 & 5,0 \\
\hline 3 e 4 & 106 & 59,2 & 89 & 54,3 & 195 & 56,9 \\
\hline 5 e 6 & 54 & 30,2 & 47 & 28,7 & 101 & 29,4 \\
\hline Mais que 6 & 7 & 3,9 & 23 & 14,0 & 30 & 8,7 \\
\hline \multicolumn{7}{|l|}{ Trabalham fora } \\
\hline 0 e 1 & 72 & 40,2 & 66 & 40,3 & 138 & 40,3 \\
\hline 2 & 90 & 50,3 & 73 & 44,5 & 163 & 47,5 \\
\hline 3 ou mais & 17 & 9,5 & 25 & 15,2 & 42 & 12,2 \\
\hline \multicolumn{7}{|l|}{ Escolaridade - PAI } \\
\hline Até a $4^{a}$ série & 13 & 7,3 & 23 & 15,0 & 36 & 10,9 \\
\hline $5^{\mathrm{a}}$ a $8^{\mathrm{a}}$ série & 29 & 16,3 & 46 & 30,1 & 75 & 22,7 \\
\hline
\end{tabular}




\begin{tabular}{|c|c|c|c|c|c|c|}
\hline $2^{\circ}$ grau & 93 & 52,2 & 65 & 42,5 & 158 & 47,7 \\
\hline Ensino Superior & 34 & 19,1 & 15 & 9,8 & 49 & 14,8 \\
\hline Não sabe & 9 & 5,1 & 4 & 2,6 & 13 & 3,9 \\
\hline \multicolumn{7}{|l|}{ Trabalho - PAI } \\
\hline Sim & 157 & 89,7 & 130 & 86,1 & 287 & 88,0 \\
\hline Não & 18 & 10,3 & 21 & 13,9 & 39 & 12,0 \\
\hline \multicolumn{7}{|l|}{ Escolaridade - MÃE } \\
\hline Até a $4^{\mathrm{a}}$ série & 14 & 7,8 & 24 & 14,6 & 38 & 11,1 \\
\hline $5^{\mathrm{a}}$ a $8^{\mathrm{a}}$ série & 38 & 21,2 & 54 & 32,9 & 92 & 26,8 \\
\hline $2^{\circ}$ grau & 85 & 47,5 & 63 & 38,4 & 148 & 43,1 \\
\hline Ensino Superior & 41 & 22,9 & 22 & 13,4 & 63 & 18,4 \\
\hline Não sabe & 1 & 0,6 & 1 & 0,6 & 2 & 0,6 \\
\hline \multicolumn{7}{|l|}{ Trabalho - MÃE } \\
\hline Sim & 119 & 66,5 & 112 & 68,3 & 231 & 67,3 \\
\hline Não & 60 & 33,5 & 52 & 31,7 & 112 & 32,7 \\
\hline \multicolumn{7}{|l|}{ Renda } \\
\hline $0 \dashv 1 \mathrm{SM}(\mathrm{R} \$ 475,00)$ * & 8 & 4,5 & 14 & 8,5 & 22 & 6,4 \\
\hline $1 \dashv 2$ SM $(R \$ 475,01$ A R $\$ 950,00)$ & 32 & 17,9 & 46 & 28,0 & 78 & 22,7 \\
\hline $2 \dashv 3 \mathrm{SM}(\mathrm{R} \$ 950,01 \mathrm{~A} R \$ 1425,00)$ & 50 & 27,9 & 48 & 29,3 & 98 & 28,7 \\
\hline $3 \dashv 4$ SM $(R \$ 1425,01$ A R $\$ 1900,00)$ & 33 & 18,4 & 25 & 15,2 & 58 & 16,9 \\
\hline $4 \dashv 5 \mathrm{SM}(\mathrm{R} \$ 1900,01 \mathrm{~A} R \$ 2375,00)$ & 27 & 15,1 & 8 & 4,9 & 35 & 10,2 \\
\hline Mais de $5 \mathrm{SM}(\mathrm{R} \$ 2375,01)$ & 19 & 10,6 & 14 & 8,5 & 33 & 9,6 \\
\hline Não sabe & 10 & 5,6 & 9 & 5,5 & 19 & 5,5 \\
\hline
\end{tabular}

Em relação ao número de pessoas que residem na casa é possível verificar que a maior proporção é 3 e 4 moradores, para residências de escolares das duas regionais. O número máximo de pessoas que moravam na residência foi de 10 , nas duas regionais. As residências de escolares da regional central têm, em média, 4,2 moradores, mediana de 4 moradores, e desvio padrão de 1,3. Já na regional periférica são, em média, 4,6 moradores na residência, com desvio padrão de 2, e mediana de 4 moradores.

Em apenas uma residência da regional central nenhum morador trabalha fora, e na regional periférica, 2 residências estão nessa situação. $O$ máximo de pessoas que trabalha fora da residência é 4, para as duas regionais. Em média, 1,7 e 1,8 pessoas por residência trabalham fora, com DP de 0,7 e 0,8, para as regionais central e periférica, respectivamente, e mediana de 2 , nas duas regionais. 
Quanto ao grau de escolaridade e se trabalhavam fora da residência, nos dados dos pais de escolares da regional central, falta uma informação de escolaridade, e quatro sobre trabalho fora do domicílio. Já na EM 2, a ausência de dados correspondentes aos pais é maior, faltam 11 dados sobre escolaridade e 13 sobre trabalho fora do lar. Isso aconteceu porque esses questionários foram preenchidos pelas mães dos escolares ou por responsáveis que não tinham informações sobre os pais dos mesmos. Dentre as justificativas para isso, apresentadas nos questionário, estão a separação do casal, cujos filhos moravam com as mães, o falecimento do pai do escolar, ou o desconhecimento da paternidade do adolescente.

É possível verificar que mais da metade dos pais dos alunos da EM central, cursou $02^{\circ}$ grau (completo e incompleto). Verificou-se o mesmo nível escolar mais frequente de pais da EM periférica. Vale destacar que a maior porcentagem dos pais que cursou o ensino superior (completo e incompleto) é de alunos da escola central, o que se inverte quando se analisa a faixa de estudo até $4^{\mathrm{a}}$ série de ensino. Quanto ao trabalho fora de casa, a maior parte dos pais tem essa ocupação nas duas escolas. Em relação à escolaridade materna, na regional central a maior parte das mães também cursou o $2^{\circ}$ grau. Do mesmo modo, o nível de escolaridade mais observado para as mães de escolares da regional periférica, é do $2^{\circ}$ grau. No que diz respeito à outra característica questionada, a maioria das mães, das duas regionais, trabalha fora do domicílio.

Quanto à renda, os responsáveis pelos estudantes responderam de quantos salários mínimos era composta a receita familiar. Na tabela verifica-se que a classe de 2 a 3 salários mínimos foi a que teve as maiores prevalências nas duas escolas.

\subsection{CONSUMO ALIMENTAR}

\subsubsection{Alimentos/grupos de alimentos}

Quanto a frequência de consumo dos alimentos/grupos de alimentos (frutas/suco natural de frutas; legumes/verduras; carnes; leite/derivados; arroz e feijão; salgados; doces; refrigerante/suco industrializado) as respostas dos adolescentes, apresentadas na Tabela 5, foram classificadas por escola. 
Tabela 5 - Distribuição dos adolescentes nas categorias de frequência do consumo de alimentos/grupos de alimentos, segundo escola. Curitiba, 2009.

\begin{tabular}{|c|c|c|c|c|c|c|}
\hline \multirow{2}{*}{$\begin{array}{c}\text { Alimentos/ } \\
\text { Grupos de alimentos }\end{array}$} & \multicolumn{2}{|c|}{ EM1 } & \multicolumn{2}{|c|}{ EM2 } & \multicolumn{2}{|c|}{ Total } \\
\hline & $\mathbf{n}$ & $\%$ & $\mathbf{n}$ & $\%$ & $\mathbf{n}$ & $\%$ \\
\hline \multicolumn{7}{|l|}{ Frutas/suco natural de frutas ${ }^{\star}$} \\
\hline 0 & 11 & 6,1 & 16 & 9,8 & 27 & 7,9 \\
\hline 1 & 61 & 34,1 & 55 & 33,5 & 116 & 33,8 \\
\hline 2 & 61 & 34,1 & 40 & 24,4 & 101 & 29,4 \\
\hline 3 & 30 & 16,8 & 42 & 25,6 & 72 & 21,0 \\
\hline 4 ou mais & 16 & 8,94 & 11 & 6,7 & 27 & 7,9 \\
\hline \multicolumn{7}{|l|}{ Legumes/verduras* $^{\star}$} \\
\hline 0 & 14 & 7,8 & 20 & 12,2 & 34 & 9,9 \\
\hline 1 & 75 & 41,9 & 60 & 36,6 & 135 & 39,4 \\
\hline 2 & 69 & 38,5 & 71 & 43,3 & 140 & 40,8 \\
\hline 3 & 16 & 8,9 & 11 & 6,7 & 27 & 7,9 \\
\hline 4 ou mais & 5 & 2,8 & 2 & 1,2 & 7 & 2,0 \\
\hline \multicolumn{7}{|l|}{ Carnes* } \\
\hline 0 & 5 & 2,8 & 2 & 1,2 & 7 & 2,0 \\
\hline 1 & 51 & 28,5 & 49 & 29,9 & 100 & 29,1 \\
\hline 2 & 102 & 57,0 & 87 & 53,0 & 189 & 55,2 \\
\hline 3 & 17 & 9,5 & 24 & 14,6 & 41 & 12,0 \\
\hline 4 ou mais & 4 & 2,2 & 2 & 1,2 & 6 & 1,7 \\
\hline \multicolumn{7}{|l|}{ Leite/derivados* } \\
\hline 0 & 4 & 2,2 & 12 & 7,3 & 16 & 4,7 \\
\hline 1 & 35 & 19,6 & 47 & 28,7 & 82 & 23,9 \\
\hline 2 & 65 & 36,3 & 51 & 31,1 & 116 & 33,8 \\
\hline 3 & 49 & 27,4 & 29 & 17,7 & 78 & 22,7 \\
\hline 4 ou mais & 26 & 14,5 & 25 & 15,2 & 51 & 14,9 \\
\hline \multicolumn{7}{|l|}{ Arroz e Feijão** } \\
\hline 0 a 2 & 17 & 9,5 & 15 & 9,1 & 32 & 9,4 \\
\hline 3 & 12 & 6,7 & 9 & 5,5 & 21 & 6,1 \\
\hline 4 & 14 & 7,8 & 7 & 4,3 & 21 & 6,1 \\
\hline 5 a 6 & 57 & 31,8 & 32 & 19,5 & 89 & 25,9 \\
\hline Todos os dias & 79 & 44.1 & 101 & 61,6 & 180 & 52,5 \\
\hline \multicolumn{7}{|l|}{ Salgados ${ }^{\star \star}$} \\
\hline 0 a 1 & 70 & 39,1 & 46 & 28,0 & 116 & 33,8 \\
\hline
\end{tabular}




\begin{tabular}{lllllll}
2 & 36 & 20,1 & 35 & 21,3 & 71 & 20,7 \\
3 & 34 & 19,0 & 33 & 20,1 & 67 & 19,5 \\
4 & 17 & 9,5 & 22 & 13,4 & 39 & 11,4 \\
5 a 6 & 11 & 6,1 & 15 & 9,1 & 26 & 7,6 \\
Todos os dias & 11 & 6,1 & 13 & 7,9 & 24 & 7,0 \\
\hline Doces $^{\star *}$ & & & & & & \\
0 a 1 & 21 & 11,7 & 17 & 10,4 & 38 & 11,1 \\
2 & 30 & 16,8 & 10 & 6,1 & 40 & 11,7 \\
3 & 34 & 19,0 & 28 & 17,1 & 62 & 18,1 \\
4 & 23 & 12,8 & 25 & 15,2 & 48 & 14,0 \\
5 a 6 & 25 & 14,9 & 20 & 12,2 & 45 & 13,1 \\
Todos os dias & 46 & 25,7 & 64 & 39,0 & 110 & 32,1 \\
\hline Refrigerante/sucos industrializados ${ }^{\star *}$ & & & & & & \\
0 a 1 & 8 & 4,5 & 14 & 8,5 & 22 & 6,4 \\
2 & 16 & 8,9 & 15 & 9,1 & 31 & 9,0 \\
3 & 15 & 8,4 & 14 & 8,5 & 29 & 8,4 \\
4 & 18 & 10,1 & 18 & 11,0 & 36 & 10,5 \\
5 a 6 & 30 & 16,8 & 28 & 17,1 & 58 & 16,9 \\
Todos os dias & 92 & 51,4 & 75 & 45,7 & 167 & 48,8 \\
\hline
\end{tabular}

*Frequência diária de consumo.

${ }^{* *}$ Frequência semanal de consumo.

Verifica-se que para o consumo de frutas/suco natural de frutas e legumes/verduras na escola central, as maiores porcentagens foram de consumo de 1 e 2 vezes ao dia para frutas, e 1 vez ao dia para legumes/verduras. Porém vale ressaltar que, cerca de $7 \%$ e $8 \%$ dos escolares não têm consumo diário de frutas e legumes/verduras, respectivamente. Nesta escola, quanto às frutas, a média de consumo foi de 1,9 vezes ao dia, com desvio padrão de 1,1. Para os legumes/verduras, a média foi de 1,6 vezes ao dia, com desvio padrão de 0,9. A mediana é de 2 vezes ao dia para os dois grupos de alimentos.

$\mathrm{Na}$ escola da regional periférica, nota-se que a maioria dos escolares consome frutas uma vez ao dia. A frequência observada mais comum para o consumo de legumes/verduras, foi de 2 vezes ao dia. Vale destacar que, cerca de $10 \%$ dos escolares desta regional não consome frutas durante o dia, e essa porcentagem foi de, aproximadamente, $12 \%$ para os legumes/verduras. Esses valores são superiores aos da escola da regional central. A média do consumo de 
frutas foi 1,9 vezes ao dia, com desvio padrão de 1,2. Nesta regional, a mediana de consumo também foi 2 vezes ao dia. Quanto a legumes/verduras, a média foi 1,5 vezes ao dia, com desvio padrão de 0,9. A mediana nesta regional também coincide com a média. Verifica-se, portanto, que os valores de tendência central e dispersão foram semelhantes para frutas e legumes/verduras nas escolas das duas regionais.

Em relação à carne e leite/derivados, verifica-se que na regional central a maior parte dos adolescentes consome carnes e leite/derivados 2 vezes ao dia. Apenas, cerca de $3 \%$ dos escolares não consomem carnes todos os dias, e para 0 leite e derivados esse valor é de $2 \%$, aproximadamente. Na escola desta regional, a média do consumo de carne é de 1,8 vezes ao dia, com desvio padrão de 0,7. A mediana para esse grupo de alimentos é igual a média. No que diz respeito ao grupo do leite e derivados, a média de consumo foi de 2,4 vezes ao dia, com desvio padrão de 1,2. Assim como no grupo das carnes, a mediana também foi de 2 vezes ao dia.

Para escolares da regional periférica, apenas 1,2\% não consomem carnes diariamente. Porém, mais adolescentes não consomem nenhuma porção de leite e derivados ao dia, cerca de 7\%. A média de consumo de carne na EM 2 é próxima a de escolares da regional central, 1,9 porções ao dia. O desvio padrão observado para esse grupo de alimentos, é de 0,7. A mediana de consumo também é a mesma para a escola central, e igual à média. Quanto ao leite e derivados, a média de consumo é de 2,2 vezes ao dia, com desvio padrão de 1,4. Da mesma maneira que na escola central, a mediana foi de 2 vezes ao dia. Nestes grupos de alimentos, verifica-se que os valores de média e mediana foram muito próximos para adolescentes das duas escolas.

A frequência semanal do consumo de arroz e feijão, e salgados em geral, apresentada na tabela revela que as maiores frequências de consumo de arroz e feijão foram de 5 a 6 vezes na semana, e todos os dias, em escolares da regional central. Quanto aos salgados, as maiores porcentagens são de escolares que não consomem ou o fazem apenas uma vez na semana. A média do consumo de arroz e feijão, nessa regional, foi de 5,5 vezes na semana, com desvio padrão de 1,8. A mediana de consumo para esses alimentos, é de 6 vezes na semana. Em relação aos salgados em geral, os adolescentes os consomem em média 2,4 vezes na semana, com desvio padrão de 1,8. Para esse grupo de alimentos, a mediana de consumo é igual a média. 
$\mathrm{Na}$ escola da regional periférica, observa-se que mais da metade dos adolescentes consomem arroz e feijão diariamente. E, assim como observado em adolescentes da escola central, a maior parte não consome, ou consome 1 vez na semana os alimentos do grupo dos salgados. Os escolares dessa regional consomem arroz e feijão em média, 5,9 vezes na semana, com desvio padrão de 1,8. Para esses alimentos, a mediana de consumo foi de 7 vezes na semana. Quanto ao grupo dos salgados, a média de consumo foi de 2,9 vezes na semana, com desvio padrão de 1,9. Nessa regional, a mediana para o consumo de salgados é igual a média.

O arroz e feijão, e os salgados são componentes mais frequentemente presentes na refeição de adolescentes da regional periférica, sendo que estes o consomem um dia a mais na semana do que os escolares da EM central.

É possível perceber ainda que, na escola central, um em cada quatro adolescentes consomem algum tipo de doce diariamente. As demais classes de frequência têm distribuição semelhante de escolares. Com relação ao refrigerante/sucos industrializados, mais da metade dos adolescentes dessa regional apresentam consumo diário dessas bebidas. As demais frequências de consumo (em ordem crescente) têm tendência de aumento no numero de adolescentes nas classes. A media de consumo de doces é de 4,1 vezes semanal, com desvio padrão de 2,2. Nessa regional, a mediana de consumo é igual a média. Quanto ao refrigerante/sucos industrializados, os adolescentes dessa regional consomem em média 5,3 vezes na semana, com desvio padrão de 2,0. No caso das bebidas, a mediana de consumo é de 7 vezes semanais, ou seja, diário.

Os escolares da regional periférica, em sua maioria, também consomem doces todos os dias. A frequência do consumo de bebidas industrializadas revela que cerca de $46 \%$ dos escolares dessa regional, o fazem diariamente. Em média, os adolescentes consomem doces 4,7 vezes na semana (valor igual ao da mediana), com desvio padrão de 2,2. Já em relação ao grupo do refrigerante/sucos industrializados, a média de consumo é de 5,1 vezes na semana, com desvio padrão de 2,2. Nessa regional, a mediana é de 6 vezes semanais. 


\subsubsection{Refeições}

$\mathrm{Na}$ Tabela 6 é apresentada a distribuição dos adolescentes segundo as refeições que realizam durante o dia. Nota-se que na regional central, quase todos os escolares tem o hábito de almoçar diariamente, cerca de $84 \%$ dos adolescentes comem ou bebem alguma coisa durante a tarde, e aproximadamente $85 \%$ deles jantam diariamente. A refeição menos realizada é o lanche da noite, ou seja, cerca de 70\% não ingerem nenhum alimento ou bebida nessa refeição.

Embora os dados não constem na tabela, foi possível verificar ainda que, entre os escolares dessa regional, 1,7\%, 14,0\%, 42,5\%,31,3\% e 10,6\% consomem 2, 3, 4, 5 e 6 refeições ao dia, respectivamente. As três refeições principais (café da manha, almoço e jantar) são realizadas por mais da metade dos adolescentes (56,4\%), e desse total (de 101 escolares), 67,3\% também consomem ou bebem algo em pelo menos dois lanches (da manhã, da tarde e/ou da noite). Os adolescentes dessa regional realizam em média 4,4 refeições ao dia, com desvio padrão de 0,9.

Em adolescentes da regional periférica, a principal refeição realizada é o almoço, mas grande parte deles realiza o lanche da tarde e o jantar. As porcentagens de adolescentes que realizam essas refeições são semelhantes às verificadas na escola da regional central. A refeição menos feita por esses escolares também foi o lanche noturno.

Além dos dados apresentados na tabela, verifica-se ainda que, na regional periférica, $5,5 \%, 20,7 \%, 32,9 \%, 28,7 \%$ e $12,2 \%$ dos escolares realizam 2, 3, 4, 5 e 6 refeições ao dia. Observa-se, portanto, que a maior porcentagem dos adolescentes realizam 4 refeições durante o dia. Em escolares dessa regional, observa-se ainda que, menos da metade (47\%) realizam as 3 grandes refeições, e deste total (77 adolescentes) cerca de 70\% também realizam pelo menos 2 lanches. A média é de 4,2 refeições ao dia, com desvio padrão de 1,1.

Tabela 6 - Distribuição dos adolescentes das EMs, segundo as refeições diárias. Curitiba, 2009.

\begin{tabular}{llllll}
\hline \multirow{2}{*}{ REFEIÇÕES } & \multicolumn{2}{c}{ EM 1 } & \multicolumn{2}{c}{ EM 2 } \\
\cline { 2 - 6 } & $\mathbf{n}$ & $\%$ & $\mathbf{n}$ & $\%$ \\
\hline Café da manhã & 120 & 67,0 & 91 & 55,5
\end{tabular}




\begin{tabular}{lrrrr} 
Não & 59 & 33,0 & 73 & 44,5 \\
\hline Lanche da manhã & 138 & 77,1 & 104 & 63,4 \\
Sim & 41 & 22,9 & 60 & 36,6 \\
Não & 178 & 99,4 & 161 & 98,2 \\
\hline Almoço & 1 & 0,6 & 3 & 1,8 \\
Sim & & & & \\
Não & 151 & 84,4 & 139 & 84,8 \\
\hline Lanche da tarde & 28 & 15,6 & 25 & 15,2 \\
Sim & & & & \\
Não & 152 & 84,9 & 144 & 87,8 \\
\hline Jantar & 27 & 15,1 & 20 & 12,2 \\
Sim & & & & \\
Não & 54 & 30,2 & 53 & 32,3 \\
\hline Lanche da noite & 125 & 69,8 & 111 & 67,7 \\
Sim & & &
\end{tabular}

\subsubsection{Uso do tempo de lazer}

Quanto ao uso do tempo de lazer, ou seja, as questões sobre as horas despendidas em frente à televisão, videogame ou computador, foram as que os adolescentes tiveram maior dificuldade em referir, principalmente das $5^{\mathrm{a}}$ e $6^{\mathrm{a}}$ séries.

Por meio dos dados apresentados na Tabela 7, verifica-se que na escola central, quase metade dos adolescentes assiste televisão por cerca de 2 horas, essa mesma proporção pode ser observada entre os adolescentes que a assistem por 5 horas ou mais. Quanto ao videogame, aproximadamente, três em cada quatro adolescentes não o jogam ou quando o fazem, a atividade dura cerca de 1 hora. Esse valor pode ser explicado devido ao fato de muitos deles não terem esse equipamento em casa, ou por, normalmente, realizarem os jogos no computador. Quanto ao uso do lazer nessa ultima ocupação, 26,8\% o fazem durante 1 hora. A média do tempo gasto em frente à televisão é de 3,4 horas ao dia (igual à mediana), com desvio padrão de 2,1. Para o videogame esses valores são 1,0 (com mediana de 0,3 horas), 1,5; e para o computador são, 2,4 (com mediana de 2 horas), 2,1, respectivamente. 
Os adolescentes da escola periférica despendem, em sua maioria, 5 horas ou mais em frente à televisão. O tempo de jogo no videogame não é realizado ou é feito com duração de 1 hora, por cerca de $80 \%$ dos adolescentes dessa regional. E a explicação para a baixa proporção de adolescentes da escola central que realizam essa atividade pode ser estendia à esta regional também. Quanto ao computador, aproximadamente $30 \%$ dos escolares gastam cerca de 1 hora nessa ocupação. A média de horas assistindo à televisão nesta regional foi de 4,0 horas (com mediana de 3 horas) e desvio padrão de 2,6. Os valores para o videogame são 0,9 (com mediana de 0 horas) e 1,5; e para o computador 2,4 (com mediana de 2 horas) e 2,1 , respectivamente.

Por meio do questionário não foi possível saber se o tempo despendido em cada atividade é feito no mesmo dia. Mas, durante a coleta de dados, foi relatado pela maioria dos adolescentes das duas escolas, que assistir à televisão e utilizar o computador, normalmente são atividades presentes no mesmo dia, e jogar no videogame é uma atividade mais frequente nos fins de semana.

Tabela 7 - Distribuição dos adolescentes das EMs, segundo horas despendidas em cada atividade. Curitiba, 2009.

\begin{tabular}{lrrrr}
\hline \multirow{2}{*}{ Atividade (horas) } & \multicolumn{2}{c}{ EM 1 } & \multicolumn{3}{c}{ EM 2 } \\
\cline { 2 - 5 } Televisão & & & & $\%$ \\
0 a 1 & 25 & 14,0 & 21 & 12,8 \\
2 & 45 & 25,1 & 24 & 14,6 \\
3 & 36 & 20,1 & 37 & 22,6 \\
4 & 28 & 15,6 & 34 & 20,7 \\
5 e mais & 45 & 25,1 & 48 & 29,3 \\
\hline Videogame & & & & \\
0 a 1 & 134 & 74,9 & 132 & 80,5 \\
2 & 20 & 11,2 & 13 & 7,9 \\
3 & 12 & 6,7 & 9 & 5,5 \\
4 e mais & 13 & 7,3 & 10 & 6,1 \\
\hline Computador & & & & \\
0 a 1 & 73 & 40,8 & 68 & 41,5 \\
2 & 27 & 15,1 & 35 & 21,3
\end{tabular}




\begin{tabular}{lrrrr}
3 & 33 & 18,4 & 19 & 11,6 \\
4 & 17 & 9,5 & 14 & 8,5 \\
5 e mais & 29 & 16,2 & 28 & 17,1 \\
\hline
\end{tabular}

\subsection{VÁRIÁVEIS RESPOSTA x COVARIÁVEIS}

Seguem as tabelas com frequências comparando cada categoria da variável resposta (adequado e inadequado) dentro de cada categoria das covariáveis consideradas, por alimento/grupo de alimentos. E em seguida, são apresentados os gráficos relacionando as categorias da variável resposta com as covariáveis contínuas, para cada alimento/grupo de alimento. Em relação à modelagem com regressão logística, apenas os resultados referentes às variáveis independentes que se associaram ao desfecho são apresentados em tabelas.

Do total de 343 adolescentes, foram excluídos 17 deles, por ausência de informações sobre escolaridade e/ou trabalho fora da residência dos pais.

\subsubsection{Frutas/suco natural de frutas}

Tabela 8 - Adequação no consumo de frutas/suco natural de frutas segundo as covariáveis. Curitiba, 2009.

\begin{tabular}{lcccccc}
\hline \multirow{2}{*}{ Variáveis } & \multicolumn{2}{c}{ Inadequado } & \multicolumn{2}{c}{ Adequado } & \multicolumn{2}{c}{ Total } \\
\cline { 2 - 7 } & $\mathbf{n}$ & $\%$ & $\mathbf{n}$ & $\%$ & $\mathbf{n}$ & $\%$ \\
\hline Sexo & & & & & & \\
Feminino & 138 & 70,8 & 57 & 29,2 & 195 & 100 \\
Masculino & 93 & 71,0 & 38 & 29,0 & 131 & 100 \\
\hline Escol. Pai & & & & & & \\
até $4^{\text {a }}$ série & 25 & 69,4 & 11 & 30,6 & 36 & 100 \\
$5^{\text {a }}$ a $8^{\text {a }}$ série & 48 & 64,9 & 26 & 35,1 & 74 & 100 \\
$2^{\circ}$ grau & 113 & 72,4 & 43 & 27,6 & 156 & 100 \\
Superior & 36 & 73,5 & 13 & 26,5 & 49 & 100 \\
Não sabe & 9 & 81,8 & 2 & 18,2 & 11 & 100 \\
\hline Escol. Mãe & & & & & & \\
até $4{ }^{\text {a }}$ série & 27 & 71,1 & 11 & 28,9 & 38 & 100 \\
$5^{\mathrm{a}}$ a $8^{\mathrm{a}}$ série & 60 & 67,4 & 29 & 32,6 & 89 & 100 \\
$2^{\circ}$ grau & 98 & 72,1 & 38 & 27,9 & 136 & 100
\end{tabular}




\begin{tabular}{|c|c|c|c|c|c|c|}
\hline Superior & 44 & 72,1 & 17 & 27,9 & 61 & 100 \\
\hline Não sabe & 2 & 100,0 & 0 & 0,0 & 2 & 100 \\
\hline \multicolumn{7}{|l|}{ Pai trabalha } \\
\hline Sim & 211 & 73,5 & 76 & 26,5 & 287 & 100 \\
\hline Não & 20 & 51,3 & 19 & 48,7 & 39 & 100 \\
\hline \multicolumn{7}{|l|}{ Mãe trabalha } \\
\hline Sim & 149 & 69,3 & 66 & 30,7 & 215 & 100 \\
\hline Não & 82 & 73,9 & 29 & 26,1 & 111 & 100 \\
\hline \multicolumn{7}{|l|}{ Renda } \\
\hline Até $1 \mathrm{SM}$ * & 12 & 60 & 8 & 40 & 20 & 100 \\
\hline $1 \dashv 3 \mathrm{SM}$ & 112 & 68,7 & 51 & 21,3 & 163 & 100 \\
\hline $3 \dashv 5 \mathrm{SM}$ & 71 & 76,3 & 22 & 23,7 & 93 & 100 \\
\hline Mais de 5 SM & 25 & 73,5 & 9 & 26,5 & 34 & 100 \\
\hline Não sabe & 7 & 43,8 & 9 & 56,3 & 16 & 100 \\
\hline
\end{tabular}

${ }^{*} \mathrm{SM}=475,00$

Figura 1 - Boxplots da adequação no consumo de frutas/suco natural de frutas segundo as covariáveis contínuas (idade, tempo de TV, tempo de vídeo game, tempo de computador, numero de moradores e quantos deles trabalham).


Situacao Alimentar - Frutas

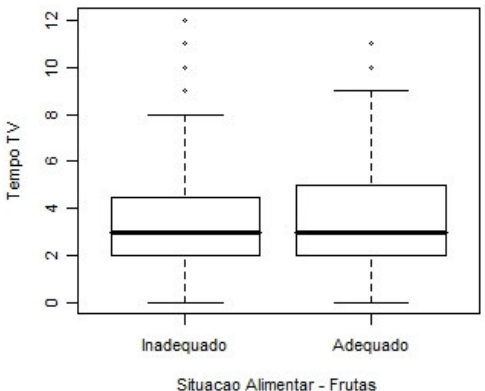

Situacao Alimentar - Frutas



Situação Alimentar - Frutas
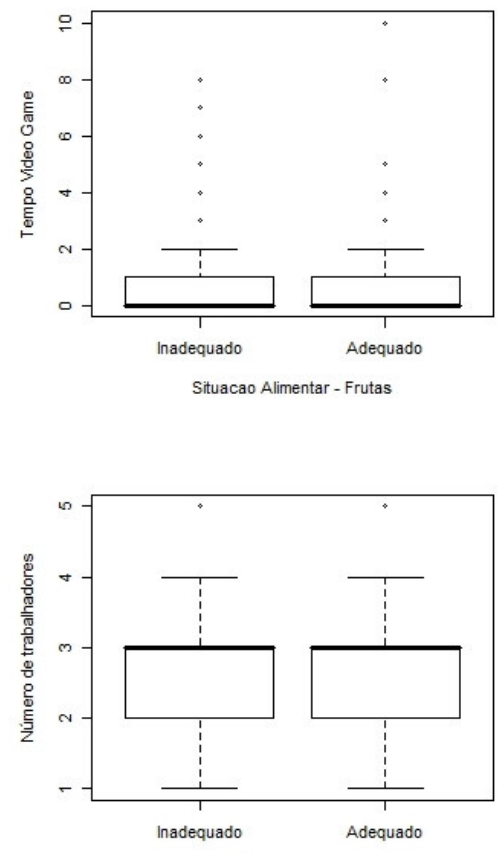

Situação Alimentar - Frutas 
Tabela 9 - Ajuste do modelo logístico para a variável resposta "Consumo de Frutas/suco natural de frutas".

\begin{tabular}{lcccc}
\hline \multicolumn{1}{c}{ Variável } & OR & $\mathbf{Z}$ & P-valor & I.C. (95\%) \\
\hline Pai trabalha fora & & & & \\
Sim & 1 & - & - & - \\
Não & 2,63 & 2,794 & 0,005 & $1,33-5,20$ \\
\hline
\end{tabular}

Analisando a tabela acima pode-se inferir que a covariável "pai trabalha fora da residência" tem uma influência significativa no consumo adequado de frutas ( $p$ valor $=0,005)$. Comparando as categorias desta covariável, é possível verificar que, quando o pai não trabalha fora, aumenta a chance do adolescente ter um consumo adequado de frutas em $2.63(1.33-5.20)$ vezes com relação aos adolescentes que o pai trabalha.

\subsubsection{Verduras/Legumes}

Tabela 10 - Adequação no consumo de verduras/Legumes segundo as covariáveis. Curitiba, 2009.

\begin{tabular}{|c|c|c|c|c|c|c|}
\hline \multirow[b]{2}{*}{ Variáveis } & \multicolumn{2}{|c|}{ Inadequado } & \multicolumn{2}{|c|}{ Adequado } & \multicolumn{2}{|c|}{ Total } \\
\hline & $\mathrm{n}$ & $\%$ & $\mathbf{n}$ & $\%$ & $\mathbf{n}$ & $\%$ \\
\hline \multicolumn{7}{|l|}{ Sexo } \\
\hline Feminino & 176 & 90,3 & 19 & 9,7 & 195 & 100 \\
\hline Masculino & 116 & 88,5 & 15 & 11,5 & 131 & 100 \\
\hline \multicolumn{7}{|l|}{ Escol. Pai } \\
\hline até $4^{\mathrm{a}}$ série & 33 & 91,7 & 3 & 8,3 & 36 & 100 \\
\hline $5^{\mathrm{a}}$ a $8^{\mathrm{a}}$ série & 67 & 90,5 & 7 & 9,5 & 74 & 100 \\
\hline $2^{\circ}$ grau & 136 & 87,2 & 20 & 12,8 & 156 & 100 \\
\hline Superior & 47 & 95,9 & 2 & 4,1 & 49 & 100 \\
\hline Não sabe & 9 & 81,8 & 2 & 18,2 & 11 & 100 \\
\hline \multicolumn{7}{|l|}{ Escol. Mãe } \\
\hline até $4^{\mathrm{a}}$ série & 35 & 92,1 & 3 & 7,9 & 38 & 100 \\
\hline $5^{\mathrm{a}}$ a $8^{\mathrm{a}}$ série & 81 & 91,0 & 8 & 9,0 & 89 & 100 \\
\hline $2^{\circ}$ grau & 119 & 87,5 & 17 & 12,5 & 136 & 100 \\
\hline Superior & 55 & 90,2 & 6 & 9,8 & 61 & 100 \\
\hline Não sabe & 2 & 100 & 0 & 0 & 2 & 100 \\
\hline \multicolumn{7}{|l|}{ Pai trabalha } \\
\hline Sim & 257 & 89,5 & 30 & 10,5 & 287 & 100 \\
\hline
\end{tabular}




\begin{tabular}{lcccccc} 
Não & 35 & 89,7 & 4 & 10,3 & 39 & 100 \\
\hline Mãe trabalha & 192 & 89,3 & 23 & 10,7 & 215 & 100 \\
Sim & 100 & 90,1 & 11 & 9,9 & 111 & 100 \\
Não & 18 & 90 & 2 & 10 & 20 & 100 \\
\hline Renda & 147 & 90,2 & 16 & 9,8 & 163 & 100 \\
Até 1 SM * & 79 & 84,9 & 14 & 15,1 & 93 & 100 \\
$1 \dashv$ 3 SM & 31 & 91,2 & 3 & 8,8 & 34 & 100 \\
$3 \dashv$ 5 SM & 15 & 93,8 & 1 & 6,2 & 16 & 100 \\
Mais de 5 SM & & & & & &
\end{tabular}

Figura 2 - Boxplots da adequação no consumo de verduras/legumes segundo as covariáveis contínuas (idade, tempo de TV, tempo de vídeo game, tempo de computador, numero de moradores e quantos deles trabalham).
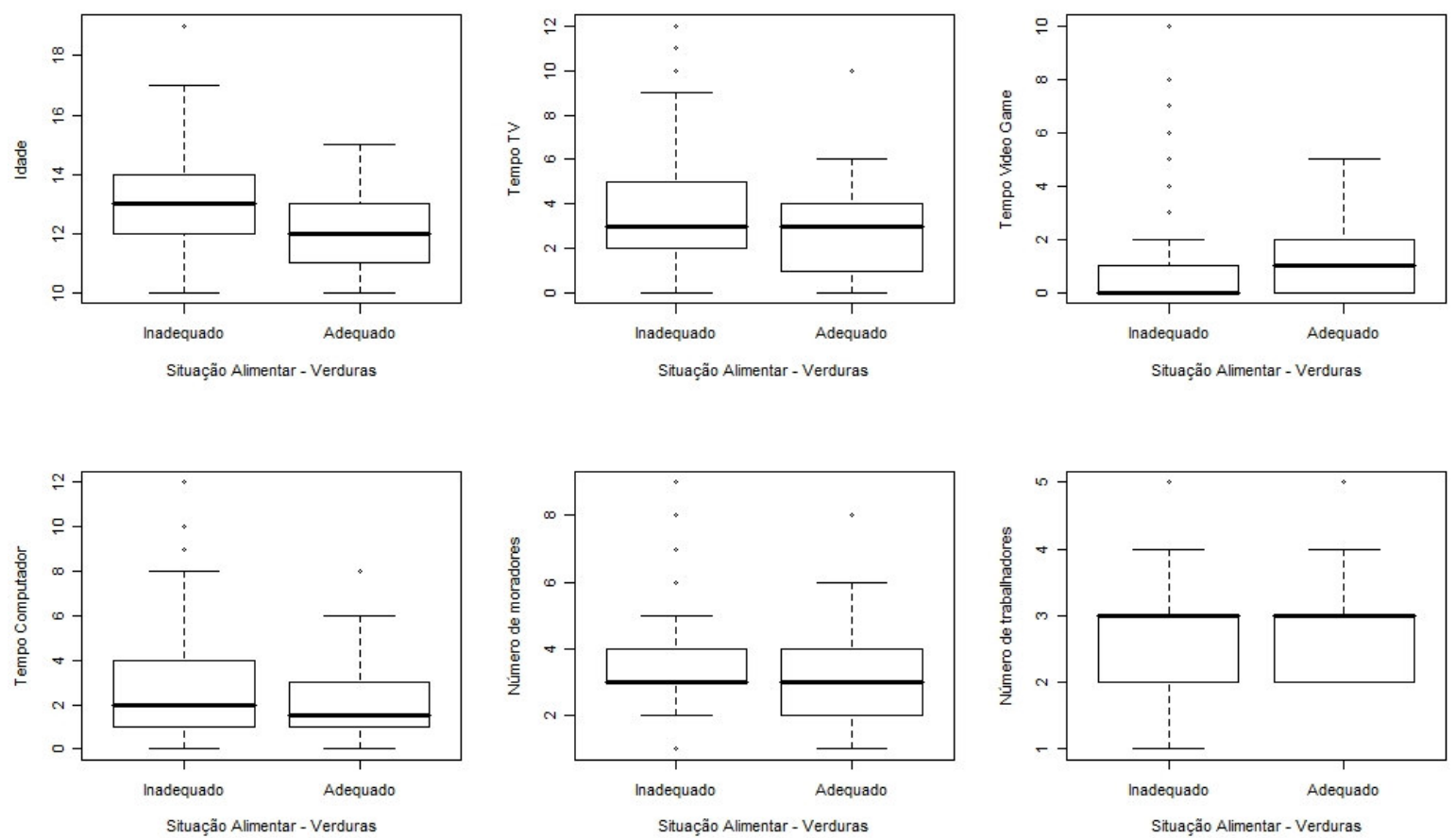

Pelos resultados não se têm evidências significativas para afirmar que existe relação do consumo de verduras/legumes e as covariáveis. 


\subsubsection{Arroz/feijão}

Tabela 11 - Adequação no consumo de arroz/feijão segundo as covariáveis. Curitiba, 2009.

\begin{tabular}{|c|c|c|c|c|c|c|}
\hline \multirow[b]{2}{*}{ Variáveis } & \multicolumn{2}{|c|}{ Inadequado } & \multicolumn{2}{|c|}{ Adequado } & \multicolumn{2}{|c|}{ Total } \\
\hline & $\mathrm{n}$ & $\%$ & $\mathbf{n}$ & $\%$ & $\mathbf{n}$ & $\%$ \\
\hline \multicolumn{7}{|l|}{ Sexo } \\
\hline Feminino & 41 & 21,0 & 154 & 79,0 & 195 & 100 \\
\hline Masculino & 29 & 22,1 & 102 & 77,9 & 131 & 100 \\
\hline \multicolumn{7}{|l|}{ Escol. Pai } \\
\hline até $4^{\mathrm{a}}$ série & 5 & 13,9 & 31 & 86,1 & 36 & 100 \\
\hline $5^{\mathrm{a}}$ a $8^{\mathrm{a}}$ série & 14 & 18,9 & 60 & 81,1 & 74 & 100 \\
\hline $2^{\circ} \mathrm{grau}$ & 37 & 23,7 & 119 & 76,3 & 156 & 100 \\
\hline Superior & 13 & 26,5 & 36 & 73,5 & 49 & 100 \\
\hline Não sabe & 1 & 9,1 & 10 & 90,9 & 11 & 100 \\
\hline \multicolumn{7}{|l|}{ Escol. Mãe } \\
\hline até $4^{\text {a }}$ série & 5 & 13,2 & 33 & 86,8 & 38 & 100 \\
\hline $5^{\mathrm{a}}$ a $8^{\mathrm{a}}$ série & 21 & 23,6 & 68 & 76,4 & 89 & 100 \\
\hline $2^{\circ} \mathrm{grau}$ & 27 & 19,9 & 109 & 80,1 & 136 & 100 \\
\hline Superior & 14 & 23,7 & 45 & 76,3 & 59 & 100 \\
\hline Não sabe & 1 & 50 & 1 & 50 & 2 & 100 \\
\hline \multicolumn{7}{|l|}{ Pai trabalha } \\
\hline Sim & 63 & 21,9 & 224 & 78,1 & 287 & 100 \\
\hline Não & 7 & 17,9 & 32 & 82,1 & 39 & 100 \\
\hline \multicolumn{7}{|l|}{ Mãe trabalha } \\
\hline Sim & 49 & 22,8 & 166 & 77,2 & 215 & 100 \\
\hline Não & 21 & 18,9 & 90 & 81,1 & 111 & 100 \\
\hline \multicolumn{7}{|l|}{ Renda } \\
\hline Até $1 \mathrm{SM}$ * & 1 & 5 & 19 & 95 & 20 & 100 \\
\hline $1 \dashv 3 \mathrm{SM}$ & 29 & 17,8 & 134 & 82,2 & 163 & 100 \\
\hline $3 \dashv 5 \mathrm{SM}$ & 27 & 29,0 & 66 & 71,0 & 93 & 100 \\
\hline Mais de 5 SM & 8 & 23,5 & 26 & 76,5 & 34 & 100 \\
\hline Não sabe & 5 & 27,8 & 11 & 72,2 & 16 & 100 \\
\hline
\end{tabular}

${ }^{\star} \mathrm{SM}=475,00$ 
Figura 3 - Boxplots da adequação no consumo de arroz/feijão segundo as covariáveis contínuas (idade, tempo de TV, tempo de vídeo game, tempo de computador, numero de moradores e quantos deles trabalham).
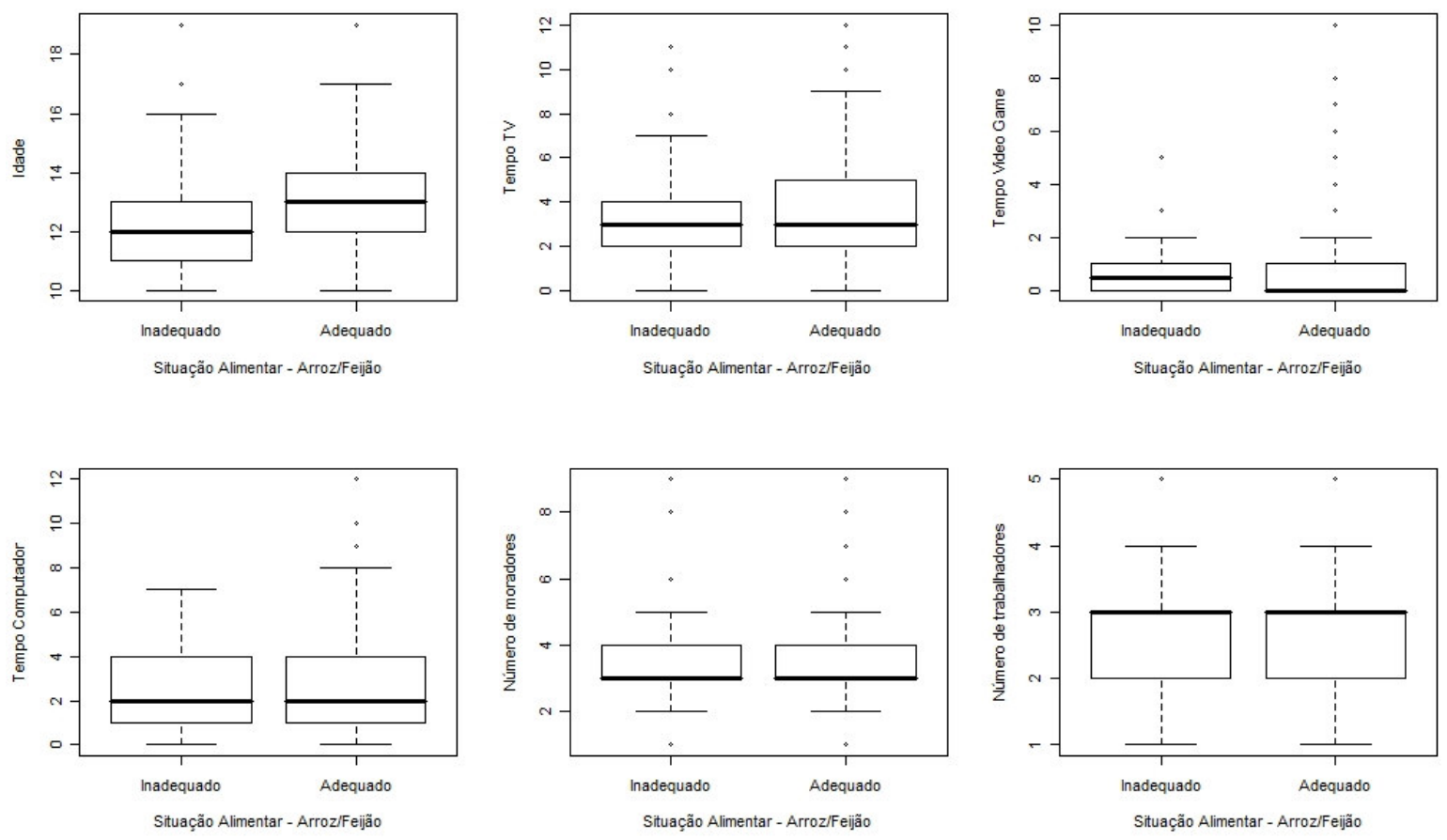

Na análise dos resultados não foi verificada associação entre a frequência de consumo de arroz/feijão e as covariáveis estudadas. 


\subsubsection{Carnes}

Tabela 12 - Adequação no consumo de carnes segundo as covariáveis. Curitiba, 2009.

\begin{tabular}{|c|c|c|c|c|c|c|}
\hline \multirow[b]{2}{*}{ Variáveis } & \multicolumn{2}{|c|}{ Inadequado } & \multicolumn{2}{|c|}{ Adequado } & \multicolumn{2}{|c|}{ Total } \\
\hline & $\mathbf{n}$ & $\%$ & $\mathbf{n}$ & $\%$ & $\mathbf{n}$ & $\%$ \\
\hline \multicolumn{7}{|l|}{ Sexo } \\
\hline Feminino & 58 & 29,7 & 137 & 70,3 & 195 & 100 \\
\hline Masculino & 30 & 22,9 & 101 & 77,1 & 131 & 100 \\
\hline \multicolumn{7}{|l|}{ Escol. Pai } \\
\hline até $4^{\mathrm{a}}$ série & 6 & 16,7 & 30 & 83,3 & 36 & 100 \\
\hline $5^{\mathrm{a}}$ a $8^{\mathrm{a}}$ série & 18 & 24,3 & 56 & 75,7 & 74 & 100 \\
\hline $2^{\circ} \mathrm{grau}$ & 44 & 28,2 & 112 & 71,8 & 156 & 100 \\
\hline Superior & 18 & 36,7 & 31 & 63,3 & 49 & 100 \\
\hline Não sabe & 2 & 18,2 & 9 & 81,8 & 11 & 100 \\
\hline \multicolumn{7}{|l|}{ Escol. Mãe } \\
\hline até $4^{\mathrm{a}}$ série & 8 & 21,1 & 30 & 78,9 & 38 & 100 \\
\hline $5^{\mathrm{a}}$ a $8^{\mathrm{a}}$ série & 19 & 21,3 & 70 & 78,7 & 89 & 100 \\
\hline $2^{\circ}$ grau & 38 & 27,9 & 98 & 72,1 & 136 & 100 \\
\hline Superior & 22 & 36,1 & 39 & 63,9 & 61 & 100 \\
\hline Não sabe & 1 & 50 & 1 & 50 & 2 & 100 \\
\hline \multicolumn{7}{|l|}{ Pai trabalha } \\
\hline Sim & 78 & 27,2 & 209 & 72,8 & 287 & 100 \\
\hline Não & 10 & 25,6 & 29 & 74,4 & 39 & 100 \\
\hline \multicolumn{7}{|l|}{ Mãe trabalha } \\
\hline Sim & 60 & 27,9 & 155 & 72,1 & 215 & 100 \\
\hline Não & 28 & 25,2 & 83 & 74,8 & 111 & 100 \\
\hline \multicolumn{7}{|l|}{ Renda } \\
\hline Até $1 \mathrm{SM}$ * & 4 & 20 & 16 & 80 & 20 & 100 \\
\hline $1 \dashv 3 \mathrm{SM}$ & 40 & 24,5 & 123 & 75,5 & 163 & 100 \\
\hline $3 \dashv 5 \mathrm{SM}$ & 28 & 30,1 & 65 & 69,9 & 93 & 100 \\
\hline Mais de $5 \mathrm{SM}$ & 13 & 38,2 & 21 & 61,8 & 34 & 100 \\
\hline Não sabe & 3 & 18,8 & 13 & 81,3 & 16 & 100 \\
\hline
\end{tabular}

${ }^{*} \mathrm{SM}=475,00$ 
Figura 4 - Boxplots da adequação no consumo de carnes segundo as covariáveis contínuas (idade, tempo de TV, tempo de vídeo game, tempo de computador, numero de moradores e quantos deles trabalham).
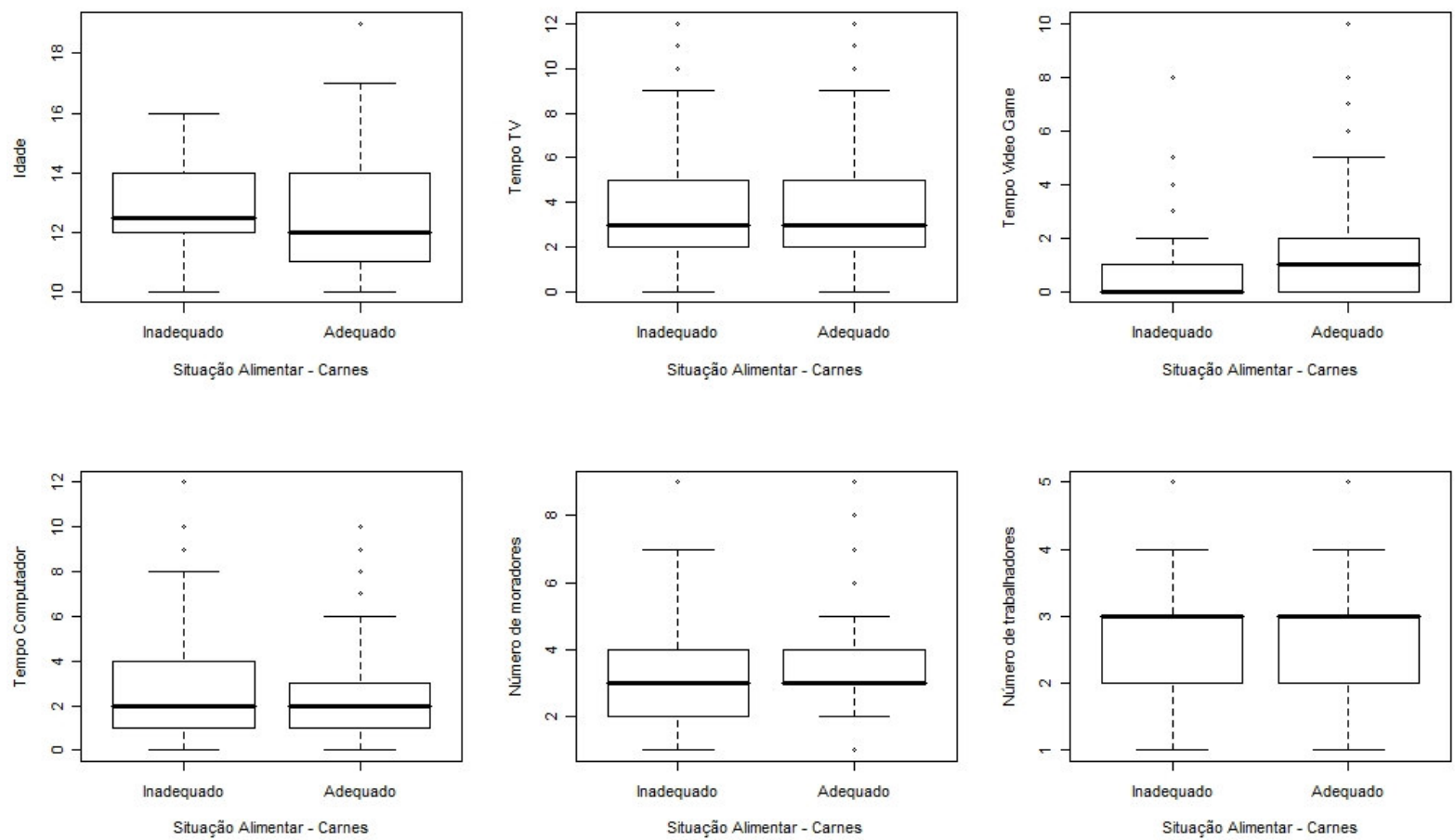

Tabela 13 - Ajuste do modelo logístico para a variável resposta "Consumo de Carnes".

\begin{tabular}{lcccc}
\hline \multicolumn{1}{c}{ Variável } & OR & Z & P-valor & I.C. (95\%) \\
\hline Atividade & & & & \\
Videogame & 1,27 & 2,168 & 0,03 & $1,02-1,576$ \\
Computador & 0,879 & $-2,224$ & 0,024 & $0,983-0,786$ \\
\hline
\end{tabular}

Pela análise dos dados pode-se verificar que o tempo de uso do vídeo game e tempo de uso do computador está associado com o consumo de carne. Pode-se verificar pela tabela que, ao aumentar 1 hora de tempo gasto utilizando o vídeo game, a chance do adolescente ter um consumo adequado de carne aumenta em 1.26 (1.02 - 1.576) vezes. Com relação ao computador o modelo permite inferir que ao aumentar uma hora no tempo de uso do computador a chance do adolescente ter um consumo adequado de carne diminui em 0,879 (0,983 - 0,786). Essas associações, entretanto, podem ser questionadas quando a sua plausibilidade. 
5.5.5 Leite e derivados

Tabela 14 - Adequação no consumo de leite/derivados segundo as covariáveis. Curitiba, 2009.

\begin{tabular}{|c|c|c|c|c|c|c|}
\hline \multirow[b]{2}{*}{ Variáveis } & \multicolumn{2}{|c|}{ Inadequado } & \multicolumn{2}{|c|}{ Adequado } & \multicolumn{2}{|c|}{ Total } \\
\hline & $n$ & $\%$ & $\mathbf{n}$ & $\%$ & $\mathbf{n}$ & $\%$ \\
\hline \multicolumn{7}{|l|}{ Sexo } \\
\hline Feminino & 43 & 22,1 & 152 & 77,9 & 195 & 100 \\
\hline Masculino & 32 & 24,4 & 99 & 75,6 & 131 & 100 \\
\hline \multicolumn{7}{|l|}{ Escol. Pai } \\
\hline até $4^{\text {a }}$ série & 12 & 33,3 & 24 & 66,7 & 36 & 100 \\
\hline $5^{\mathrm{a}}$ a $8^{\mathrm{a}}$ série & 13 & 17,6 & 61 & 82,4 & 74 & 100 \\
\hline $2^{\circ}$ grau & 36 & 23,1 & 120 & 76,9 & 156 & 100 \\
\hline Superior & 14 & 28,6 & 35 & 71,4 & 49 & 100 \\
\hline Não sabe & 0 & 0 & 11 & 100 & 11 & 100 \\
\hline \multicolumn{7}{|l|}{ Escol. Mãe } \\
\hline até $4^{\mathrm{a}}$ série & 10 & 26,3 & 28 & 73,7 & 38 & 100 \\
\hline $5^{\mathrm{a}}$ a $8^{\mathrm{a}}$ série & 21 & 23,6 & 68 & 76,4 & 89 & 100 \\
\hline $2^{\circ}$ grau & 32 & 23,5 & 104 & 76,5 & 136 & 100 \\
\hline Superior & 11 & 18 & 50 & 82 & 61 & 100 \\
\hline Não sabe & 1 & 50 & 1 & 50 & 2 & 100 \\
\hline \multicolumn{7}{|l|}{ Pai trabalha } \\
\hline Sim & 63 & 21,9 & 224 & 78,1 & 287 & 100 \\
\hline Não & 12 & 30,8 & 27 & 69,2 & 39 & 100 \\
\hline \multicolumn{7}{|l|}{ Mãe trabalha } \\
\hline Sim & 48 & 22,3 & 167 & 77,7 & 215 & 100 \\
\hline Não & 27 & 24,3 & 84 & 75,7 & 111 & 100 \\
\hline \multicolumn{7}{|l|}{ Renda } \\
\hline Até $1 \mathrm{SM}$ * & 8 & 40 & 12 & 60 & 20 & 100 \\
\hline $1 \dashv 3 \mathrm{SM}$ & 32 & 19,6 & 131 & 80,4 & 163 & 100 \\
\hline $3 \dashv 5 \mathrm{SM}$ & 19 & 20,4 & 74 & 79,6 & 93 & 100 \\
\hline Mais de $5 \mathrm{SM}$ & 8 & 23,5 & 26 & 76,5 & 34 & 100 \\
\hline Não sabe & 6 & 37,5 & 10 & 62,5 & 16 & 100 \\
\hline
\end{tabular}

${ }^{*} \mathrm{SM}=475,00$ 
Figura 5 - Boxplots da adequação no consumo de leite/derivados segundo covariáveis contínuas (idade, tempo de TV, tempo de vídeo game, tempo de computador, numero de moradores e quantos deles trabalham).



Situação Alimentar - Leite e derivados



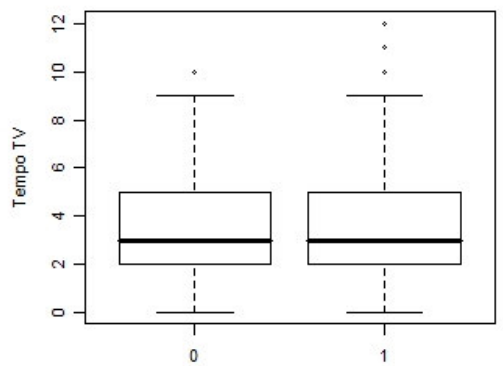

Situação Alimentar - Leite e derivados

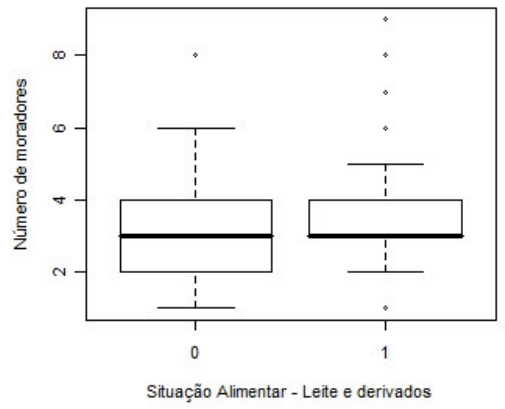





De acordo com os dados não se verificaram associações entre as covariáveis consideradas e o consumo de leite e derivados. 


\subsubsection{Doces}

Tabela 15 - Adequação no consumo de doces segundo as covariáveis. Curitiba, 2009.

\begin{tabular}{|c|c|c|c|c|c|c|}
\hline \multirow[b]{2}{*}{ Variáveis } & \multicolumn{2}{|c|}{ Inadequado } & \multicolumn{2}{|c|}{ Adequado } & \multicolumn{2}{|c|}{ Total } \\
\hline & $\mathbf{n}$ & $\%$ & $\mathbf{n}$ & $\%$ & $\mathbf{n}$ & $\%$ \\
\hline \multicolumn{7}{|l|}{ Sexo } \\
\hline Feminino & 149 & 76,4 & 46 & 23,6 & 195 & 100 \\
\hline Masculino & 100 & 76,3 & 31 & 23,7 & 131 & 100 \\
\hline \multicolumn{7}{|l|}{ Escol. Pai } \\
\hline até $4^{\mathrm{a}}$ série & 28 & 77,8 & 8 & 22,2 & 36 & 100 \\
\hline $5^{\mathrm{a}}$ a $8^{\mathrm{a}}$ série & 57 & 77,0 & 17 & 23,0 & 74 & 100 \\
\hline $2^{\circ}$ grau & 119 & 76,3 & 37 & 23,7 & 156 & 100 \\
\hline Superior & 36 & 73,5 & 13 & 26,5 & 49 & 100 \\
\hline Não sabe & 9 & 81,8 & 2 & 18,2 & 11 & 100 \\
\hline \multicolumn{7}{|l|}{ Escol. Mãe } \\
\hline até $4^{\mathrm{a}}$ série & 29 & 76,3 & 9 & 23,7 & 38 & 100 \\
\hline $5^{\mathrm{a}}$ a $8^{\mathrm{a}}$ série & 77 & 86,5 & 12 & 13,5 & 89 & 100 \\
\hline $2^{\circ}$ grau & 100 & 73,5 & 36 & 26,5 & 136 & 100 \\
\hline Superior & 42 & 68,9 & 19 & 31,1 & 61 & 100 \\
\hline Não sabe & 1 & 50 & 1 & 50 & 2 & 100 \\
\hline \multicolumn{7}{|l|}{ Pai trabalha } \\
\hline Sim & 218 & 76,0 & 69 & 24,0 & 287 & 100 \\
\hline Não & 31 & 79,5 & 8 & 20,5 & 39 & 100 \\
\hline \multicolumn{7}{|l|}{ Mãe trabalha } \\
\hline Sim & 163 & 75,8 & 52 & 24,2 & 215 & 100 \\
\hline Não & 86 & 77,5 & 25 & 22,5 & 111 & 100 \\
\hline \multicolumn{7}{|l|}{ Renda } \\
\hline Até $1 \mathrm{SM}$ * & 16 & 80 & 4 & 20 & 20 & 100 \\
\hline $1 \dashv 3 \mathrm{SM}$ & 126 & 77,3 & 37 & 22,7 & 163 & 100 \\
\hline $3 \dashv 5 \mathrm{SM}$ & 72 & 77,4 & 21 & 22,6 & 93 & 100 \\
\hline Mais de $5 \mathrm{SM}$ & 27 & 79,4 & 7 & 20,6 & 34 & 100 \\
\hline Não sabe & 9 & 56,3 & 7 & 43,8 & 16 & 100 \\
\hline
\end{tabular}

${ }^{*} \mathrm{SM}=475,00$ 
Figura 6 - Boxplots da adequação no consumo de doces segundo as covariáveis contínuas (idade, tempo de TV, tempo de vídeo game, tempo de computador, numero de moradores e quantos deles trabalham).
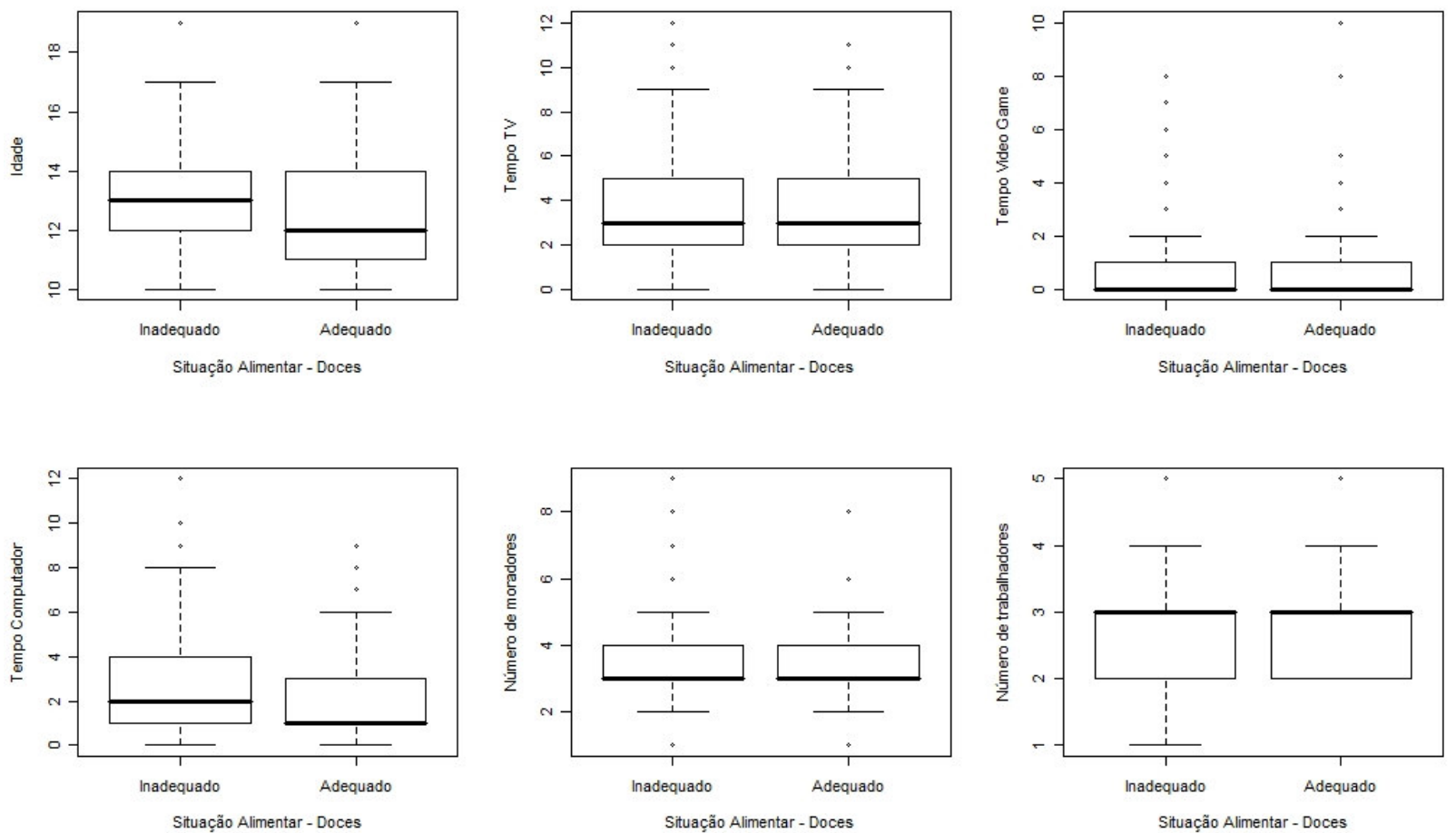

Tabela 16 - Ajuste do modelo logístico para a variável resposta "Consumo de Doces".

\begin{tabular}{lcccc}
\hline \multicolumn{1}{c}{ Variável } & OR & Z & P-valor & I.C. (95\%) \\
\hline Atividade & & & & \\
TV & 0,867 & $-2,13$ & 0,032 & $0,988-0,764$ \\
Computador & 0,844 & $-2,334$ & 0,019 & $0,974-0,732$ \\
\hline
\end{tabular}

A análise dos dados permite verificar que as covariáveis tempo assistindo TV e tempo de uso do computador têm relação significativa com o consumo de doces. O modelo mostra que ao aumentar em uma hora o tempo de TV a chance do adolescente apresentar um consumo adequado de doces diminui em 0,867 (0,988$0,764)$. Com relação ao tempo de uso do computador verifica-se que ao aumentar em uma hora o tempo de uso do computador diminui a chance do adolescente ter um consumo adequado de doces em $0,844(0,974-0,732)$. 


\subsubsection{Salgados}

Tabela 17 - Adequação no consumo de salgados segundo as covariáveis. Curitiba, 2009.

\begin{tabular}{|c|c|c|c|c|c|c|}
\hline \multirow[b]{2}{*}{ Variáveis } & \multicolumn{2}{|c|}{ Inadequado } & \multicolumn{2}{|c|}{ Adequado } & \multicolumn{2}{|c|}{ Total } \\
\hline & $n$ & $\%$ & $\mathbf{n}$ & $\%$ & $n$ & $\%$ \\
\hline \multicolumn{7}{|l|}{ Sexo } \\
\hline Feminino & 87 & 44,6 & 108 & 55,4 & 195 & 100 \\
\hline Masculino & 60 & 45,8 & 71 & 54,2 & 131 & 100 \\
\hline \multicolumn{7}{|l|}{ Escol. Pai } \\
\hline até $4^{\mathrm{a}}$ série & 14 & 38,9 & 22 & 61,1 & 36 & 100 \\
\hline $5^{\mathrm{a}}$ a $8^{\mathrm{a}}$ série & 34 & 45,9 & 40 & 54,1 & 74 & 100 \\
\hline $2^{\circ}$ grau & 77 & 49,4 & 79 & 50,6 & 156 & 100 \\
\hline Superior & 17 & 34,7 & 32 & 65,3 & 49 & 100 \\
\hline Não sabe & 5 & 45,4 & 6 & 54,6 & 11 & 100 \\
\hline \multicolumn{7}{|l|}{ Escol. Mãe } \\
\hline até $4^{\text {a }}$ série & 17 & 44,7 & 21 & 55,3 & 38 & 100 \\
\hline $5^{\mathrm{a}}$ a $8^{\mathrm{a}}$ série & 43 & 48,3 & 46 & 51,7 & 89 & 100 \\
\hline $2^{\circ}$ grau & 63 & 46,3 & 73 & 53,7 & 136 & 100 \\
\hline Superior & 24 & 39,3 & 37 & 60,7 & 61 & 100 \\
\hline Não sabe & 0 & 0 & 2 & 100 & 2 & 100 \\
\hline \multicolumn{7}{|l|}{ Pai trabalha } \\
\hline Sim & 130 & 45,3 & 157 & 54,7 & 287 & 100 \\
\hline Não & 17 & 43,6 & 22 & 56,4 & 39 & 100 \\
\hline \multicolumn{7}{|l|}{ Mãe trabalha } \\
\hline Sim & 102 & 47,4 & 113 & 52,6 & 215 & 100 \\
\hline Não & 45 & 40,5 & 66 & 59,5 & 111 & 100 \\
\hline \multicolumn{7}{|l|}{ Renda } \\
\hline Até $1 \mathrm{SM}$ * & 9 & 45 & 11 & 55 & 20 & 100 \\
\hline $1 \dashv 3 \mathrm{SM}$ & 74 & 45,4 & 89 & 54,6 & 163 & 100 \\
\hline $3 \dashv 5 \mathrm{SM}$ & 44 & 47,3 & 49 & 52,7 & 93 & 100 \\
\hline Mais de $5 \mathrm{SM}$ & 16 & 47,1 & 18 & 52,9 & 34 & 100 \\
\hline Não sabe & 6 & 33,3 & 12 & 66,7 & 18 & 100 \\
\hline
\end{tabular}

${ }^{*} \mathrm{SM}=475,00$ 
Figura 7 - Boxplots da adequação no consumo de salgados segundo as covariáveis contínuas (idade, tempo de TV, tempo de vídeo game, tempo de computador, numero de moradores e quantos deles trabalham).

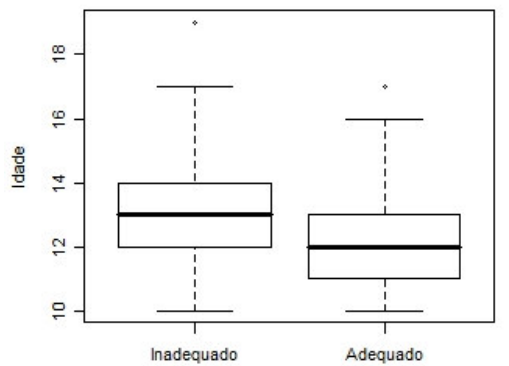

Situação Alimentar - Salgados

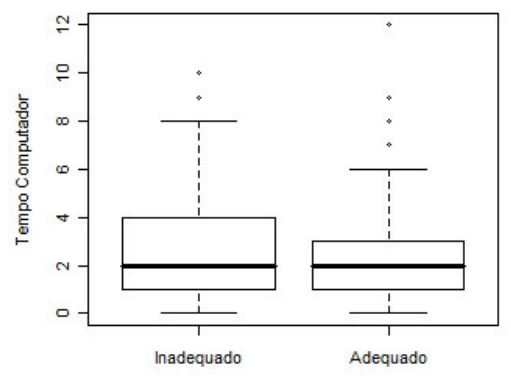

Situação Alimentar - Salgados

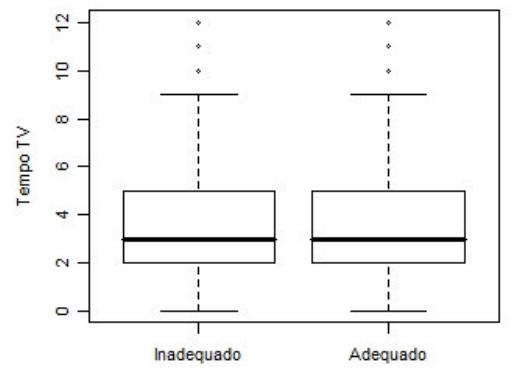

Situação Alimentar - Salgados

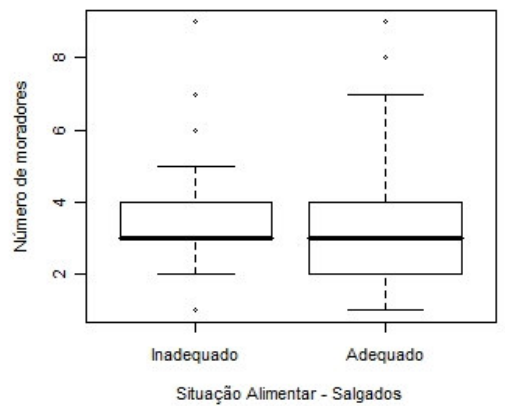

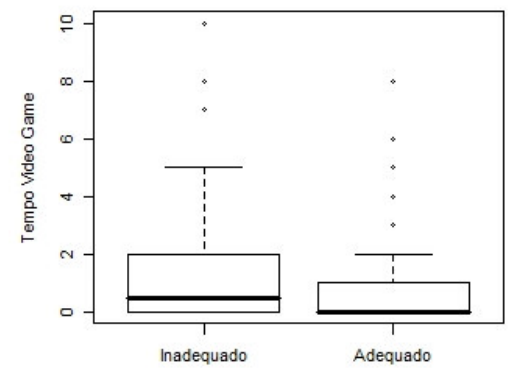

Situação Alimentar - Salgados

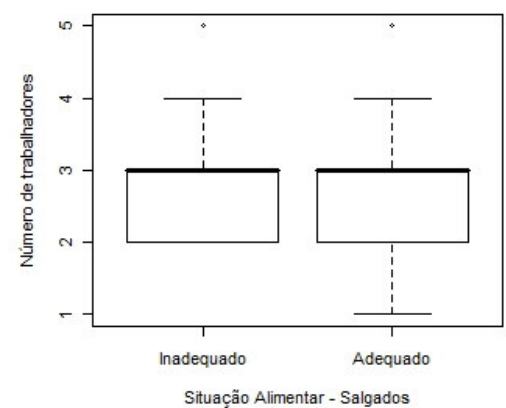

Tabela 18 - Ajuste do modelo logístico para a variável resposta "Consumo de Salgados".

\begin{tabular}{ccccc}
\hline Variável & OR & Z & P-valor & I.C. (95\%) \\
\hline Idade & 0,846 & $-2,187$ & 0,028 & $0,983-0,728$ \\
\hline
\end{tabular}

É possível afirmar que o consumo de salgados está associado com a idade. $O$ modelo mostra que ao aumentar em um ano a idade do adolescente, a chance deste ter um consumo adequado de salgados diminui em 0,846 $(0,983-0,728)$. 
5.5.8 Refrigerantes/suco industrializado

Tabela 19 - Adequação no consumo de refrigerante/suco industrializado segundo as covariáveis. Curitiba, 2009.

\begin{tabular}{|c|c|c|c|c|c|c|}
\hline \multirow[b]{2}{*}{ Variáveis } & \multicolumn{2}{|c|}{ Inadequado } & \multicolumn{2}{|c|}{ Adequado } & \multicolumn{2}{|c|}{ Total } \\
\hline & $\mathbf{n}$ & $\%$ & $n$ & $\%$ &  & $\%$ \\
\hline \multicolumn{7}{|l|}{ Sexo } \\
\hline Feminino & 162 & 83,1 & 33 & 16,9 & 195 & 100 \\
\hline Masculino & 113 & 86,3 & 18 & 13,7 & 131 & 100 \\
\hline \multicolumn{7}{|l|}{ Escol. Pai } \\
\hline até $4^{\text {a }}$ série & 14 & 38,9 & 22 & 61,1 & 36 & 100 \\
\hline $5^{\mathrm{a}}$ a $8^{\mathrm{a}}$ série & 45 & 60,8 & 29 & 39,2 & 74 & 100 \\
\hline $2^{\circ}$ grau & 94 & 60,3 & 62 & 39,7 & 156 & 100 \\
\hline Superior & 35 & 71,4 & 14 & 28,6 & 49 & 100 \\
\hline Não sabe & 3 & 27,3 & 8 & 72,7 & 11 & 100 \\
\hline \multicolumn{7}{|l|}{ Escol. Mãe } \\
\hline até $4^{\mathrm{a}}$ série & 34 & 89,5 & 4 & 10,5 & 38 & 100 \\
\hline $5^{a}$ a $8^{a}$ série & 76 & 85,4 & 13 & 14,6 & 89 & 100 \\
\hline $2^{\circ}$ grau & 112 & 82,4 & 24 & 17,6 & 136 & 100 \\
\hline Superior & 52 & 85,2 & 9 & 14,8 & 61 & 100 \\
\hline Não sabe & 1 & 50 & 1 & 50 & 2 & 100 \\
\hline \multicolumn{7}{|l|}{ Pai trabalha } \\
\hline Sim & 243 & 84,7 & 44 & 15,3 & 287 & 100 \\
\hline Não & 32 & 82,1 & 7 & 17,9 & 39 & 100 \\
\hline \multicolumn{7}{|l|}{ Mãe trabalha } \\
\hline Sim & 184 & 85,6 & 31 & 14,4 & 215 & 100 \\
\hline Não & 91 & 82,0 & 20 & 18,0 & 111 & 100 \\
\hline \multicolumn{7}{|l|}{ Renda } \\
\hline Até $1 \mathrm{SM}$ * & 18 & 90 & 2 & 10 & 20 & 100 \\
\hline $1 \dashv 3 \mathrm{SM}$ & 139 & 85,3 & 24 & 14,7 & 163 & 100 \\
\hline $3 \dashv 5 \mathrm{SM}$ & 81 & 87,1 & 12 & 12,9 & 93 & 100 \\
\hline Mais de $5 \mathrm{SM}$ & 26 & 76,5 & 8 & 23,5 & 34 & 100 \\
\hline Não sabe & 11 & 68,8 & 5 & 31,3 & 16 & 100 \\
\hline
\end{tabular}

${ }^{\star} \mathrm{SM}=475,00$ 
Figura 8 - Boxplots da adequação no consumo de refrigerantes/suco industrializado segundo as covariáveis contínuas (idade, tempo de TV, tempo de vídeo game, tempo de computador, numero de moradores e quantos deles trabalham).
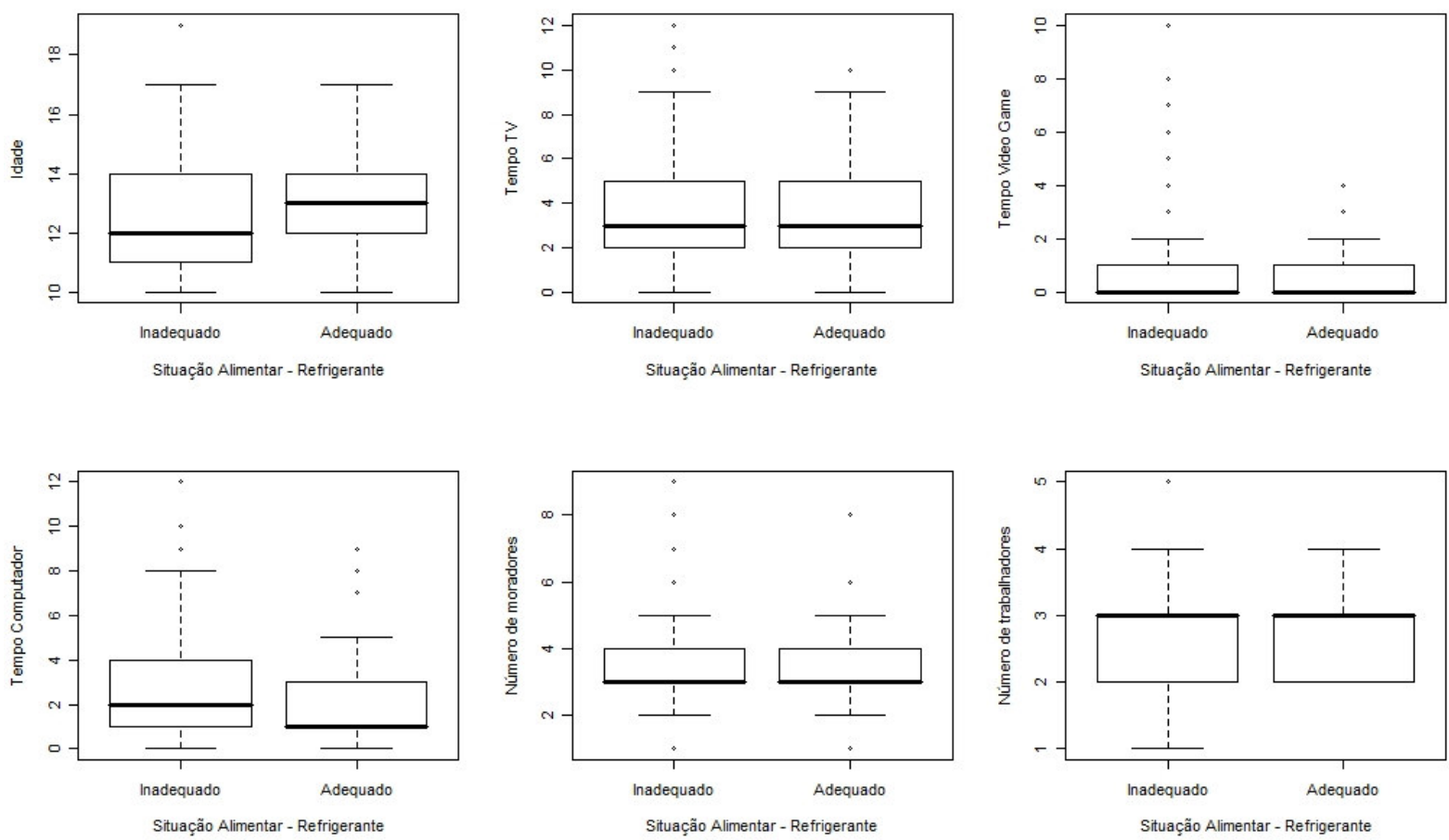

Tabela 20 - Ajuste do modelo logístico para a variável resposta "Consumo de Refrigerante".

\begin{tabular}{lcccc}
\hline \multicolumn{1}{c}{ Variável } & OR & Z & P-valor & I.C. (90\%) \\
\hline Idade & 1,202 & 1,927 & 0,054 & $1,026-1,407$ \\
Computador & 0.870 & $-1,692$ & 0,09 & $0,997-0,759$ \\
\hline
\end{tabular}

Por meio da análise dos dados é possível verificar que as covariáveis idade e tempo de uso do computador estão relacionadas com o consumo de refrigerante. Com relação à idade verifica-se que o aumento de um ano na idade aumenta a chance de consumo adequado de refrigerante em 1.202 (1.026 - 1.407), com intervalo de $90 \%$ de confiança. Para a covariável tempo de uso do computador verifica-se que ao aumentar em uma hora o tempo desta atividade diminui a chance do adolescente apresentar um consumo adequado de refrigerante em 0,870 (0,997 $0,759)$. 


\subsubsection{Refeições}

Tabela 21 - Adequação do número de refeições segundo as covariáveis. Curitiba, 2009.

\begin{tabular}{|c|c|c|c|c|c|c|}
\hline \multirow[b]{2}{*}{ Variáveis } & \multicolumn{2}{|c|}{ Inadequado } & \multicolumn{2}{|c|}{ Adequado } & \multicolumn{2}{|c|}{ Total } \\
\hline & $\mathbf{n}$ & $\%$ & $\mathbf{n}$ & $\%$ & $\mathbf{n}$ & $\%$ \\
\hline \multicolumn{7}{|l|}{ Sexo } \\
\hline Feminino & 125 & 64,1 & 70 & 35,9 & 195 & 100 \\
\hline Masculino & 66 & 50,4 & 65 & 49,6 & 131 & 100 \\
\hline \multicolumn{7}{|l|}{ Escol. Pai } \\
\hline até $4^{\mathrm{a}}$ série & 14 & 38,9 & 22 & 61,1 & 36 & 100 \\
\hline $5^{\mathrm{a}}$ a $8^{\mathrm{a}}$ série & 45 & 60,8 & 29 & 39,2 & 74 & 100 \\
\hline $2^{\circ}$ grau & 94 & 60,3 & 62 & 39,7 & 156 & 100 \\
\hline Superior & 35 & 71,4 & 14 & 28,6 & 49 & 100 \\
\hline Não sabe & 3 & 27,3 & 8 & 72,7 & 11 & 100 \\
\hline \multicolumn{7}{|l|}{ Escol. Mãe } \\
\hline até $4^{\mathrm{a}}$ série & 20 & 52,6 & 18 & 47,4 & 38 & 100 \\
\hline $5^{\mathrm{a}}$ a $8^{\mathrm{a}}$ série & 53 & 59,6 & 36 & 40,4 & 89 & 100 \\
\hline $2^{\circ}$ grau & 81 & 59,6 & 55 & 40,4 & 136 & 100 \\
\hline Superior & 35 & 57,4 & 26 & 42,6 & 61 & 100 \\
\hline Não sabe & 2 & 100 & 0 & 0 & 2 & 100 \\
\hline \multicolumn{7}{|l|}{ Pai trabalha } \\
\hline Sim & 165 & 57,5 & 122 & 42,5 & 287 & 100 \\
\hline Não & 26 & 66,7 & 13 & 33,3 & 39 & 100 \\
\hline \multicolumn{7}{|l|}{ Mãe trabalha } \\
\hline Sim & 124 & 57,7 & 91 & 42,3 & 215 & 100 \\
\hline Não & 67 & 60,4 & 44 & 39,6 & 111 & 100 \\
\hline \multicolumn{7}{|l|}{ Renda } \\
\hline Até $1 \mathrm{SM}$ * & 11 & 55 & 9 & 45 & 20 & 100 \\
\hline $1 \dashv 3 \mathrm{SM}$ & 91 & 55,8 & 72 & 44,2 & 163 & 100 \\
\hline $3 \dashv 5 \mathrm{SM}$ & 58 & 62,4 & 35 & 37,6 & 93 & 100 \\
\hline Mais de $5 \mathrm{SM}$ & 20 & 58,8 & 14 & 41,2 & 34 & 100 \\
\hline Não sabe & 12 & 75 & 4 & 25 & 16 & 100 \\
\hline
\end{tabular}

${ }^{*} \mathrm{SM}=475,00$ 
Figura 9 - Boxplots da adequação no numero de refeições ao dia segundo as covariáveis contínuas (idade, tempo de TV, tempo de vídeo game, tempo de computador, numero de moradores e quantos deles trabalham).

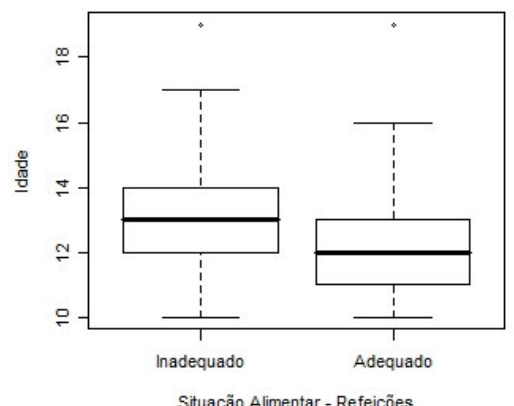

Situação Alimentar - Refeições

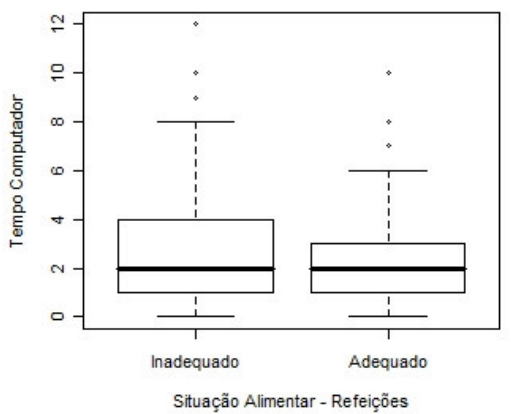

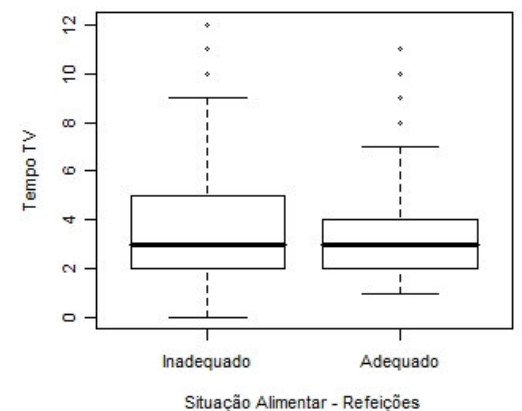



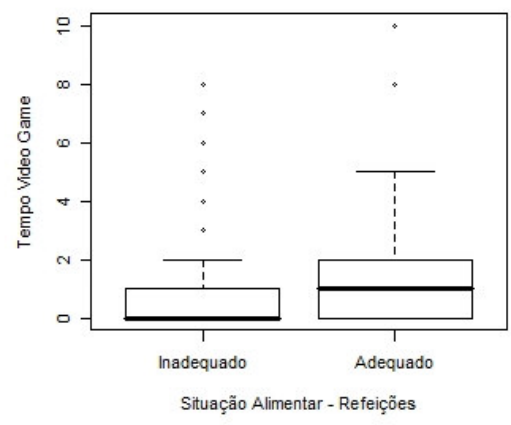

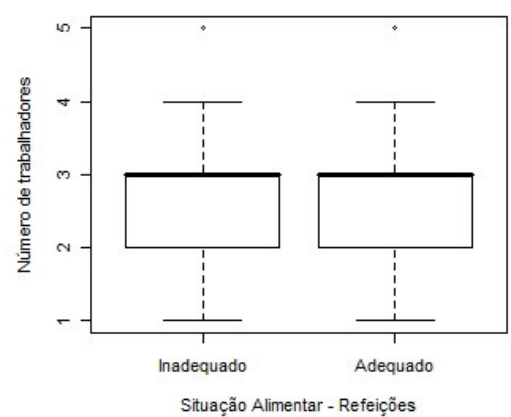

Tabela 22 - Ajuste do modelo logístico para a variável resposta "Número de refeições".

\begin{tabular}{lcccc}
\hline \multicolumn{1}{c}{ Variável } & OR & Z & P-valor & I.C. (95\%) \\
\hline Sexo feminino & 1 & - & - & - \\
Sexo masculino & 1,748 & 2,42 & 0,015 & $1,113-2,473$ \\
Computador & 0,911 & $-1,668$ & 0,095 & $0,999-0,831$ \\
\hline
\end{tabular}

A análise dos dados revela que a variável "número de refeições ao dia" apresenta relação significativa com as covariáveis sexo e tempo de uso do computador. Com relação ao sexo é possível inferir que o sexo masculino tem 1.748 (1.113 - 2.743) vezes mais chances de realizar o número de refeições adequado quando comparado com o sexo feminino. Com relação ao tempo de uso do computador verifica-se que com o aumento de uma hora desta atividade, diminui a chance do adolescente realizar o número adequado de refeições em 0,911 (0,999 0,831), porém essa associação só é verificada com 10\% de significância. 


\section{DISCUSSÃO}

Este trabalho buscou investigar aspectos do consumo de alimentos/grupos alimentares e do estilo de vida de adolescentes de $5^{\mathrm{a}}$ a $8^{\mathrm{a}}$ séries de escolas da rede municipal de ensino localizadas em regionais diferentes da cidade de Curitiba.

Uma das principais limitações do trabalho, como descrito nos resultados, foi a baixa participação dos adolescentes. Outros estudos observaram comportamento semelhante, como o desenvolvido por Toral et al (2007) com adolescentes de 10 a 17 anos da cidade de Piracicaba, em que os autores destacaram que as maiores perdas foram devido ao não fornecimento de informações socioeconômicas por pais ou responsáveis pelos adolescentes. Possivelmente, as elevadas perdas nesse trabalho também poderiam ser justificadas pelo fato do preenchimento do questionário socioeconômico enviado aos pais com os demais documentos, ser condicionante para a participação do escolar na pesquisa. Esse, juntamente com os outros fatores citados anteriormente, colaboraram para as perdas apresentadas.

Outra limitação diz respeito à utilização de uma amostra não probabilística, por conveniência, que se deu pela necessidade de se realizar uma pesquisa factível, em decorrência dos recursos disponíveis. Entretanto, outros estudos que utilizaram o mesmo processo de amostragem não aleatória conseguiram verificar comportamentos inadequados de consumo alimentar em adolescentes, como o baixo consumo de frutas e verduras visto na pesquisa de Toral et al (2006).

Quanto ao sexo dos participantes, verificou-se que as meninas tiveram maior participação na pesquisa, principalmente na escola da regional periférica. Zancul et al (2004) em sua pesquisa sobre a alimentação de adolescentes de escolas da rede municipal, estadual e particular de ensino de Ribeirão Preto, observou o mesmo comportamento, descrevendo que as adolescentes, além de maior empenho em participar, tinham também mais informações sobre alimentação.

Nessa pesquisa, a média de idade dos adolescentes foi semelhante à outros estudos como o de Toral et al, em que a média foi de 12,4 anos, e o de Nunes et al, de escolares com idade média de 12,8 anos (TORAL et al, 2007; NUNES et al, 2007).

Pela análise das respostas do questionário socioeconômico, observou-se que a mediana do número de pessoas que mora na casa e de pessoas que trabalham 
foram semelhantes nas duas regionais. Com base nos dados habitacionais do "Censo 2000" realizado em Curitiba pelo IPPUC em parceria com o IBGE, verificouse uma redução significativa do número de moradores por domicílio nos últimos 30 anos. Especialmente, na década de 90, o Censo registrou a existência de 3,65 pessoas por moradia. Em 1996, a relação moradores/domicílio havia caído para 3,43 e, na ultima verificação, a queda foi ainda maior, atingindo a média de 2,93 habitantes por domicílio. Mais especificamente nos bairros, o Censo 2000, revela que a média de moradores por domicilio do bairro Novo Mundo, onde se encontra a EM1, é de 3,30. E, com pouca diferença, o bairro Cidade Industrial, onde se localiza a EM2, apresentou média de 3,59 moradores/domicilio (IPPUC, 2000; IPPUC, 2009).

$\mathrm{Na}$ maioria das residências dos escolares das duas regionais, pelo menos dois adultos trabalham fora do domicilio, em média. Nesse estudo, ainda foi possível observar que, os pais têm ocupação fora do domicilio em porcentagens maiores que das mães.

As informações de quantas pessoas moram na residência e quantas delas trabalham auxiliam, subjetivamente, a inferir sobre as condições econômicas (renda familiar) e de moradia dos escolares. Além disso, alguns autores referenciaram que a obesidade em crianças e adolescentes está também associada à ocupação dos pais, e outros fatores como o tamanho da família, classe social e o nível de educação dos pais, que podem influenciar profundamente nos hábitos dietéticos e de atividade física (SALBE \& RAVUSSIN, 2002 apud ILHA, 2004). Outros autores destacam ainda que, a significativa inserção da mulher no mercado de trabalho dificultou a prática do aleitamento materno exclusivo até o sexto mês e, posteriormente, o preparo de refeições no domicílio, o que, por sua vez, propiciou o consumo de alimentos industrializados e a ingestão maior de açúcares e gordura por crianças e adolescentes (RINALDI et al, 2008).

Outro aspecto importante sobre a condição socioeconômica é o nível de escolaridade dos pais. Quanto a isso foi possível perceber que os dados do IPPUC sobre as condições socioeconômica dos bairros onde se localizam as escolas confirmam o que foi verificado no estudo. O Censo revela que a maior parte dos responsáveis pelos domicílios da regional periférica possuem de 4 a 7 anos de estudo, enquanto que na regional central, esses valores são de 11 a 14 anos (IPPUC, 2008). Semelhantemente, no estudo de Toral et al (2007), com 
adolescentes de escolas públicas de Piracicaba, foi constatado que a maioria $(57,2 \%)$ dos pais ou responsáveis cursou até o $1^{\circ}$ grau.

Quanto à renda familiar, semelhante aos resultados desse estudo, pelos dados do IPPUC nota-se que a renda da maioria de domicílios da regional periférica é de 3 a 5 salários mínimos, e de 5 a 10, na maioria dos domicílios da regional central (IPPUC, 2008). No estudo de Toral et al (2007), pôde ser visto que cerca de $80 \%$ das famílias dispunham de uma renda total composta por 5 salários mínimos, mas a média encontrada foi de 3 salários mínimos.

A respeito do consumo de frutas/suco natural de frutas, é possível verificar que a frequência de consumo diário está inferior ao recomendado pelo MS nos "10 passos para uma alimentação saudável", que é de no mínimo 3 porções. No mesmo sentido, estudo sobre os hábitos alimentares e de estilo de vida de adolescentes de diferentes classes socioeconômicas de Campina Grande - PB, verificou que apenas $4,5 \%$ dos adolescentes das duas escolas consomem frutas diariamente (NUNES et al, 2007). Na pesquisa sobre hábitos alimentares e do estilo de vida com adolescentes de escolas públicas e privadas de Florianópolis-SC, os autores verificaram que, aproximadamente dois em cada três escolares, relataram não consumir frutas diariamente (FARIAS JR \& LOPES, 2004).

Outro estudo desenvolvido por Toral et al (2006) sobre o consumo de frutas e verduras por adolescentes de São Paulo, observou que a mediana de consumo foi de 0,97 e 1,2 porções diárias para frutas e verduras, respectivamente. Sendo que apenas $12,4 \%$ e $10,3 \%$ deles consumiam frutas e verduras, respectivamente, conforme o recomendado pela Pirâmide Alimentar. Essa recomendação, proposta por Philippi et al (1999), sugere como adequado o consumo de 3 a 5 porções diárias de frutas e de 4 a 5 porções diárias de verduras.

Do mesmo modo, com relação aos legumes e verduras, a frequência diária de consumo desse grupo de alimentos também está abaixo do preconizado pelo MS, que é de 3 porções ao dia. O estudo desenvolvido por Ximenes et al (2006) sobre os hábitos alimentares de adolescentes com idade média de 14 anos de escolas estaduais e particulares da cidade do Recife, reforça esse aspecto, constando esse grupo de alimentos como o menos consumido (34,5\% consomem). No estudo já citado com adolescentes de Florianópolis, os autores encontraram que o consumo diário de verduras não foi referido por $74,3 \%$ dos rapazes e $65,8 \%$ das moças (FARIAS JR \& LOPES, 2004). 
Esses achados reforçam o que tem sido discutido na literatura atualmente, como o padrão alimentar característico do adolescente, que inclui reduzida ingestão de frutas e hortaliças, e o consumo excessivo de refrigerantes, doces e sanduíches (FISBERG et al, 2000; 2004).

O consumo de frutas mostrou-se associado à covariável "trabalho do pai". O fato do pai não trabalhar fora, relacionou-se favoravelmente ao consumo adequado de frutas pelos adolescentes. Porém a presença paterna não influenciou o consumo de outros alimentos. Não são encontrados estudos que tenham verificado essa associação, portanto, esse fato, de difícil explicação, talvez possa ter ocorrido devido ao número pequeno de casos (apenas 39 pais não trabalhavam fora de casa).

A presença de frutas e verduras na alimentação, respeitando as quantidades e frequências recomendadas, é essencial para a prevenção da obesidade infantojuvenil, em conjunto com outras mudanças na alimentação e no estilo de vida. A promoção do consumo desses alimentos implica também na ingestão de vitaminas, minerais e fibras, tão necessários para crescimento e desenvolvimento adequados nessa faixa etária e para um bom funcionamento do organismo em geral (WHO, 2003).

No estudo de Claro et al (2007) foi possível encontrar associação entre renda e participação de frutas, legumes e verduras (FLV) no consumo alimentar de famílias do município de São Paulo. Foi possível verificar que a participação de FLV, no total de calorias adquirido pela família, aumentou com o incremento da renda familiar, aumento do preço dos demais alimentos e diminuição do próprio preço de FLV.

Diante do crescimento da obesidade e de doenças crônicas associadas à alimentação em todo mundo, o desejável é que FLV estejam presentes em substituição à alimentos altamente calóricos e pouco nutritivos.

Os resultados do estudo citado, do autor Claro e colaboradores (2007), indicam o aumento da renda familiar ou a redução do preço de FLV como possíveis formas de aumentar a participação desses alimentos na dieta. Para que isso aconteça, investimentos na melhoria das condições socioeconômicas da população devem ser um dos objetivos das políticas públicas, como programas de transferência de renda, cursos de capacitação para subsídio de melhores oportunidades de emprego, estímulo à redução de preços e/ou extensão e divulgação de programas como o Câmbio Verde. 
Esse programa da Prefeitura de Curitiba, criado em 1991, com parceria entre as secretarias municipais do Meio Ambiente e do Abastecimento, permite a troca de lixo reciclável ou óleo de cozinha usado, por hortifrutigranjeiros. O Programa atende prioritariamente famílias de baixa renda em comunidades periféricas e os alimentos trocados são adquiridos de pequenos produtores rurais. Portanto, iniciativas como essa ajudam na preservação ambiental, alem de incentivar a economia local e o consumo de FLV sem custos à população (PREFEITURA DE CURITIBA, 2009).

Outro grupo de alimentos avaliado foi o das carnes, sendo que a frequência diária de consumo encontrada está dentro do recomendado nos passos para uma alimentação saudável (no mínimo 1 porção diária). Em uma pesquisa com estudantes de 14 a 19 anos, residentes em Fortaleza-CE, foi visto que 60,6\% delas consome carnes 4 vezes na semana (SILVA et al, 2009).

O consumo adequado de carnes associou-se positivamente ao tempo de uso do videogame e negativamente ao do computador. Não existem referências sobre essas associações na literatura. Chama atenção a contradição verificada sugerindo uma associação espúrea. Verificou-se ainda, que a distribuição do tempo nas atividades de lazer apresentou grande variação. Talvez a realização de outros estudos, que avaliem essas variáveis de formas diferentes, seja necessária.

Da mesma maneira, o consumo de leite/derivados encontra-se inferior ao preconizado, que é de 3 porções diárias. Com comportamento semelhante, uma investigação sobre o hábito alimentar de adolescentes do oeste do Paraná, verificou que apenas metade dos entrevistados consumia leite integral diariamente (DALLA COSTA et al, 2007). Esses alimentos são considerados importantes fontes de Cálcio da alimentação. Nesse sentido, Lerner et al (2000), pesquisaram sobre o consumo de Cálcio oriundo de alimentos lácteos por adolescentes de escolas públicas de Osasco. Os autores verificaram que o consumo médio diário estimado de cálcio dos adolescentes ficou muito abaixo das recomendações. Sendo que redução da ingestão de leite e suco de frutas naturais tem sido associada ao aumento no consumo de refrigerantes (KAUR, 2003 apud RINALDI et al, 2008).

Esses fatos chamam a atenção, pois, já é consenso entre os especialistas que indivíduos que não alcançam a maior densidade de massa óssea durante o pico de formação, que se dá nos anos da adolescência, encontram-se em maior risco de vir a desenvolver osteoporose em idades mais avançadas (HEANEY, 1992 e MATKOVIC et al., 1993, apud LERNER et al, 2000). 
O consumo de arroz e feijão foi visto nesse estudo como um hábito muito frequente na semana dos adolescentes, estando de acordo com a recomendada pelo MS, que é de consumir essa combinação de alimentos, todos os dias ou pelo menos 5 vezes na semana. Em um estudo sobre o perfil antropométrico e o consumo alimentar de adolescentes das escolas públicas de Teixeira Freitas - BA, foi possível constatar que mais de $90,0 \%$ dos estudantes consumiam esse alimentos, pelo menos 4 vezes na semana (SANTOS et al, 2005). Portanto, percebe-se que esses alimentos ainda são frequentemente presentes na alimentação, mesmo após a análise da evolução dos padrões de consumo alimentar, principalmente nas últimas três décadas, sinalizar declínio no consumo de alimentos básicos como o arroz e o feijão pela população brasileira (IBGE, 2004).

Um aspecto que tem sido observado atualmente, na alimentação dos adolescentes é o consumo de lanches como sanduíches, frituras, salgadinhos industrializados, entre outros. A recomendação do MS sugere evitar o consumo de tais alimentos, porém sem estipular uma frequência considerada adequada. No estudo já citado com adolescentes de Florianópolis-SC, foi observado consumo diário de frituras (batata frita, salgadinhos, hambúrguer), por $8 \%$ dos adolescentes (FARIAS JR \& LOPES, 2004). Em outro estudo, já citado, com adolescentes de Campina Grande - PB, pôde ser visto que o consumo diário de salgadinhos foi mais presente em adolescentes com sobrepeso, mas, os escolares eutróficos, foram os que mais consumiram sanduíches (NUNES et al, 2007).

BLASI MARCHIORI \& CAMPOS (2009), em seu estudo com adolescentes obesos de 10 a 19 anos, pertencentes à cidade de Cascavel - PR, observou que $33,3 \%$ dos adolescentes consumiam salgadinhos e frituras com frequência de consumo de 1 a 3 vezes na semana, semelhantemente ao presente estudo.

Foi possível verificar associação inversa entre o consumo adequado de salgados e frituras, e a idade, ou seja, o aumento na idade faz com que a chance de se ter um consumo dentro do recomendado diminua. Possivelmente, adolescentes com idades menores tenham sua alimentação um pouco mais controlada e estipulada pela família. Adolescentes mais velhos, talvez sofram mais influência do grupo de amizades e da mídia na escolha de sua alimentação. Com o intuito de observar essa relação, o estudo já citado de Farias Junior \& Lopes (2004), constatou que a proporção de jovens que consumia frituras diariamente, tanto entre rapazes quanto entre moças mostrou-se dissociada da idade. 
Andrade et al (2003) em seu estudo sobre o consumo alimentar de adolescentes com e sem sobrepeso do Município do Rio de Janeiro, verificou que os alimentos de alta densidade energética que mais contribuíram para o consumo total de energia de meninos e meninas com e sem sobrepeso foram: açúcar, batata-frita e refrigerantes.

Quanto ao consumo de doces, a maioria dos adolescentes os consome diariamente, principalmente na regional periférica. Semelhantemente, no estudo de Toral et al (2007), quase a totalidade dos adolescentes (96,9\%) apresentou um consumo de doces acima de uma porção diária. Santos et al (2005), em seu estudo com adolescentes baianos, verificou que mais de $50,0 \%$ dos adolescentes consumiam semanalmente alimentos como pão doce e biscoitos, bolo, caramelos, sorvete e suco em pó. No mesmo sentido, uma pesquisa com adolescentes da rede pública de ensino de Piracicaba-SP, observou um consumo médio de 3,8 porções diárias de doces (CARMO et al, 2006).

A frequência adequada do consumo de doces associou-se negativamente ao aumento do tempo dispendido assistindo à TV e utilizando o computador. Esse fato pode ser explicado pela exposição à mídia de indústrias que vendem bolachas recheadas, chocolates, balas, etc, a que os adolescentes estão sujeitos. Nesse sentido, autores têm apontado a associação do número de horas diárias que o adolescente gasta na frente da TV, com os modismos a eles impostos, que podem influenciar na escolha de determinado produto, favorecendo a aquisição de hábitos alimentares inadequados e o sedentarismo. Ou seja, o tempo de exposição à TV e ao computador pode servir como indicador de atividade sedentária e, consequentemente, contribuir para o desenvolvimento do sobrepeso e obesidade (SILVA \& MALINA, 2003).

Estudos têm revelado que uma exposição de apenas 30 segundos a comerciais de alimentos é capaz de influenciar a escolha de crianças a determinado produto, mostrando, portanto, a influência da TV nos hábitos alimentares (BORZEKOWSKI \& ROBINSON, 2001 apud ALMEIDA et al, 2002).

Além de ser um comportamento sedentário, diante da TV, uma criança pode aprender concepções incorretas sobre o que é um alimento saudável. Comprovando essa observação, um estudo buscou analisar a quantidade e a qualidade de produtos alimentícios veiculados por três redes principais de canal aberto da televisão brasileira em três períodos do dia. Tal estudo verificou que os comerciais 
de alimentos estão distribuídos por todos os períodos do dia, sendo que a maioria dos alimentos veiculados possui elevados índices de gorduras, óleos, açúcares e sal (ALMEIDA et al, 2002).

No mesmo sentido, o estudo de Frutuoso et al (2003) que investigou a inatividade física e a influência da televisão na prática alimentar de adolescentes de São Paulo, verificou que $78,1 \%$ dos meninos e $72,4 \%$ das meninas consumiam alimentos enquanto assistiam televisão, dentre eles destaca-se como os mais citados biscoitos, refrigerantes, salgadinhos industrializados, pipoca e pães.

Em pesquisa realizada por Doyle \& Feldman (1997), mais de 80\% dos adolescentes residentes na Região Norte do Brasil apontaram a televisão como responsável por suas preferências alimentares. Portanto, medidas de alteração do padrão de exposição de jovens à TV devem ser avaliadas, em conjunto à políticas de educação alimentar, no intuito de prevenir o aumento nas taxas de obesidade.

Os resultados deste estudo apontam ainda elevada proporção de adolescentes que consumiam refrigerantes/sucos industrializados diariamente, o que foi semelhante à outras pesquisas. No estudo com adolescentes de Teixeira Freitas - BA, pôde ser visto que o item industrializado mais consumido foi o refrigerante. Sendo que, 34,7\% dos escolares ingeriam esse tipo bebida mais de 4 vezes na semana, e o suco em pó teve a mesma frequência de consumo por 28,8\% deles (SANTOS et al, 2005). Do mesmo modo, 31,6\% dos adolescentes de Campina Grande-PB, consomem refrigerantes diariamente (NUNES et al, 2007).

O consumo adequado de refrigerante mostrou-se associado positivamente com a idade e inversamente com o tempo de uso do computador. De maneira contrária, um estudo de base populacional nos Estados Unidos avaliou a tendência de consumo de refrigerantes entre 1977/1978 e 1994/1998 em crianças de 6 a 17 anos e mostrou que os aumentos do percentual de energia proveniente de refrigerantes foram maiores entre os mais velhos (FRENCH et al, 2003 apud SICHIERI \& SOUZA, 2009).

Mattos et al (2005) em seu estudo sobre o isolamento de crianças que utilizam o computador verificou que há casos extremos de distanciamento familiar em que a criança perde a noção do tempo, tornando seus hábitos alimentares irregulares e prejudiciais, pois o fato de ficar em frente ao computador acaba impedindo a mesma de se sentar à mesa para se alimentar. Com isso, sua alimentação acaba restringindo-se a lanches, salgadinho e refrigerante. 
O papel das bebidas açucaradas na promoção da obesidade tem sido debatido extensivamente em estudos recentes e a redução do seu consumo tem sido considerada uma estratégia importante no controle de peso de jovens (HARRINGTON, 2008).

A recomendação do Ministério da Saúde para o grupo de alimentos/bebidas doces é que se evite o consumo de refrigerantes e sucos industrializados, bolos, biscoitos doces e recheados, sobremesas doces e outras guloseimas. Essa orientação se baseia no fato de que vários estudos têm associado o consumo frequente de refrigerantes e outras bebidas adoçadas ao ganho de peso. Além disso, "deve-se diminuir o consumo de refrigerantes e de sucos industrializados, pois a maioria dessas bebidas contém corantes, aromatizantes, açúcar ou edulcorantes (adoçantes artificiais), que não são bons para a saúde" (MS, 2004; 2005b).

Outra informação importante do hábito alimentar dos adolescentes é o numero de refeições feitas ao dia. Quanto a esse aspecto, os adolescentes da regional central seguem em sua maioria, a frequência de refeições recomendada nos Dez passos para uma Alimentação Saudável, que é de se realizar pelo menos três refeições (café da manhã, almoço e jantar) e dois lanches por dia. Porém, vale destacar que nesse material orienta-se que além da frequência correta, os lanches sejam "saudáveis", o que não se pode afirmar nessa população. É recomendado ainda evitar o "jejum prolongado, diminuindo o risco de ter gastrite e de fome excessiva, o que pode gerar a um exagero na quantidade de alimentos a serem consumidas na próxima refeição" (MS, 2005b).

De forma semelhante, no estudo de Santos et al (2005) com adolescentes baianos foi observado que $96,6 \%$ dos adolescentes realizavam três ou mais refeições diárias, sendo que destes, a maior parte $(36,7 \%)$ fazia quatro refeições/dia. Garcia et al (2003), em seu estudo com adolescentes de um centro de juventude da cidade de São Paulo, verificou que $94 \%$ dos adolescentes realizavam pelo menos três refeições diárias. Mas, o café da manhã foi não foi realizado por $14,8 \%$ das meninas e $9,8 \%$ dos meninos. Neste estudo, porcentagens maiores de adolescentes que negligenciam o café da manhã foram encontradas.

Com isso, nota-se que além dos aspectos de hábitos alimentares abordados até então, é essencial conhecer o uso do tempo de lazer, com foco especial às atividades sedentárias, pois esse fator têm sido associado ao excesso de peso (DIETZ et al, 1985; DIETZ,1993). 
Da mesma maneira que nesta pesquisa, no estudo realizado na Paraíba, já citado anteriormente, foi possível verificar que, assistem à TV mais de 3 horas por dia, $57,5 \%, 52,5 \%$ e $62,8 \%$ dos adolescentes com sobrepeso, obesidade e peso normal, respectivamente. Em uma pesquisa sobre a prevalência de sedentarismo em adolescentes participantes do Estudo de Coorte de Nascimentos de 1993 em Pelotas - RS, foi verificado que a média diária de tempo gasto assistindo à televisão foi de 3,3 horas. O percentual de adolescentes que relataram jogar videogame por uma hora ou mais por dia foi de $22,4 \%$, enquanto $9,7 \%$ dos adolescentes relataram que usam o computador por uma hora ou mais por dia (HALLAL et al, 2006).

No estudo de Silva e Malina (2000), sobre o nível de atividade física dos adolescentes de Niterói (RJ), foi possível verificar que a média de tempo assistindo TV foi de 4,4 e 4,9 horas/dia para os sexos masculino e feminino, respectivamente. Autores têm afirmado que o hábito de assistir a televisão por mais de três horas ao dia está associado com sobrepeso e obesidade (CAROLI et al, 2004). Hancox et al, citados no estudo de Nunes et al, observaram que esse hábito também estava associado com baixa aptidão física, tabagismo e dislipidemia na vida adulta (HANCOX et al, 2004 apud NUNES et al, 2007). No mesmo estudo, os autores afirmam que assistir a TV em excesso, além de ser um hábito que inibe a atividade física, expõe as crianças e os adolescentes a vários tipos de estímulos alimentares não saudáveis (NUNES et al, 2007). Alguns estudos têm apontado que escolares que assistem mais televisão também ingerem maior quantidade de refrigerantes e são mais obesos (GIAMMATEl et al, 2003 apud MS, 2004).

A redução do nível de atividade física e sua relação com a ascensão na prevalência da obesidade refere-se, entre outros fatores, à alterações nas atividades de lazer, que passam de atividades de gasto energético, como práticas esportivas, para longas horas diante da televisão ou do computador (MENDONÇA \& ANJOS, 2004).

O Ministério da Saúde preconiza, de maneira geral, que as pessoas tenham práticas de lazer mais ativas, recomendando a realização de pelo menos 30 minutos de atividade física todos os dias, para, entre outros objetivos, evitar o excesso de peso (MS, 2004; 2005b).

Da relação entre o consumo de grupos alimentares e numero de refeições ao dia, com as covariáveis analisadas foi possível constatar, ainda, que as porcentagens de inadequação foram elevadas para o numero de refeições ao dia 
(em torno dos $60 \%$ ), para o grupo das frutas/suco natural de frutas (em torno dos $70 \%$ ) e doces (em torno dos $80 \%$ ). Ainda maiores proporções de inadequação, cerca de $90 \%$, foram observadas para o grupo do refrigerante/suco industrializado e verduras, segundo todas as covariáveis.

Diferentemente, o grupo do arroz/feijão, carnes e leite/derivados foram os que apresentaram maiores proporções de adequação do consumo, cerca de $80 \%$. Nesse mesmo sentido, o consumo de salgados apresentou-se adequado segundo todas as covariáveis, porém com menores porcentagens.

Existem evidências científicas que apontam de forma inequívoca o impacto da alimentação e estilo de vida saudáveis na prevenção da obesidade que, por si só, aumenta o risco de DCNT como diabetes e hipertensão.

Portanto, com o objetivo de reunir orientações de como se ter uma alimentação saudável e fazer escolhas alimentares mais adequadas, o Ministério da Saúde lançou os "Dez Passos para uma Alimentação Saudável". Este material busca contribuir para a melhoria da qualidade de vida e a prevenção de doenças relacionadas à alimentação e nutrição, como obesidade, diabetes e hipertensão, por meio de orientações práticas.

Como propôs a Organização Mundial da Saúde, a prevenção e acompanhamento da obesidade em crianças e adolescentes deve envolver, entre outros aspectos, a promoção de um estilo de vida ativo, com estipulação de limite do tempo gasto em frente à televisão ou computador; promoção do consumo adequado de frutas e verduras; restrição do consumo de alimentos como salgadinhos, bolachas recheadas, sanduíches, doces, refrigerantes e frituras; além de receberem as informações necessárias para fazer escolhas alimentares saudáveis (WHO, 2003). 
Este trabalho permitiu estimar a frequência do consumo de grupos de alimentos, do número de refeições ao dia e do uso do tempo de lazer, de escolares adolescentes, e verificar a existência de relação com variáveis socioeconômicas.

Houve baixa adesão dos adolescentes em participar da pesquisa em ambas as escolas, mas principalmente na escola periférica. A maior parte dos participantes era do sexo feminino, e com idade média de 13 anos.

As medianas do número de pessoas que mora na casa e de pessoas que trabalham foram semelhantes nas duas regionais. O nível de escolaridade dos pais de escolares da regional periférica foi inferior ao dos pais de adolescentes da escola central. E as faixas de menor renda foram mais comuns em famílias da regional periférica, enquanto as de renda superior foram mais frequentes nas famílias de escolares da regional central. Estudos têm verificado que alguns fatores familiares como a ocupação e nível de educação dos pais, o tamanho da família e a classe social, podem influenciar os hábitos dietéticos e de atividade física em crianças e adolescentes, e levar à obesidade, daí a importância de estudá-los.

O consumo de frutas/suco natural de frutas, legumes/verduras e leite/derivados, por escolares das duas regionais, encontra-se inferior ao preconizado nos Dez passos para uma alimentação saudável. Já, as frequências do consumo de carnes, e arroz/feijão, estão dentro do recomendado pelo MS. Para o grupo dos sanduíches, frituras, salgadinhos, doces e refrigerantes/sucos industrializados, não há recomendação sobre a frequência em que devem ser consumidos. Entretanto, é indicado que se evite sua ingestão por estarem associados ao ganho de peso. Os achados desse estudo reforçam o que tem sido apontado na literatura atual, como padrão alimentar característico do adolescente, caracterizado pela redução da ingestão de frutas e hortaliças, e laticínios, e o consumo excessivo de refrigerantes, açúcares e sanduíches.

Mais da metade dos adolescentes consome as três principais refeições e algum alimento em pelo menos dois lanches, o que respeita a recomendação do MS quanto ao numero de refeições ao dia. No entanto, uma grande parte deles não realiza o café da manhã. 
Os adolescentes desse estudo permanecem mais tempo em frente à televisão, em segundo lugar, utilizando o computador, e em terceiro lugar, jogando no videogame.

As relações verificadas entre as variáveis independentes "trabalho do pai" e "tempo de uso de vídeo game e computador" e a frequência de consumo de alguns alimentos/grupos de alimentos são de difícil explicação. O consumo adequado de doces foi associado negativamente com o aumento do uso da TV e computador. Possivelmente por influência da exposição à mídia de indústrias que vendem esses produtos. $\mathrm{O}$ aumento da idade se relacionou negativamente à chance de se ter um consumo adequado de salgados e frituras, e positivamente ao consumo adequado de refrigerante e sucos industrializados. Porém, o aumento do tempo usando $\mathrm{O}$ computador aumenta a chance do adolescente ter maior consumo de refrigerante. A realização do numero adequado de refeições ao dia apresentou relação positiva com o sexo masculino e negativa com o tempo de uso do computador.

A existência ou não, e a clareza das associações entre as categorias de consumo e as variáveis demográficas, socioeconômicas e comportamentais, podem ser melhor estudadas em novos trabalhos que coletem ou classifiquem as variáveis de outra forma que não em categorias de frequência. Porém, mesmo utilizando esse critério foi possível observar maiores porcentagens de comportamento inadequado para o número de refeições ao dia, consumo de frutas/suco natural de frutas, doces, refrigerante/suco industrializado e verduras. E, diferentemente, os grupos do arroz/feijão, carnes, leite/derivados e salgados foram os que apresentaram maiores proporções de adequação do consumo.

De acordo com os princípios de uma alimentação saudável, todos os grupos de alimentos devem compor a dieta diária. Juntamente, a atividade física regular compõe um elemento fundamental para manutenção da saúde e do peso saudável. O processo de formação dos hábitos alimentares ocorre de modo gradual. Portanto, a promoção de hábitos saudáveis de vida tem o setor saúde como um dos protagonistas para a consecução da segurança alimentar e nutricional, mas requer a integração de outros setores e atores sociais, como escolas, familiares, entre outros. 


\section{REFERÊNCIAS}

ALMEIDA, S. de S.; NASCIMENTO, P.C.B.D.; QUAIOTI, T.C.B. Quantidade e qualidade de produtos alimentícios anunciados na televisão brasileira. Rev Saúde Pública; 36(3):353-5, 2002.

ANDRADE, R.G.; PEREIRA, R.A.; SICHIERI, R. Consumo alimentar de adolescentes com e sem sobrepeso do município do Rio de Janeiro. Cad Saúde Publica. 19(5):1485-95, 2003.

AQUINO, R. de C. de ; PHILIPPI, S. T. O consumo de alimentos industrializados ricos em lipídios entre as crianças do município de São Paulo. Revista da Sociedade de Cardiologia do Estado de São Paulo, São Paulo, v. 10, n. Supl Esp, p. $71,2000$.

ARANCETA, J.; PEREZ-RODRIGO, C.; RIBAS, L.; SERRA-MAJEM, L.I. Sociodemografic and lifestyle determinants of food patterns in Spanish children and adolescents: the endkid study. Eur J Clin Nutr:; 57Supl1:S40-S4, 2003.

BARBA, L.R.; VAL, V.A.; MAJEM, L.S. Estúdios transversales em Nutrición. In: MAJEN, L.I.S., BARTINA, J.A., VERDÚ, J.M. Nutrición y salud pública: métodos, base científicas y aplicaciones. Barcelona: Masson, 1995. p.113-119.

BLASI MARCHIORI; B. CAMPOS, L.C. Relação do consumo alimentar de adolescentes obesos com escolaridade materna e renda familiar. [Trabalho de conclusão de curso]. Paraná: Graduação em Nutrição da Faculdade Assis Gurgacz, 2009. Disponível

em: http://www.fag.edu.br/tcc/2008/Nutri\%E7\%E3o/relacao do consumo alimentar de adolescentes obesos com esco.pdf. Acesso em: 01 de Out, 2009.

CARLINI-COTRIM, B.; GAZAL-CARVALHO, C.; GOUVEIA, N. Comportamentos de saúde entre jovens estudantes das redes pública e privada da área metropolitana do Estado de São Paulo. Rev Saúde Pública, 34: 636-45, 2000.

CARMO, M.B. do; TORAL, N.; SILVA, M.V. da. Consumo de doces, refrigerantes e bebidas com adição de açúcar entre adolescentes da rede pública de ensino de Piracicaba, São Paulo. Rev Bras Epidemiol; 9(1): 121-30, 2006.

CAROLI, M.; ARGENTIERI, L.; CARDONE, M.; MASI, A. Role of television in childhood obesity prevention. Int $\mathbf{J}$ Obes Relat Metab Disord. 28 (Suppl 3): S104-8, 2004.

CAVADINI, C.; SIEGA - RIZ, A.M.; POPKIN, B.M. US adolescent food intake trends from 1965 to 1996. Arch Dis Child; 83:18-24, Jul 2000.

CAVALCANTE, A.A.M.; PRIORE, S.E.; FRANCESCHINI, S.C.C. Estudos de consumo alimentar: aspectos metodológicos gerais e o seu emprego na avaliação de crianças e adolescentes. Rev. Bras. Saúde Matern. Infant., Recife, 4 (3): 229-240, jul. / set. 2004. 
CLARO, R.M.; CARMO, H.C.E.; MACHADO, F.M.S.; et al. Renda, preço dos alimentos e participação de frutas e hortaliças na dieta. Rev Saúde Pública; 41(4):557-64, 2007.

DALLA COSTA, M.C.; CORDONI JUNIOR, L.. MATSUO, T. Hábito alimentar de escolares adolescentes de um município do oeste do Paraná. Rev. Nutr., Campinas, 20(5):461-471, set./out., 2007.

DAMIANI, D.; CARVALHO, D.P.; OLIVEIRA, R.G. Obesidade na infância: um grande desafio. Pediatria Moderna, v.36, n.8, p.489-523, ago. 2000.

DIETZ, W. H. Factors increasing risk of obesity and potencial for prevention overweight in childhood. In: Workshop in Prevention of Obesity Population at Risk, Etiologic Factors and Intervention Strategies, Baltimore, National Institutes of Health/ National Institute of Diabetes and Digestive and Kidney Diseases, 1993. p.64.

DIETZ, W.H.; GORTMAKER, S.L. Do we fatten our children at the television set? Obesity and television viewing in children and adolescents. Pediatrics, 75: 80712, 1985.

DOYLE, E.I; FELDMAN, R.H.L. Factors affecting nutrition behavior among middle-class adolescents in urban area of Northern region of Brazil. Rev. Saúde Pública, vol. 31, no. 4, São Paulo, Aug. 1997.

DREWNOWSKI, A.; POPKIN, B.M. The nutrition transition: new trends in the global diet. Nutrition Reviews, 55:31- 43, 1997.

FARIAS JR., J. C.; LOPES, A. S. Comportamentos de risco relacionados à saúde em adolescentes. R. bras. Ci e Mov.; 12(1): 7-12, 2004.

FISBERG, M.; BANDEIRA, C.R.S.; BONILHA, E.A. et al. Hábitos alimentares na adolescência. Pediatria moderna, v. 36, n. 11, p. 724-734, nov. 2000.

FISBERG, M. Atualização em obesidade na infância e adolescência. São Paulo: Atheneu; 2004.

FOOD AND AGRICULTURE ORGANIZATION (FAO) OF THE UNITED NATIONS. FAOSTAT - FAO Statistics database [homepage on the Internet]. Rome: Food Agriculture Organization; 1999. Disponível em: http://apps.fao.org/. Acesso em: 17 de Fev, 2009.

FRUTUOSO, M.F.P.; BISMARCK-NASR, E.M.; GAMBARDELLA, A.M.D. Redução do dispêndio energético e excesso de peso corporal em adolescentes. Rev. Nutr., Campinas, v. 16, n. 3, Sept. 2003.

GALEAZZI, M.A.M.; DOMENE, S.M.A.; SICHIERI, R. Estudo Multicêntrico sobre Consumo Alimentar. Cadernos de Debate, 1997; p.1-62.

GAMBARDELLA, A.M.D.; FRUTUOSO, M.F.P.; FRANCHI, C. Prática alimentar de adolescentes. Revista de Nutrição, v. 12, n.1, p.55-63, jan./abr. 1999. 
GARCIA, G.C.B.; GAMBARDELLA, A.M.D.; FRUTUOSO, M.F.P. Estado nutricional e consumo alimentar de adolescentes de um centro de juventude da cidade de São Paulo. Rev. Nutr., Campinas, 16(1):41-50, jan./mar., 2003.

HALLAL, P.C.; BERTOLDI, A.D.; GONÇALVES, H.; et al. Prevalência de sedentarismo e fatores associados em adolescentes de 10-12 anos de idade. Cad. Saúde Pública, Rio de Janeiro, 22(6):1277-1287, jun, 2006.

HARRINGTON, S. The Role of Sugar-Sweetened Beverage Consumption in Adolescent Obesity: A Review of the Literature. The Journal of School Nursing, Vol. 24, No. 1, 3-12; 2008.

ILHA, P.M.V. Relação entre nível de atividade física e hábitos alimentares de adolescentes e estilo de vida dos pais [dissertação de mestrado]. Santa Catarina: Pós Graduação em Educação Física da Universidade Federal de Santa Catarina; 2004.

INSTITUTO BRASILEIRO DE GEOGRAFIA E ESTATISTICA (IBGE). Estudo Nacional de Despesa Familiar (ENDEF), 1974-1975. Diretoria de Pesquisas. Coordenação de Índices de Preços.

INSTITUTO BRASILEIRO DE GEOGRAFIA E ESTATISTICA (IBGE). Pesquisa de Orçamentos Familiares (POF) 2002-2003. Antropometria e análise do Estado Nutricional de crianças e adolescentes no Brasil. Rio de Janeiro: 2006.

INSTITUTO BRASILEIRO DE GEOGRAFIA E ESTATíSTICA (IBGE). Pesquisa de orçamentos familiares (POF), 2002-2003. Aquisição alimentar domiciliar per capita, Brasil e grandes regiões. Rio de Janeiro: 2004.

IPPUC - INSTITUTO DE PESQUISA E PLANEJAMENTO URBANO DE CURITIBA. Curitiba em dados. Prefeitura de Curitiba. Disponível em: http://ippucnet.ippuc.org.br/Bancodedados/Curitibaemdados/Curitiba em dados Pe squisa.asp. Acesso em: 24 de Julho de 2008 e em 12 de Agosto de 2009.

IPPUC - INSTITUTO DE PESQUISA E PLANEJAMENTO URBANO DE CURITIBA. Censo 2000 - Bairros de Curitiba. Prefeitura de Curitiba. Disponível em: http://www.ippuc.org.br/informando/index censo2000.htm. Acesso em: 12 de Agosto de 2009.

LAMOUNIER, J.A. Situação da obesidade na adolescência no Brasil. In: SIMPÓSIO OBESIDADE E ANEMIA CARENCIAL NA ADOLESCENCIA. Salvador, 2000. Obesidade e anemia carencial na adolescência. São Paulo: Instituto Danone, 2000. p. 15-31.

LERNER, B. R. A Alimentação e a Anemia Carencial em Adolescentes. Cadernos de Saúde Pública, Rio de Janeiro, v. 10, n. 3, p. 410-411, 1994.

LERNER, B.R.; LEI, D.L.M.; CHAVES, S.P.; et al. O CÁLCIO CONSUMIDO POR ADOLESCENTES DE ESCOLAS PÚBLICAS DE OSASCO, SÃO PAULO. ReV. Nutr., Campinas, 13(1): 57-63, jan./abr., 2000. 
LEVY-COSTA, R.B.; SICHIERI, R.; PONTES, N.S.; MONTEIRO, C.A. Disponibilidade de alimentos no Brasil: distribuição e evolução (1974-2003). Rev Saude Publica.; 39(4):530-40, 2005.

LUDWIG, D.S.; PETERSON, K.E., GORMAKAER, S.L. Relation between consumption of sugar-sweetened drinks and childhood obesity: a prospective, observational analysis. Lancet, 357:505 - 508, 2001.

MAHAN, L.K.; ESCOTT-STUMP, S. Krause: Alimentos, Nutrição e Dietoterapia. 11 ed. São Paulo: Roca, 2005. p. 201-202.

MATTOS, A. M. P.; MATIAS, E. C.; REZENDE, F. C. et al. Isolamento de Crianças que Utilizam o Computador e Problemas Relacionados. [projeto de pesquisa Grupo de Pesquisas em Informática]. Paraná: Sistemas de Informação da Sociedade Paranaense de Ensino e Informática - Faculdades SPEI, 2005. Disponível em: http://servicos.spei.br/site/arquivos/ii wcs/ll-WCS 2005 01.pdf. Acesso em: 14 de Out de 2009.

MATTES, R.D. Dietary compensation by humans for supplemental energy provided as ethanol or carbohydrate in fluids. Physiology and Behaviour, 59:179 187, 1996.

MENDONÇA, C.P.; ANJOS, L.A. dos. Aspectos das práticas alimentares e da atividade física como determinantes do crescimento do sobrepeso/obesidade no Brasil. Cad. Saúde Pública, Rio de Janeiro, 20(3):698-709, mai-jun, 2004

MINISTÉRIO DA SAÚDE (MS). ANÁLISE DA ESTRATÉGIA GLOBAL PARA ALIMENTAÇÃO SAUDÁVEL, ATIVIDADE FÍSICA E SAÚDE. Documento realizado pelo Grupo técnico assessor instituído pela Portaria do Ministério da Saúde, $n^{\circ} 596$, de 8 de abril de 2004.

MINISTÉRIO DA SAÚDE (MS). ANÁLISE DA ESTRATÉGIA GLOBAL PARA ALIMENTAÇÃO, ATIVIDADE FÍSICA E SAÚDE, DA ORGANIZAÇÃO MUNDIAL DA SAÚDE. Epidemiologia e Serviços de Saúde. Revista do Sistema Único de Saúde. Volume 14 - No 1 - jan/mar de 2005a.

MINISTÉRIO DA SAÚDE (MS). GUIA ALIMENTAR PARA A POPULAÇÃO BRASILEIRA - Promovendo a Alimentação Saudável. Edição Especial. Série A. Normas e Manuais Técnicos. Brasília, 2005b.

MINISTÉRIO DA SAÚDE (MS). GUIA ALIMENTAR PARA A POPULAÇÃO BRASILEIRA - Promovendo a Alimentação Saudável. Brasília, 2006.

NEUTZLING, M. B.; ARAÚJO, C. L. P.; VIEIRA, M. F. A.; HALLAL, P. C.; MENEZES, A. M. B. Frequência de consumo de dietas ricas em gordura e pobres em fibra entre adolescentes. Rev. Saúde Pública, São Paulo, v. 41, n. 3, June 2007.

NUNES, M.M. de A.; FIGUEIROA, J.N.; ALVES, J.G.B. Excesso de peso, atividade física e hábitos alimentares entre adolescentes de diferentes classes econômicas em Campina Grande (PB). Rev Assoc Med Bras 2007; 53(2): 130-4. 
PHILIPPI, S.T.; LATTERZA, A.R.; CRUZ, A.T.R.; RIBEIRO, L.C. Pirâmide alimentar adaptada: guia para escolha dos alimentos. Rev Nutr.; 12(1):65-80, 1999.

PREFEITURA DE CURITIBA. Prefeitura instala o 89 ponto do programa Câmbio Verde. Publicado em: Publicado em 14/10/2009. Disponível em: http://www.curitiba.pr.gov.br/publico/noticia. aspx?codigo=17646\&Prefeitura-instala-o89\%C2\%BA-ponto-do-programa-C\%C3\%A2mbio-Verde. Acesso em: 11 de Dez 2009.

PRIORE, S.E. Composição corporal e hábitos alimentares de adolescentes: uma contribuição à interpretação dos indicadores de estado nutricional [tese de doutorado]. São Paulo: Escola Paulista de Medicina da Universidade Federal de São Paulo; 1998.

RINALDI, A.E.M.; PEREIRA, A.F.; MACEDO, C.S. e cols. Contribuições das práticas alimentares e inatividade física para o excesso de peso infantil. Rev Paul Pediatr, 26(3):271-7, 2008;

ROLLS, B.J. Fat and sugar substitutes and the control of food intake. Annals of the New York Academy of Sciences, 819:180-193, 1997.

SANTOS, J.S.; COSTA, M.C.O.; NASCIMENTOS SOBRINHO, C.L. e cols. Perfil antropométrico e consumo alimentar de adolescentes de Teixeira de Freitas Bahia. Rev. Nutr., Campinas, 18(5):623-632, set./out., 2005.

SCAGLIUSI, F. B.; LANCHA JÚNIOR, A.H. Subnotificação da ingestão energética na avaliação do consumo alimentar. Rev. Nutr., Campinas, 16(4):471-481, out./dez., 2003.

SICHIERI, R.; SOUZA, R. A. de. Estratégias para prevenção da obesidade em crianças e adolescentes. Cad. Saúde Pública, Rio de Janeiro, 2009.

SILVA, A.R.V.; DAMASCENO, M.M.C.; MARINHO, N.B.P. et al. Hábitos alimentares de adolescentes de escolas públicas de Fortaleza, CE, Brasil. Rev Bras Enferm, Brasília; 62(1): 18-24, jan-fev 2009.

SILVA, R.C. R.; MALINA, R.M. Nível de atividade física em adolescentes do Município de Niterói, Rio de Janeiro, Brasil. Cad. Saúde Pública, Rio de Janeiro, v. 16, n. 4, Dec. 2000.

SILVA, R.C.R.; MALINA, R.M. Sobrepeso, atividade física e tempo de televisão entre adolescentes de Niterói, Rio de Janeiro, Brasil. R. bras. Ci. e Mov. 2003; 11(4): 63-66.

SME - Secretaria Municipal de Educação de Curitiba - Gerencia de alimentação. Resultados anuais do SISVAN - ESCOLAR. Postado por: Nelson Nakagawa / Fonte: Gerência de Alimentação (2007). Disponível em: http://www.cidadedoconhecimento.org.br/cidadedoconhecimento/index.php?subcan= 7\&cod not=4624. Acesso em: 6 de Junho de 2008. 
TOJO, R.; LEIS, R.; RECAREY, M.D.; PAVON, P. Hábitos alimentares das crianças em idade pré-escolar e escolar: riscos para a saúde e estratégias para a intervenção. In: Nestlé Nutrition Services. A alimentação da idade pré-escolar até a adolescência. São Paulo; 1995. p. 11-13 (Seminário Nestlé Nutrition, 37).

TORAL, N.; SLATER, B.; CINTRA, I. de P.; et al. Comportamento alimentar de adolescentes em relação ao consumo de frutas e verduras. Rev. Nutr., Campinas, 19(3):331-340, maio/jun., 2006.

TORAL, N.; SLATER, N.; SILVA, M.V. da. Consumo alimentar e excesso de peso de adolescentes de Piracicaba, São Paulo. Rev. Nutr., Campinas, 20(5):449-459, set./out., 2007.

VIEIRA, V.C.R.; PRIORE, S.E.; RIBEIRO, S.M.R.; et al. Perfil socioeconômico, de saúde e nutrição de adolescentes recém-ingressos em uma universidade pública brasileira. Rev Nutr; 15: 273-82, 2002.

VILLAR, B.S. Desenvolvimento e validação de um questionário semiquantitativo de frequência alimentar para adolescentes [tese doutorado]. São Paulo: Faculdade de Saúde Pública da Universidade de São Paulo; 2001.

WANG, Y.; MONTEIRO, C.A.; POPKIN, B.M. Trends of obesity and underweight in older children and adolescents in the United States, Brazil, China and Russia. American Journal of Clinical Nutrition; 75:971-977, 2002.

WORLD HEALTH ORGANIZATION (WHO). Global Strategy on diet, physical activity and health. Fifty seventhy word health assembly [WHA57.17]. 57 Assembléia Mundial de Saúde, 2004. Tradução não oficial realizada pela CGPAN/MS.

WORLD HEALTH ORGANIZATION (WHO). The world report 2002: reducing risks, promoting healthy life. World Health Report. Geneva: 2002.

WORLD HEALTH ORGANIZATION (WHO). World Health Organization. Diet, nutrition and the prevention of chronic diseases. Report of a Joint WHO/FAO Expert Consultation. Geneva: WHO; 2003. WHO Technical Report Series, 916.

XIMENES, R.; LEIMIG, L.; COUTO, G.B. et al. Hábitos alimentares em uma população de adolescentes. Odontologia. Clín.-Científ., Recife, 5 (4): 287-292, out/dez., 2006

ZANCUL, M.S. ; FABBRO, A. L.D.; BETTIOLH. et al. Consumo alimentar de alunos nas escolas de ensino fundamental em Ribeirão Preto (SP) [dissertação de mestrado]. Ribeirão Preto: Faculdade de Medicina de Ribeirão Preto da Universidade de São Paulo; 2004. 


\section{APÊNDICES - APÊNDICE 1}

\section{CARTA AOS DIRETORES DAS ESCOLAS}

Prezado (a) Diretor (a),

Sou aluno de Mestrado em Nutrição em Saúde Pública da FACULDADE DE SAÚDE PÚBLICA - USP, e orientanda da Professora Dra. Sônia Buongermino de Souza.

Pretendo desenvolver uma pesquisa intitulada "Avaliação do consumo alimentar de adolescentes de escolas da rede municipal de ensino da cidade de Curitiba”, que se realizará em escolas da rede municipal do ensino de Curitiba, para a qual será necessária a participação de alguns alunos de $5^{\circ}$ a $8^{\circ}$ séries.

Este estudo tem como objetivo realizar o diagnóstico alimentar dos escolares de $5^{\circ}$ a $8^{\circ}$ séries matriculados em escolas da Rede Municipal de Ensino de duas regionais do Município de Curitiba - PR. A participação dos escolares se resumirá a responderem um questionário sobre a frequência do consumo de alguns grupos alimentares. Para informações sobre as condições demográficas e socioeconômicas, um questionário simples deverá ser respondido pelo pai ou responsável pelo adolescente, devendo este ser devolvido ao pesquisador juntamente com o termo de consentimento livre e esclarecido assinado pelo pai ou responsável, caso concordem em participar.

O presente estudo não trará nenhum risco para a integridade física ou moral do participante. As informações do resultado geral, obtidas neste estudo, poderão ser divulgadas em publicações e congressos, entretanto, sem a identificação dos participantes, sendo úteis cientificamente, para possibilitar o desenvolvimento do estudo.

Para tanto, gostaria de solicitar sua autorização para a realização da pesquisa nesta escola.

Agradeço a compreensão. Atenciosamente.

Fernanda Dias Batista Monticelli.

São Paulo, de de 20 .

Contato: Profa Sonia Buongermino de Souza (Orientadora) - (011) 3061-7705 e professoras da Faculdade Evangélica do Paraná - FEPAR: Kátia Yumi Uchimura e Flávia Emília Leite de Lima, no telefone 3240-5544. 


\section{APÊNDICE 2}

\section{DECLARAÇÃO DE ANUÊNCIA e TERMO DE COMPROMISSO}

Declaro que conheço e cumprirei os requisitos da Res. CNS 196/96 e suas complementares. Comprometo-me a utilizar os materiais e dados coletados exclusivamente para os fins previstos no protocolo de pesquisa intitulado "Consumo alimentar de adolescentes de escolas da rede municipal de ensino da cidade de Curitiba".

Declaro, ainda, estar ciente da realização da pesquisa acima intitulada, nas dependências da Escola determinada e, como esta instituição tem condições para o desenvolvimento deste projeto, autorizo sua execução.

Curitiba, 19 de Fevereiro de 2009.

Nome:

Função:

Escola: 


\section{APÊNDICE 3}

\section{CARTA AOS PAIS OU RESPONSÁVEIS}

Prezados Pais/Responsáveis

Sou aluno de Mestrado em Nutrição em Saúde Pública da FACULDADE DE SAÚDE PÚBLICA - USP, e orientanda da Professora Dra. Sônia Buongermino de Souza.

Pretendo desenvolver uma pesquisa intitulada "Consumo alimentar de adolescentes de escolas da rede municipal de ensino da cidade de Curitiba", que se realizará em escolas da rede municipal do ensino de Curitiba, para a qual será necessária a participação de alguns alunos de $5^{\circ}$ a $8^{\circ}$ séries. Este estudo o objetivo de estimar a frequência do consumo de alguns alimentos, número de refeições realizadas ao dia e uso do tempo de lazer, de adolescentes, e verificar a influência de variáveis demográficas e socioeconômicas nesses fatores. Os alunos responderão ao questionário na escola, em horário de aula, cedida pelo professor, com concordância da direção da escola.

Para a realização deste estudo os escolares precisarão responder um questionário sobre a frequência do consumo de alguns grupos alimentares. Para informações sobre as condições demográficas e socioeconômicas, um questionário simples deverá ser respondido pelo pai ou responsável pelo estudante.

$\underline{\text { O questionário socioeconômico e o Termo de Consentimento serão levados pelo }}$ adolescente ao pai ou responsável e caso concordem, deverão ser assinados e devolvidos para que o (a) aluno (a) possa participar do estudo, caso o tutor ou responsável concorde com a participação do adolescente na pesquisa.

Agradeço a compreensão.

Atenciosamente.

Fernanda Dias Batista Monticelli.

Curitiba, de de 20 .

Contato: Profa Sonia Buongermino de Souza (Orientadora) - (011) 3061-7705 e professoras da Faculdade Evangélica do Paraná - FEPAR: Kátia Yumi Uchimura e Flávia Emília Leite de Lima, no telefone 3240-5544. 


\section{APÊNDICE 4}

TERMO DE CONSENTIMENTO LIVRE E ESCLARECIDO

Resolução n. 196 de 10 de outubro de 1996, Conselho Nacional de Saúde.

Título do Projeto: Consumo alimentar de adolescentes de escolas da rede municipal de ensino da cidade de Curitiba.

Pesquisadora Responsável: Fernanda Dias Batista Monticelli.

Com o intuito de avaliar o comportamento alimentar de adolescentes da rede municipal de ensino de Curitiba, este protejo tem o objetivo de estimar a frequência do consumo de alguns grupos alimentares e verificar a influência de variáveis socioeconômicas.

Para isso, os participantes precisarão responder sobre a frequência do consumo de alguns grupos alimentares. E, para informações sobre as condições demográficas e socioeconômicas, um questionário deverá ser preenchido pelo pai ou responsável pelo adolescente, sendo devolvido ao pesquisador juntamente com este termo de consentimento assinado pelo pai ou responsável, caso concordem em participar.

Estou ciente de que o presente estudo não trará riscos para a integridade física ou moral do participante. E, as informações coletadas serão úteis para possibilitar o desenvolvimento do estudo, e posteriormente para auxiliar a direcionar as ações de educação nutricional da Secretaria Municipal de Educação de Curitiba.

A participação no estudo não acarretará custos para você e não será disponível nenhuma compensação financeira adicional.

Após ler e receber explicações sobre a pesquisa, e ter meus direitos de:

- receber resposta a qualquer pergunta e esclarecimento sobre os procedimentos, riscos, benefícios e outros relacionados à pesquisa com a pesquisadora, orientada pela Prof Dra. Sônia Buongermino de Souza - (011) 3061-7705 - e as professoras da Faculdade Evangélica do Paraná - FEPAR: Kátia Yumi Uchimura e Flávia Emília Leite de Lima - (41) 3240-5544.

- recusar-se a participar, retirar meu consentimento ou interromper a participação a qualquer momento (a sua participação é voluntária e a recusa em participar não irá acarretar qualquer penalidade ou perda de benefícios);

- não ser identificado e ser mantido o caráter confidencial das informações relacionadas à privacidade (a identidade do participante será tratada com sigilo, e sem identificação em nenhuma publicação futura);

- arquivar uma cópia deste termo de consentimento (outra cópia será arquivado no Curso de Nutrição em Saúde Pública da Faculdade de Saúde Pública da Universidade de São Paulo);

- procurar esclarecimentos com o Comitê de Ética em Pesquisa da Faculdade de Saúde Pública da Universidade de São Paulo, no telefone (011) 30617779 ou Av. Dr. Arnaldo, 715 - Cerqueira César, São Paulo - SP, em caso de dúvidas ou notificação de acontecimentos não previstos.

Eu, ciente do exposto, autorizo livremente

a participação de menor sob minha responsabilidade, nesta pesquisa. 


\section{APÊNDICE 5}

QUESTIONÁRIO SOBRE O CONSUMO ALIMENTAR

NOME:

SÉRIE:

DATA DE NASCIMENTO:

\section{RESPONDA SOBRE A SUA ALIMENTACÃ̃ HABITUAL (Marque com " $x$ ")}

\section{FRUTAS OU SUCO NATURAL DE FRUTAS}

1) Em geral, quantas vezes POR DIA você come frutas ou toma suco natural de frutas?

$\begin{array}{ll}( & \text { ) Nenhuma } \\ ( & \text { ) Uma } \\ ( & \text { ) Duas } \\ ( & \text { ) Três }\end{array}$

( ) Quatro

( ) Cinco

( ) Seis ou mais

\section{LEGUMES E VERDURAS}

2) Em geral, quantas vezes POR DIA você come legumes e verduras?

Exemplos: tomate, alface, cenoura, beterraba, brócolis, pepino, entre outros.

$\begin{array}{ll}( & \text { ) Nenhuma } \\ ( & \text { ) Uma } \\ ( & \text { ) Duas } \\ ( & \text { ) Três }\end{array}$

( ) Quatro

( ) Cinco

( ) Seis ou mais

\section{CARNES}

3) Em geral, quantas vezes POR DIA você come carne: de frango, bovina, peixe ou ovo?

( ) Nenhuma

( ) Uma

( ) Quatro

( ) Duas

( ) Cinco

( ) Três

( ) Seis ou mais 


\section{LEITE E DERIVADOS DO LEITE}

4) Em geral, quantas vezes POR DIA você toma leite ou come derivados do leite (iogurte, queijos, requeijão)?

( ) Nenhuma

( ) Quatro

( ) Uma

( ) Cinco

( ) Duas

( ) Seis ou mais

( ) Três

\section{ARROZ E FEIJÃO}

5) Em geral, quantas vezes POR SEMANA você come arroz $\underline{\text { e feijão? }}$

$$
\begin{array}{ll}
( & \text { ) Nenhuma } \\
( & \text { ) Uma } \\
( & \text { ) Duas } \\
( & \text { ) Três }
\end{array}
$$$$
\text { ( ) Quatro }
$$$$
\text { ( ) Cinco }
$$$$
\text { ( ) Seis }
$$$$
\text { ( ) Todos os dias }
$$

\section{DOCES}

6) Em geral, quantas vezes POR SEMANA você come bolo, biscoito recheado ou guloseimas (balas, sorvetes, chocolate, entre outras)?
( ) Nenhuma
( ) Quatro
( ) Uma
( ) Cinco
( ) Duas
( ) Seis
( ) Três
( ) Todos os dias

\section{SALGADOS}

7) Em geral, quantas vezes POR SEMANA você come frituras (coxinha, pastel, batata-frita, mandioca frita, entre outras), salgadinhos de pacote, sanduíches (cachorro-quente, $x$-salada, entre outros)?
( ) Nenhuma
( ) Quatro
( ) Uma
( ) Cinco
( ) Duas
( ) Seis
( ) Três
( ) Todos os dias 


\section{REFRIGERANTE OU SUCO INDUSTRIALIZADO}

8) Em geral, quantas vezes POR SEMANA você toma refrigerante ou suco industrializado?

( ) Nenhuma

( ) Quatro

( ) Uma

( ) Cinco

( ) Duas

( ) Seis

( ) Três

( ) Todos os dias

\section{REFEICÕ̃ES}

9) Quais refeições você faz POR DIA?
（） Café da manhã
( ) Lanche da tarde
( ） Lanche da manhã
( ) Jantar
( ) Almoço

\section{USO DO TEMPO DE LAZER}

10) Quantas horas POR DIA você ocupa com as seguintes atividades:

a) Assistindo à televisão (TV): horas

b) Jogando videogame: horas

c) Utilizando o computador: horas 


\section{APÊNDICE 6}

\section{QUESTIONÁRIO SOCIOECONÔMICO}

\section{DADOS INICIAIS}

NOME (de quem preenche o questionário):

DATA DE NASCIMENTO (de quem preenche o questionário):

NOME DO ESCOLAR:

1) Quantas pessoas moram na casa? Quantas delas trabalham?

\begin{tabular}{|c|l|c|l|}
\hline OPÇÕES & $\begin{array}{c}\text { QUANTAS PESSOAS } \\
\text { MORAM NA SUA CASA } \\
\text { (CONTANDO COM VOCÊ) }\end{array}$ & OPÇÕES & \multicolumn{1}{|c|}{$\begin{array}{c}\text { QUANTAS DELAS } \\
\text { TRABALHAM }\end{array}$} \\
\hline$(\quad)$ & Duas & $(\quad)$ & Nenhuma \\
\hline$(\quad)$ & Três & $(\quad)$ & Uma \\
\hline$(\quad)$ & Quatro & $(\quad)$ & Duas \\
\hline$(\quad)$ & Cinco & $(\quad)$ & Três \\
\hline$(\quad)$ & Mais. Quantas? : & $(\quad)$ & Mais. Quantas? : \\
\hline
\end{tabular}

2) Até quando o pai do escolar estudou? Marque uma das opções.

( ) Não estudou.

( ) Ensino fundamental: da 1aa $4^{\underline{a}}$ série (antigo primário).

( ) Ensino fundamental: da $5^{\mathrm{a}}$ à $8^{\mathrm{a}}$ série (antigo ginásio).

( ) Ensino médio ( $2^{\circ}$ grau) incompleto.

( ) Ensino médio (2 grau) completo.

( ) Ensino superior incompleto.

( ) Ensino superior completo.

( ) Não sei.

3) Até quando a mãe do escolar estudou? Marque uma das opções.

( ) Não estudou.

( ) Ensino fundamental: da 1a à $4^{a}$ série (antigo primário).

( ) Ensino fundamental: da $5^{\mathrm{a}}$ à $8^{\mathrm{a}}$ série (antigo ginásio).

( ) Ensino médio ( $2^{\circ}$ grau) incompleto.

( ) Ensino médio (2ํgrau) completo.

( ) Ensino superior incompleto.

( ) Ensino superior completo.

( ) Não sei.

4) O pai do escolar trabalha fora de casa?

( ) Sim
( ) Não 
5) A mãe do escolar trabalha fora de casa?

( ) Sim

6) Somando a sua renda com a renda das pessoas que moram com você, quanto é, a renda familiar? (considere a renda de todos que moram na sua casa) Marque uma das opções.

) até $R \$ 475,00$.

) de $R \$ 475,01$ a $R \$ 950,00$

) de $R \$ 950,01$ a $R \$ 1.425,00$.

) de $R \$ 1.425,01$ a $R \$ 1.900,00$.

) de $R \$ 1.900,01$ a $R \$ 2.375,00$.

) Mais de $R \$ 2.375,01$.

) Nenhuma renda.

) Não sabe. 


\section{ANEXO 1 - APROVAÇÃO DO COMITÊ DE ÉTICA}

COMITE DE ÉTICA EM PESQUISA - COEP/FSP
Universidade de São Paulo
Faculdade de Saúde Pública

05 de DEZEMBRO de 2008.

Prezadio(a) Orientador(a),

O Comitê de Ética em Pesquisa da Faculdade de Saúde Pública da Universidade de São Paulo - COEP analisou, em sua 10. \%08 Sessão ORDINÁRIA, realizada em 28/11/2008, de acordo com os requisitos da Resolução CNS/196/96 e suas complementares, o protocolo de pesquisa acima intitulada e o considerou APROVADO.

Cabe lembrar que conforme Resolução CNS/196/96 são deveres do (a) pesquisador (a):

1. Comunicar, de imediato, qualquer alteração no projeto e aguardar manifestação deste CEP (Comitê de Ética em Pesquisa), para dar continuidade à pesquisa;

2. Manter sob sua guarda e em local seguro, pelo prazo de 5 (cinco) anos, os dados da pesquisa, contendo fichas individuais e todos os demais documentos recomendados pelo CEP, no caso eventual auditoria;

3. Comunicar, formalmente a este Comitê, quando do encerramento deste projeto;

4. Elaborar e apresentar relatórios parciais e final;

5. Justificar, perante o CEP, interrupção do projeto ou a não publicação dos resultados.

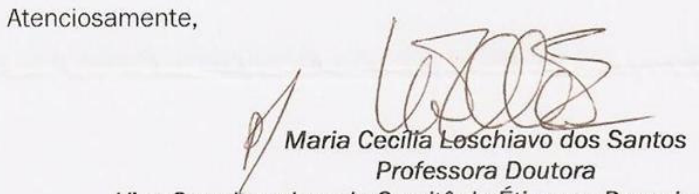

Vice-Coordenadora do Comitê de Ética em Pesquisa - FSP/COEP

IIm. ${ }^{a} \mathrm{Sr}^{\mathrm{a}}$

Prof. ${ }^{a}$ Dr. a SONIA BUONGERMINO DE SOUZA

DEPARTAMENTO DE NUTRICAAOO

FACULDADE DE SAÚDE PÚBLICA

UNIVERSIDADE DE SÃO PAULO

Av. Dr. Arnaldo, 715 - Assessoria Acadêmica - CEP: 01246-904 - São Paulo - SP

Telefones: (55-11) 3061-7779/7742 e-mail: coep@fsp.usp.br site www.fsp.usp.br 